\title{
INCORPORATING ENTERPRISE
}

\author{
STRATEGIC PLANS \\ INTO \\ ENTERPRISE ARCHITECTURE
}

Carlos Lins Borges Azevedo 


\title{
INCORPORATING ENTERPRISE
}

\author{
STRATEGIC PLANS
}

INTO

ENTERPRISE ARCHITECTURE

DISSERTATION

to obtain

the degree of doctor at the University of Twente,

on the authority of the rector magnificus, prof.dr. T.T.M. Palstra,

on account of the decision of the graduation committee, to be publicly defended

on Wednesday the $29^{\text {th }}$ of November, 2017 at 12.45 .

by

\section{Carlos Lins Borges Azevedo}

born on the $25^{\text {th }}$ of February, 1987

in Vitória, Espírito Santo, Brazil

This doctoral degree program was undertaken jointly with the Federal University of Espírito Santo (Brazil) and the University of Twente (The Netherlands) 
This dissertation has been approved by:

Supervisor:

Prof. Dr. R. J. Wieringa

Co-supervisors:

Dr. Ir. M. J. van Sinderen

Dr. Ir. L. Ferreira Pires

(C) 2017: Carlos Lins Borges Azevedo, the Netherlands

Cover: designed by Aline Silva Gomes

ISBN: 978-90-365-4434-4

URL: https: / / doi.org/10.3990/1.9789036544344

Printed by Ipskamp, Enschede, the Netherlands 


\section{Graduation Committee}

Chairman/secretary

Supervisor(s)

Co-supervisor(s)

Committee Members:

Referee:
Prof. Dr. P.M.G. Apers

Prof. Dr. R.J. Wieringa

Dr. Ir. M.J. van Sinderen

Dr. Ir. L. Ferreira Pires

Prof. Dr. J.P.A. Almeida

Prof. Dr. G. Poels

Prof. Dr. A.B.J.M. Wijnhoven

Dr. M.E. Iacob

Prof. Dr. F. Matthes 


\section{INCORPORATING ENTERPRISE \\ STRATEGIC PLANS \\ INTO \\ ENTERPRISE ARCHITECTURE}

\section{PROEFSCHRIFT}

ter verkrijging van de graad van doctor aan de Universiteit Twente, op gezag van de rector magnificus, prof.dr. T.T.M. Palstra, volgens besluit van het College voor Promoties in het openbaar te verdedigen op woensdag 29 November 2017 te 12.45 uur.

door

Carlos Lins Borges Azevedo geboren op 25 Feb 1987

te Vitória, Espírito Santo, Brazilië 
Dit proefschrift is goedgekeurd door:

Prof. Dr. Roel J. Wieringa (promotor)

Dr. Marten J. van Sinderen (assistent-promotor)

Dr. Luís Ferreira Pires (assistent-promotor)

Copyright (C) 2017, Carlos Lins Borges Azevedo, the Netherlands 
UNIVERSIDADE FEDERAL DO ESPÍRITO SANTO

DEPARTAMENTO DE INFORMÁTICA

DOUTORADO EM CIÊNCIA DA COMPUTAÇÃO

CARLOS LINS BORGES AZEVEDO

\section{INCORPORATING ENTERPRISE STRATEGIC PLANS \\ INTO}

ENTERPRISE ARCHITECTURE

DOCTORAL THESIS

VITÓRIA-ES, BRAZIL

DECEMBER, 2017 
Composição da Banca Examinadora:

Orientador:

Prof. Dr. João Paulo Andrade Almeida, Universidade Federal do Espírito Santo (UFES), Brasil

Coorientadores:

Prof. Dr. Marten J. van Sinderen, Universidade de Twente, Holanda

Prof. Dr. Luís Ferreira Pires, Universidade de Twente, Holanda

Membros:

Prof. Dr. Geert Poels, Universidade de Ghent, Bélgica

Prof. Dr. Maria-Eugenia Iacob, Universidade de Twente, Holanda

Prof. Dr. Renata Silva Souza Guizzardi, UFES, Brasil

Prof. Dr. Vítor Estêvão Silva Souza, UFES, Brasil 


\section{Abstract}

In the last years, information technology (IT) executives have identified ITbusiness strategic alignment as a top management concern. In the information technology area, emphasis has been given to the Enterprise Architecture (EA) discipline with respect to enterprise management. The focus of the discipline has been on the operational components of the enterprise, undermining its strategic aspects. As a consequence, the incorporation of strategic level concerns and strategic plans in the EA discipline is still incipient. To incorporate strategic plans into the EA discipline, several challenges need to be addressed, from the representation of strategy in enterprise architectures to the relation between a particular strategy and the whole EA, including its operational level. An additional challenge lies in identifying a precise conceptualization for strategic management elements in EA. This thesis aims to incorporate enterprise strategic plans into the enterprise architecture discipline, thereby enabling the expression of strategic plans, as well as the expression of their relations to the operational aspects of an enterprise architecture. We hypothesize that using the notion of capabilities and resources from management theories, it is possible to incorporate enterprise strategic plans into the enterprise architecture discipline. Recent developments have identified capabilities as a plausible solution to link business and IT, to link business outcomes to IT, and to improve the business and IT alignment. In this setting, resources and capabilities serve as abstractions of enterprise architecture behavioral and structural elements, and are key to relate strategic level and operational level concerns. We have built a theoretical foundation for using capabilities and resources, from management, in the enterprise architecture discipline. We employ a comprehensive foundational ontology that incorporates concepts to deal with plans, objects, relations, roles, events and dispositions, as well as social and intentional concepts. We also explored and precisely defined a semantic foundation to express strategic plans in EA. We use these to express strategic-level concerns, including strategic plans, and to relate them to enterprise architecture. The theoretical foundation has been 
used to revise the ArchiMate language metamodel, extending it in order to enable the representation of concepts related to strategic plans, capabilities and resources in EA. In order to validate our proposal, we have performed four case studies. 


\section{Samenvatting}

Leidinggevende personen in de informatietechnologie (IT) hebben in de afgelopen jaren aangegeven dat de strategische afstemming tussen bedrijfsvoering en IT van groot belang is. In het IT domein is het vooral de Enterprise Architecture (EA) discipline die aandacht besteedt aan de relatie tussen bedrijfsvoering en IT. De nadruk ligt hier op de operationele componenten van een bedrijf, ten koste van aandacht voor strategische zaken. De behandeling van strategisch niveau acties en plannen staat daardoor nog in de kinderschoenen. Het opnemen van strategische plannen in een EA komt met verschillende uitdagingen, waaronder het representeren van strategie in een EA en van de relatie tussen een bepaalde strategie en de rest van de EA, inclusief het operationele niveau. Een extra uitdaging is de precieze conceptualisatie van de strategische management elementen. Dit proefschrift beoogt om strategische plannen te introduceren in de EA discipline, waardoor het uitdrukken van zowel strategische plannen als de relatie tussen de strategische plannen en operationele onderdelen van een EA mogelijk wordt. Wij gaan uit van de veronderstelling dat de begrippen capability en resource uit de management theorie bruikbaar zijn voor dit doel. Deze veronderstelling is gebaseerd op recente ontwikkelingen die aannemelijk maken dat capabilities een oplossing bieden voor het verbinden van bedrijfsvoering en IT, en van bedrijfsresultaten en IT, en voor het verbeteren van de afstemming tussen bedrijfsvoering en IT. In dit verband zijn capabilities en resources abstracties van EA elementen voor gedrag en structuur, en zijn ze essentieel om strategisch niveau en operationeel niveau te relateren. We hebben een theoretische fundering ontwikkeld, gebaseerd op een studie van de management literatuur, om capabilities en resources te gebruiken in de EA discipline. We passen een fundamentele ontologie toe die concepten omvat om plannen, objecten, relaties, rollen, gebeurtenissen en eigenschappen te behandelen, alsmede ook sociale en intentionele concepten. We hebben tevens een semantische fundering onderzocht en precies gedefinieerd. Met deze fundering is het mogelijk om strategische plannen uit te drukken. We gebruiken de semantische fundering om strategisch 
niveau zaken te modelleren, inclusief strategische plannen, in relatie tot EA. De theoretische fundering hebben we gebruikt om het metamodel van de ArchiMate taal te herzien, en uit te breiden voor het representeren van concepten voor strategische plannen, capabilities en resources. We hebben ons voorstel gevalideerd met behulp van vier case studies. 


\section{Acknowledgements}

First of all, I would like to express my gratitude to my supervisors. I appreciate all the guidance, patience and motivation throughout this journey. You have been of great importance to my academic knowledge and career.

João Paulo, we have been working together since the beginning of my master and I am more than glad to have worked with you. You are one of the most brilliant persons I have worked with. Marten, we also have worked since my master and you have been of great importance to both works and for my academic growth. This work would not be the same without your guidance. Luís, thanks for all the guidance, help and many insights throughout this work. Professor Wieringa, I am thankful that you have accommodated and guided this work within the SCS group.

I would also like to thank some specific people that contributed to this thesis. Maria Iacob, thanks for all the discussions about ArchiMate, capabilities, capability-based planning and so much more. I would like to thank Dick Quartel and BiZZdesign for the year-round we spent together working on this thesis subject. Anilton and UFES, thanks for all the support and for sponsoring one of the case studies presented in this thesis. I would also like to express my gratitude to all the professors at Nemo and at the SCS group for sharing their immense knowledge, and to my fellow lab mates for the stimulating discussions and for the fun moments. I particularly thank my colleagues Victorio and Julio for sharing with me the incertitude and angsts of being a doctoral candidate. I thank my friends José, Robson, João, Bel, Glaucia and Sergio Vasquez for all the great times we had while I was living in the Netherlands. I would also like to express my gratitude to Suse Engbers for all her support in many administrative tasks.

My eternal gratitude to my mother, to whom I owe a lot in my life. I also would like to express my gratitude to my family, friends and to Aline for being part of my life.

Finally, I thank the Brazilian national agencies CAPES and $\mathrm{CNPq}$ for financial support. 



\section{Contents}

1. Introduction 9

1.1 Context and Motivation 9

1.2 Challenges 11

1.3 Research Objectives 12

1.4 Research Hypothesis 12

1.5 Approach 14

1.6 Non-scope and Limitations 19

$\begin{array}{lll}1.7 & \text { Thesis Structure } & 19\end{array}$

2. Strategic Planning 23

2.1 Strategic Planning Theories 23

2.2 Strategic Planning Models 25

2.3 Resources and Capabilities in the Enterprise 27

2.4 Conclusions 29

3. Enterprise Architecture 31

3.1 Introduction 31

3.2 Requirements for Strategic Plan Support in EA 32

3.3 Current Support for Strategic Plans in EA Frameworks 35

3.4 Discussions 47

4. Ontological Basis $\quad 49$

4.1 Introduction 49

4.2 The Unified Foundational Ontology (UFO) 50

4.3 Bratman's Intention, Plans and Practical Reasoning Theory 58

4.4 Ontological Analysis Approach 59

5. Capturing Strategic Plans in EA $\quad 63$

5.1 A Conceptual Model for Strategic Plans 63

5.2 Modeling Strategic Plans in EA 69

5.3 Related Work 76

5.4 Conclusions 78

6. Relating Strategic and Operational Aspects of EA using $\begin{array}{lr}\text { Capabilities and Resources } & \mathbf{8 1}\end{array}$

6.1 Current Support for Modeling Capabilities and Resources 82

6.2 Ontological Analysis of Resource $\quad 87$

6.3 Ontological Analysis of Capability 92 
6.4 Ontological Analysis of Competence 96

6.5 Revisited Support for Modeling Capabilities and Resources 98

6.6 Related Work 105

$\begin{array}{lll}6.7 \text { Conclusions } & 106\end{array}$

$\begin{array}{lr}\text { 7. Validation } & 109\end{array}$

$\begin{array}{lll}7.1 & \text { Introduction } & 109\end{array}$

7.2 Case Study: Toyota Supplier Capability Enhancement 110

7.3 Case Study: IT Consolidation for an European Energy Supplier 117

7.4 Case Study: Strategic Planning in a Mid-Size University 130

$\begin{array}{lll}7.5 \text { Conclusions } & 140\end{array}$

8. Conclusions and Future Work $\quad 143$

8.1 Main Contributions 143

8.2 Objectives and Thesis Hypothesis Discussion 146

8.3 Further Research Opportunities 149

$\begin{array}{lr}\text { Remarks Concerning ArchiMate 3.0 } & 153\end{array}$

$\begin{array}{lr}\text { Author Publications } & 157\end{array}$

$\begin{array}{lr}\text { References } & 159\end{array}$ 


\section{Introduction}

This thesis contributes to incorporate enterprise strategies and strategic plans into enterprise architecture (EA), in the information technology area. In this chapter we present the context and motivate the relevance of the work reported here, in section 1.1. We discuss the main challenges in section 1.2 and define the main objectives of our research in section 1.3, presenting the thesis hypothesis in section 1.4. We also present the approach we follow to accomplish the defined objectives, in section 1.5, as well as the thesis non-scope and limitations, in section 1.6. We conclude the chapter by presenting an overview of the thesis structure in section 1.7.

\subsection{Context and Motivation}

In the last years, information technology (IT) executives have identified ITbusiness strategic alignment as a top management concern (Kappelman et al., 2013) (Forbes Magazine and SAP, 2009). Research suggests that alignment between business strategies and IT increases profitability and the ability to gain a sustainable competitive advantage (Baker et al., 2011) (Sabegh and Motlagh, 2012).

Additionally, practitioner books and articles focus on innovation and increased efficiency derived from IT-business alignment, such as improved decision making, automation of internal business processes, and improvement of customer satisfaction (Ross, Weill and Robertson, 2006) (Forbes Magazine and SAP, 2009). Practitioners report that this alignment is a means to develop firms' competitive capabilities, such as improving workflow and incorporating IT into strategic thinking (Ray, Barney and Muhanna, 2004) (Sabegh and Motlagh, 2012) (Weihong et al., 2010).

Due to the potential benefits of IT-business alignment, practitioners and scholars have considered this alignment a priority for firms (Chan and Reich, 
2007) (Kappelman et al., 2013) (Forbes Magazine and SAP, 2009) (Ross, Weill and Robertson, 2006). Many sources observe that failure to align could result in wasted resources and failed initiatives, leading to adverse financial and organizational outcomes (Chen et al., 2010) (Ravishankar, Pan and Leidner, 2011).

From the perspective of research in business management, researchers have worked on detailing and understanding how aligning business and IT generates value for firms (Bart, Bontis and Taggar, 2001; Pijpers, Gordijn and Akkermans, 2009) (Engelsman et al., 2011) (Gerow et al., 2014). The research includes general financial performance (Miller and Cardinal, 1994)(Song et al., 2011), improved operational efficiency (Dibrell, Craig and Neubaum, 2014), cost reductions (Porter, 1980) (Quartel, Steen and Lankhorst, 2010), and enhanced customer value (Venkatraman, 2000) (Pijpers, Gordijn and Akkermans, 2009).

From the perspective of research in information technology, much emphasis has been given to the Enterprise Architecture discipline with respect to enterprise management (Ross, Weill and Robertson, 2006) (Lankhorst, 2005)(Op 't Land et al., 2009) (The Open Group, 2009). The Enterprise Architecture discipline (EAD) has been established in order to support the design, modeling and management of the different components (or parts) of an enterprise and their interaction (Lankhorst, 2005) (Ross, Weill and Robertson, 2006).

In accordance with the IEEE 12204 (IEEE, 2000), an architecture is defined as "the fundamental organization of a system embodied in its components, their relationships to each other and to the environment, and the principles guiding its design and evolution". This has led to the use of the term architecture at the enterprise level: enterprise architecture (Op 't Land et al., 2009) (Lankhorst, 2005). In an enterprise architecture (EA), the enterprise is the system, and the architecture is focused on the design, relationships and evolution of the enterprise related components, such as its organizational structure, motivation, business processes, services, products, IT assets and infrastructure. EA is used as a means to obtain, maintain and manage the combination of enterprise elements and their complex relationships.

Despite these motivations for using EA, the focus of the enterprise architecture discipline has been on the operational components of the enterprise, undermining its strategic aspects. As a consequence, enterprise architecture is not yet integrated with strategic planning and it remains challenging to relate strategy and strategic plans to their actual implementation at the level of processes, IT systems and infrastructure.

Enterprise's strategy and strategic plans concern the survival and competitiveness of the enterprise in the long-term. Empirical studies have shown that defining and following a strategic plan can improve an enterprise's financial performance (Miller and Cardinal, 1994) (Song et al., 2011) (Ansoff, 1991) (Al- 
Shammari and Hussein, 2007) (Bart, Bontis and Taggar, 2001). A strategic plan defines an enterprise's strategy for a certain period of time. It considers which goals the enterprise wants to achieve and how the enterprise plans to pursue them. It establishes where the enterprise should focus its energy and resources, and which operations to strengthen. It also helps stakeholders work toward common goals and align the enterprise's operations towards achieving those goals (Bryson, 1988). In this sense, a strategic plan provides a 'direction' for the enterprise, influencing its products, services, capabilities and behavior.

Due to their relevance and range of influence, strategic plans are already used to provide an initial direction for an Enterprise Architecture (The Open Group, 2009) (Ross, Weill and Robertson, 2006). Further, they also motivate architectural decisions and changes to established EAs (The Open Group, 2009).

\subsection{Challenges}

Despite their importance in motivating and driving Enterprise Architecture choices, enterprise strategic aspects are not explicitly reflected in EA practices (Carlos L B Azevedo, Van Sinderen, et al., 2015) (Cardoso, Almeida and Guizzardi, 2010). In fact, the incorporation of strategic level concerns and strategic plans in EA is still incipient (Ross, Weill and Robertson, 2006) (The Open Group, 2009) (Sowa and Zachman, 1992) (Quartel, Engelsman and Jonkers, 2010) (Cardoso, Almeida and Guizzardi, 2010).

Current EA frameworks and languages mostly cover operational and infrastructure parts of enterprises (Cardoso, Almeida and Guizzardi, 2010), and EA frameworks are still struggling to cover goal modeling (Cardoso, Almeida and Guizzardi, 2010) (Carlos L B Azevedo, Van Sinderen, et al., 2015). EA frameworks and languages often lack expressiveness for concerns at higher levels of abstraction, such as enterprise strategy and strategic plans (Cardoso, Almeida and Guizzardi, 2010) (Carlos L B Azevedo, Van Sinderen, et al., 2015) (Carlos L B Azevedo, Almeida, et al., 2015), which poses a challenge to enterprise architects.

Another challenge concerns the relation between a particular strategy and the whole EA (Ross, Weill and Robertson, 2006). In particular, one needs to address the traceability between the contents of a strategic plan, at a strategic level, to the enterprise architecture, at a more operational level. Operational aspects include an enterprises' organizational structure, its business processes, services and products, as well as its IT infrastructure. This traceability can be further used to justify particular EA choices.

An additional challenge to incorporate strategic aspects from management into the enterprise architecture discipline lies in identifying a precise 
conceptualization for strategic management elements in EA. A precise conceptualization is required, because semantic problems have been observed to arise when integrating management notions in the EA discipline without rigorous semantic definitions (see, e.g., the issues identified and discussed in (Azevedo et al., 2011), (Recker et al., 2010) and (Santos Jr et al., 2013)).

These open challenges suggest that a novel approach is required to incorporate strategic plans into enterprise architecture.

\subsection{Research Objectives}

The general objective of this thesis is to incorporate enterprise strategic plans into the enterprise architecture discipline thereby enabling the expression of strategic plans, as well as the expression of their relations to the operational aspects of an enterprise architecture.

In order to pursue this general objective, the following specific objectives are defined:

S01 - To establish a theoretical foundation for the elements of strategic plans that are relevant for incorporation into the enterprise architecture discipline. In this process, we select a number of key notions from the strategic management literature and combine them at the light of a foundational ontology. This forms the conceptual basis for further application of strategic planning concepts into enterprise architecture.

S02 - To enrich this theoretical foundation in order to relate enterprises strategic plans, at a strategic level, to EA, at a more operational level, which includes enterprises' organizational structure, business processes, services, products, IT assets and infrastructure. To accomplish that, we use the resourcebased and capability-based theories from management to bridge the gap between strategic and operational aspects, incorporating these notions, at the light of a foundational ontology, into the overall theoretical foundation.

S03 - To provide support to express the concepts of strategic plans, as well as their relations to EA operational aspects, into EA models. To accomplish that, we extend and revise a widely-used enterprise architecture modeling language. This enables practical application of the theoretical foundation defined.

\subsection{Research Hypothesis}

Our research hypothesis is that using the notion of capabilities and resources from management theories, it is possible to incorporate enterprise strategic plans into the enterprise architecture discipline. In this setting, resources and capabilities serve as 
abstractions of enterprise architecture behavioral and structural elements, and are key to relate strategic level and operational level concerns.

Strategic level concerns deal with survival and competitiveness in the longterm, despite the unknown facts inherent of the future. This has led to the formulation of multiple theories, with a focus on Resources (Barney, 1991) and Capabilities (Teece and Pisano, 1994), (Eisenhardt and Martin, 2000) as sources of competitive advantage.

Resource-based theories regard an organization as a bundle of resources (Grant, 1996). They suggest that the resources' properties (e.g., rare, valuable, non-substitutable or inimitable) confer organizations competitive advantage (Barney, 1991) (Peteraf and Barney, 2003). The idea is that enterprises with appropriate resources should be able to leverage the required capabilities and to sustain competitive advantages regardless of scenario.

Several major limitations to resource-based theories have been identified. The most relevant are that valuable, rare, inimitable, and non-substitutable resources are neither necessary nor sufficient for sustaining competitive advantage in a dynamic environment (Kraaijenbrink, Spender and Groen, 2010). Resources by themselves are not useful unless they are correctly employed. The way resources are used defines the outcome: (Penrose, 1959) stated that "exactly the same resources when used for different purposes or in different ways and in combination with different types or amounts of other resources provide a different service or set of services”. As a response to this criticism and to complement the resource-based theories, capability-based theories have been introduced.

According to capability-based theories, an enterprise needs to know the capabilities it wants to leverage in order to use and plan to acquire resources in an intended manner. Whereas resource-based theories focus on accumulating resources, capability-based theories focus on "adapting, integrating, and reconfiguring internal and external organizational skills, resources, and functional competences toward a changing environment" (Teece and Pisano, 1994). In the work presented in (McKelvie and Davidsson, 2009), many organizations have been analyzed in order to answer the question "to what extent do access and changes to resource bases influence the development of dynamic capabilities in new firms?". The work provides statistical evidence for the relationship between the organizational resources and the subsequent capabilities of the organization. Different resources lead to different capabilities, and the changes of resources over time have a great impact on organizations' capabilities (McKelvie and Davidsson, 2009).

Recent developments have identified capabilities as the way to link business and IT (Danesh and Yu, 2014), (Stirna et al., 2012), to link business outcomes to IT (Miklos, 2012), and as a solution for improving the business and IT alignment 
(Lee and Song, 2011), (Zdravkovic et al., 2013). We believe capabilities and resources can be used as an abstraction to specify behavioral and structural requirements in EA and that this can be used for incorporating strategic plans into the EAD.

The usage of capabilities and resources as abstractions to specify behavior and structural requirements in EA enables the future-related uncertainty inherent to strategic planning to be accounted for in EA, especially in EA planning, avoiding unnecessary commitments with lower level details. The EA operational details can be later described, or planned, as they are needed for implementation.

In EA long-term planning, the enterprise can consider the capabilities and resources required to achieve desired states, without actually having to pursue a complete and extended view on the business processes and tasks that are necessary to realize that state. This means that the strategic management level is able to continue focusing on its proper level of abstraction. This contributes to the alignment of the strategic planning and enterprise architecture disciplines.

Further, a key benefit of this approach is an "end-to-end" traceability from enterprise strategic plans to their implementation in the EA. The approach allows both the future-related uncertainty inherent to strategic planning to be accounted for in EA, as well as the traceability between the strategic level concerns and the EA operational aspects.

Finally, from the perspective of the EA discipline, knowledge concerning enterprise's intended capabilities and resources would contribute to the planning of the various EA transformations over time. This is key to support enterprise's strategic plan achievement, with the EAD explicitly supporting enterprises' planned capabilities, products and services.

The notions of capability and resource are employed to allow the EAD to accommodate future changes in the operational parts of the EA while at the same time allowing EA planning for the realization of enterprise's strategic plan. This creates a loose coupling between higher-level capabilities and other operational enterprise architecture elements, contributing to flexibility and maintainability of the resulting enterprise architecture descriptions. This is especially valuable to enterprises with competitive and changing environments, which requires both planning and ability to adapt.

\subsection{Approach}

This thesis follows the design science methodology (Hevner et al., 2004) (Wieringa, 2010). According to Wieringa (2010), in design science we iterate over two activities: "designing an artifact that improves something for stakeholders and empirically investigating the performance of an artifact in a 
context". In this thesis, the object of study is an artifact, i.e., something created in order to satisfy stakeholders goals in a context. In our case, the goal is to incorporate strategic plans into EA, in order to improve the EAD. Thus, the EAD is the artifact context and its stakeholders are EA users. The artifact is the theoretical foundation and the consequently proposed EA language extensions. In order to perform the required research and propose our theoretical foundation, we make use of Hevner's relevance and rigor perspectives (Hevner et al., 2004).

\section{Evidences of Relevance}

As evidences of relevance, there is ample support from the information systems and EA literature on the benefits of incorporating enterprise motivational aspects in EA (Ross, Weill and Robertson, 2006) (The Open Group, 2009) (Department of Defense Architecture Framework Working Group, 2007) (UK Ministry of Defense, 2013). There is also ample support in the business literature on the relevance of capabilities and resources for enterprises and discussing the key role capabilities and resources have in strategic management (Ray, Barney and Muhanna, 2004) (Barroero, Motta and Pignatelli, 2010) (Teece, Pisano and Shuen, 1997) (Lee, 2001) (Kogut and Zander, 1992) (Barreto, 2009) (Barney, 1991). Further, capability-based planning (Barroero, Motta and Pignatelli, 2010) (Keller, 2010) has had major interest from research efforts in the literature as well as from the practice in EA, with frameworks such as TOGAF introducing basic notions of capability-based planning and its role in designing, planning and implementing organizational change (The Open Group, 2009). The notions of strategic plan, resources and capabilities are thus relevant for industrial and academic efforts.

\section{Evidences of Rigor}

As evidences of rigor, we have adopted a well-established ontological analysis methodology (Guizzardi, Falbo and Guizzardi, 2008) (Bringuente, Falbo and Guizzardi, 2010) (Azevedo et al., 2011) (Almeida and Guizzardi, 2013), and clearly defined ontological foundations (Guizzardi, 2005) (Guizzardi, Falbo and Guizzardi, 2008). When required, these foundations are extended in line with the philosophy literature (e.g., Bratman's planning theory (1999); George Molnar's powers theory (2006)) or with the management literature (e.g. Barney's account on resources (1991); Porter's (1991) and Mintzberg's (1998) accounts on enterprise strategy).

A main challenge of incorporating the notions from strategic management, as strategic plans, capabilities and resources in the EAD is to identify a precise conceptualization for these notions. Careful definition of the semantics of strategic-level concepts is required, especially when considering that it addresses subjective aspects of the enterprise. Without such a precise conceptualization, 
rigorous definition of the semantics of any proposed modeling element is problematic, and modeling and communication problems arise. For example, when various modelers share a model without clear semantics, False Agreement most likely ensues (Guarino, 1998). In that case, different modelers come to different interpretations of the same model and are not aware of the conflict. This would result in enterprise architecture models that cannot properly serve their purpose as tools for communication between stakeholders, decreasing the value of enterprise architecture models in the pursuit of informed decision-making.

Our approach relies on the strong relation of enterprise architecture modeling to the strategic management concepts as they are used in strategic management, and, most importantly, in the clear semantics we provide for the proposed EA modeling elements through ontological analysis and the usage of foundational ontologies.

The foundational ontology adopted in this research is the Unified Foundational Ontology (UFO) (Guizzardi, 2005) (Guizzardi, Falbo and Guizzardi, 2008). This foundational ontology is used for supporting the development of the theoretical foundation. The choice of using UFO is justified by its ability to describe social phenomena when contrasted to other foundational ontologies (G. Guizzardi et al., 2013) (R. Guizzardi et al., 2013) (Almeida and Guizzardi, 2013) and by the successful application of this foundational ontology in previous works to evaluate, redesign, and ground models, modeling languages and frameworks of several research areas, such as Software Engineering, Conceptual Modeling and, especially, Enterprise Architecture Modeling (Guizzardi, Falbo and Guizzardi, 2008) (Bringuente, Falbo and Guizzardi, 2010) (Santos Jr et al., 2010) (Azevedo et al., 2011) (Almeida and Guizzardi, 2013) (Almeida, Guizzardi and Santos Jr, 2009). We complement the UFO concepts with notions explored by Bratman in his theory of intention and practical reasoning (1999). We also augment UFO with Molnar's Powers theory (2006), used in conjunction with UFO's disposition concept as a basis to provide the semantics for enterprises' capabilities. This theoretical foundation is then used to perform an ontology-based analysis in order to extend the ArchiMate EA modeling language.

\section{Solution Approach}

As previously stated, our approach relies on the strong relation of enterprise architecture modeling to the strategic management concepts as they are used in strategic management. In order to perform our work, we analyzed strategic plans, from the management literature point of view, in order to verify which requirements an approach to incorporate strategic plans in EA should fulfill. Further, we analyzed the requirements from the EA perspective, including the EA as a discipline and EA frameworks to verify which requirements an approach to incorporate strategic plans in EA should fulfill, as illustrated in Figure 1. 

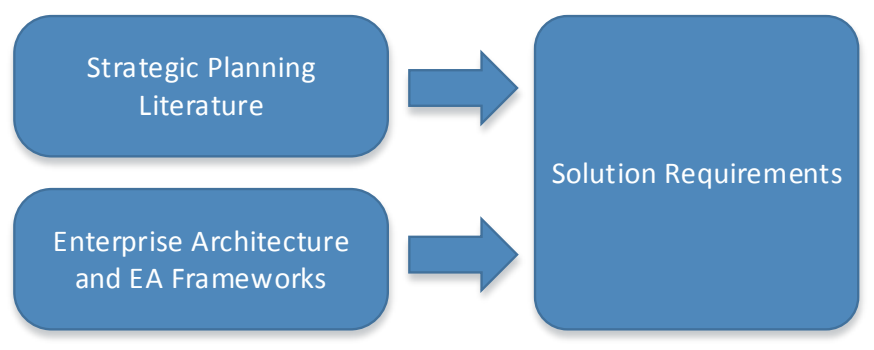

Figure 1 - Solution Requirements

Then, we focus on proposing a solution to successfully fulfill the presented requirements. As stated, our approach relies in providing a clear semantics for the proposed EA modeling elements. For such, we make use of the UFO foundational ontology, in conjunction with Bratman's Plans, Intentions and Practical Reasoning Theory and Molnar's Powers theory. The selection of these theories and its joint usage is what we term our ontological basis, as illustrated in Figure 2.

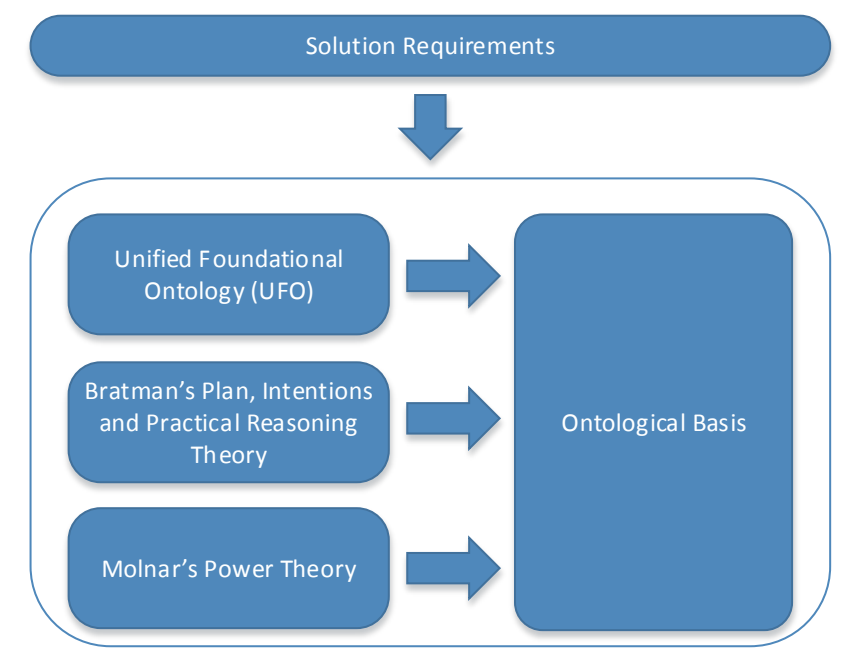

Figure 2 - Ontological Basis

Using the ontological basis and the management theories, we propose our theoretical foundation, as illustrated in Figure 3. 


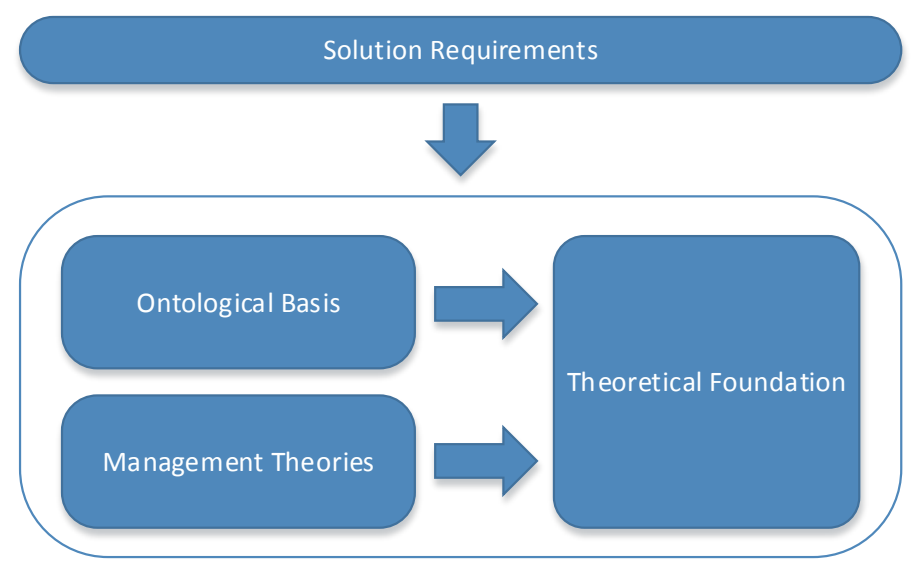

Figure 3 - Theoretical Foundation

And finally, for practical application, we use our theoretical foundation and perform an ontological analysis. Using the ontological analysis result, we propose metamodel revisions and extensions to the ArchiMate EA modeling language, as illustrated in Figure 4.

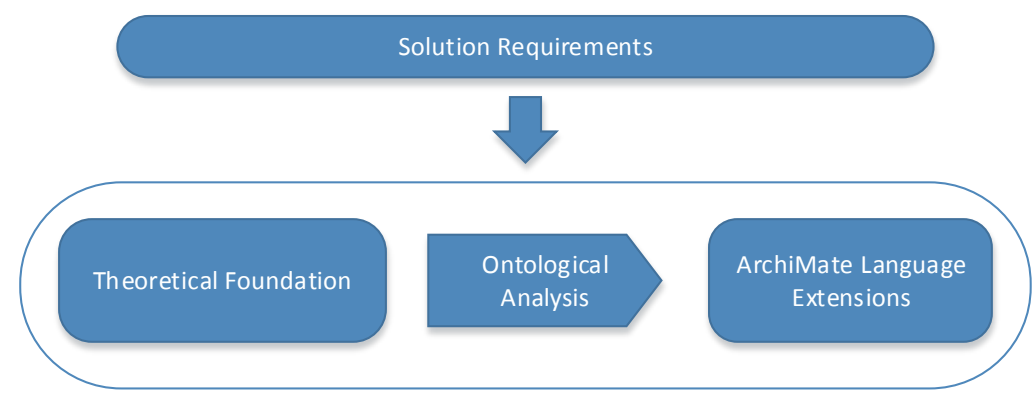

Figure 4 - Practical Application

The solution is then validated using four case studies.

\section{Validation}

In order to investigate the performance of the theoretical foundation and the ArchiMate EA modeling language extension in its context, we make use of case studies. We evaluated the artifact using four case studies. The first case study uses the strategic plan of a mid-to-large Brazilian pension fund enterprise. This case study has been used to verify that our approach is able to represent a real-world strategic plan. This is used in this thesis as a running example for the introduction 
of strategic plan concepts in the EAD ${ }^{1}$. The second case study is about an Automotive industry supplier. The case study has been taken from literature and is used to show the relevance of capabilities and resources for the EAD. The case study is instructive in that it shows that the EA model without capabilities and resources is not able to capture key enterprise concerns in the case study. These key concerns are revealed using our approach. The third case study is about an European Energy Supplier. The case is instructive in that it links capabilities and resources to enterprise goals, at a strategic level, and to the EA, at an operational level, thus showing enterprise traceability. It also describes the usage of the capability and resource concepts in the setting of an operational-level reconfiguration while maintaining enterprises' services and products. The fourth case study uses a Brazilian mid-size university strategic plan. The university currently does not make use of enterprise architecture models. The case study models the university strategic plan and its enterprise architecture. The case study showed gaps in the university strategic plan, which were revealed when modeling the strategic plan using the proposed ArchiMate extensions.

\subsection{Non-scope and Limitations}

The objective of this thesis is to incorporate enterprise strategic plans into the enterprise architecture discipline. While the results of this thesis can be used to foster alignment between strategic plans and particular enterprise architectures, the prescription of a method to analyze or to diagnose if there is an alignment or the degree of alignment in an enterprise between any particular enterprise architecture and its enterprise strategy is outside the scope of this thesis.

It is also outside the scope of this thesis to prescribe any method or methodology in order for an enterprise to perform an alignment between its strategic plan to its enterprise architecture. Further, the planning of the EA over time in order to achieve the enterprise strategic plan is also outside of the scope of this thesis.

\subsection{Thesis Structure}

This thesis is presented according to the two design science major cycles: the design cycle and the empirical cycle. In the first cycle, the required background is presented in Chapters 2 and 3. This allows us to define requirements for the

\footnotetext{
${ }^{1}$ Only fragments of the plan are revealed in this thesis, as this strategic plan belongs to a private enterprise and we have not been authorized to disclose it completely in this thesis.
} 
theoretical foundation and the ArchiMate modeling language extensions. The theoretical foundation and the ArchiMate modeling language extensions are presented then in Chapters 4, 5 and 6. In the second cycle, we evaluate the theoretical foundation and the ArchiMate modeling language extensions in its context. The results of this evaluation are presented in Chapter 7. Finally, Chapter 8 concludes the thesis. The remaining of this thesis is structured as follows:

- Chapter 2 - Strategic Planning: This chapter describes the management theories on strategic plans, capabilities and resources that are relevant to this thesis, focusing on requirements that an approach to incorporate strategic plans into EA should satisfy.

- Chapter 3 - Enterprise Architecture: This chapter presents the enterprise architecture discipline and its main frameworks. The chapter discusses requirements to incorporate strategic plans into EA, from the enterprise architecture discipline point of view, discussing challenges that need to be addressed. The chapter also discusses EA frameworks' current support for representing strategic plans.

- Chapter 4 - Ontological Basis: This chapter presents this thesis ontological basis. The chapter introduces ontological analysis, the foundational ontology used in this work, the theory used to introduce capabilities in EA and Bratman's Intention, Plan and Practical Reason theory. The ontological basis presented in this Chapter is used to ground our approach to incorporate strategic plans into EA.

- Chapter 5 - Capturing Strategic Plans in EA: This chapter discusses how strategic plans are introduced into the Enterprise Architecture discipline. It presents our theoretical foundation for strategic plan usage and representation in EA, encompassing the notions of mission, vision, goal and strategy. Further, it presents an extension to the ArchiMate EA modeling language that allows practical application.

- Chapter 6 - Relating Strategic and Operational Aspects of EA using Capabilities and Resources: This chapter presents our approach to relate enterprise strategic plans with EA, including EA operational aspects. The chapter introduces capabilities and resources into the enterprise architecture discipline. It presents our theoretical foundation for using these concepts in the enterprise architecture discipline, while performing an ontological analysis of the concepts, which is build up on a previously proposed language extension to ArchiMate. Further, it presents an extension to the ArchiMate EA modeling language for practical application. 
- Chapter 7 - Validation: This chapter presents the evaluation of the work developed in this thesis. The chapter presents three case studies developed within this thesis context, which are used to show the approach's practical application ability to model enterprise strategic plans into EA and to relate strategic plans to EA operational aspects. Further, the chapter discusses the case studies with respect to the thesis specific objectives.

- Chapter 8 - Conclusions and Future Work: This chapter concludes the thesis by outlining our main contributions and by proposing topics for further investigation.

- Appendix A - Remarks Concerning ArchiMate 3.0: While the research of this thesis was performed, the ArchiMate modeling language has evolved. The bulk of the thesis work was performed with ArchiMate version 2.1 and proposed extensions. This appendix briefly discusses the ArchiMate 3.0 introduced elements and considers the impact of this new version to the analysis performed in Chapters 5 and 6 . 



\section{Strategic Planning}

In this chapter we present the relevant strategic planning theories and models ${ }^{2}$ from the management literature, in sections 2.1 and 2.2. Reviewing the most common strategic planning theories and models allows us to identify requirements that an EA approach should satisfy when augmented with strategic planning elements.

We describe the two main categories of strategic planning theories, the prescriptive theories and the descriptive theories, and then we pay special attention to the goal-based strategic model, which is widely-used in the industry (McNamara, 2001) (Bryson, 2011) and that we consider to be the most common model in strategic planning (McNamara, 2001).

Further, we present and discuss the role of Resource-based and Capabilitybased theories in section 2.3, as research indicated that they are key elements that interfere in enterprise performance (Barney, 2001) (Leiblein, 2011). Finally, we conclude the chapter in section 2.4 .

\subsection{Strategic Planning Theories}

A strategic plan defines an enterprise's strategy for a certain period of time. It sets the enterprise priorities, considering the goals the enterprise wants to achieve and how the enterprise aims to pursue them. The strategic plan is used to focus the enterprise towards these priorities and influences the whole enterprise, including its products, services, capabilities and behavior.

2 In the management literature, the term model is used with a broader sense than in the information systems literature. We chose to preserve the strategic management terminology. The reader is not to understand the term 'model' as in the information systems domain, in which specific semantics and diagrams would be expected. 
Strategic plans often focus on the entire enterprise, although a strategic plan can be made for a specific part or department. The outcomes and the way in which a strategic plan is developed depend on the nature of the enterprise and on the nature of the challenges the enterprise is facing.

Two main categories of theories are used to support the definition of strategic plans in the management area (Mintzberg, Ahlstrand and Lampel, 1998): prescription theories, which recognize the so-called deliberate strategies; and description theories, which recognize the so-called emergent strategies.

Prescription theories are based on a clear distinction between the design of the strategic plan and its implementation. On the design part, one or more executives and consultants define the strategy to be followed in the enterprise. The strategy can be unique and tailored to a specific enterprise, or it can be defined from a generic one, after some analysis of the enterprise in its particular circumstances and selecting the strategy that should fit the enterprise best (Porter, 1980) (Porter, 1991). The strategy is first completely designed, including the goals the enterprise wants to achieve, when and how, and then the strategy is communicated to the enterprise and the defined plan is implemented.

In contrast, description theories assume that the realm of strategies is too complex and that the design approach underestimates it, understanding that it is not possible to define what goals to achieve and how to achieve them a priori. Description theories assume the strategy to be designed during its implementation. According to these theories, strategy does not emerge from planning, but it emerges from practice, once an enterprise takes a series of actions repeatedly. Once recognized as recurrent, a series of actions might be understood as formally deliberated and, then, guide the overall enterprise behavior, as an enterprise behavior pattern. These behavior patterns are called the enterprise strategy and are not initially anticipated or intended (Mintzberg, Ahlstrand and Lampel, 1998).

The criticism on these strategic planning theories is that purely prescriptive strategic planning would imply in no adaptation and purely descriptive strategic planning would imply in no control. In fact, few, if any, strategies are purely deliberate and just as few are purely emergent. Strategy in the real world invariably involves both planning on the future and adapting the plan during operation. Most companies pursue a strategy informally termed as 'umbrella strategy', in which there is a mix of deliberate and emergent strategies (Mintzberg, Ahlstrand and Lampel, 1998) (Trainer, 2004). In this case, the general guidelines are deliberated and the details are left to be deliberated (or emerge) later in the process (Mintzberg, Ahlstrand and Lampel, 1998). Effective strategists mix deliberate and emergent strategies to reflect the conditions at hand, notably the expectation to deal with unknown elements, as they need to handle partial knowledge of future matters and to react to unexpected events. 
Thus, a requirement to an approach that aims to incorporate enterprise strategic plans into enterprise architecture is to allow both prescriptive and descriptive theories to be used in combination, in order to encompass the socalled 'umbrella strategy'.

\subsection{Strategic Planning Models}

Although the usage of each model depends on the theory used (prescriptive or descriptive), strategic planning is essentially defined in a few types of models (McNamara, 2001), (Bryson, 2011).

\subsubsection{Goal-Based Strategic Model}

The Goal-Based Model, also called Vision-Based, is widely-used in the industry and it is based on the mix of prescriptive and descriptive theories (McNamara, 2001) (Bryson, 2011) ${ }^{3}$. Further, it is considered to be the most adopted model of strategic planning (McNamara, 2001).

The Goal-Based strategic model is related to the prescriptive theories and the 'umbrella strategy'. To define the Goal-Based strategic model, it is necessary to express the enterprise mission, vision and its planned goals.

The planned enterprise goals are among the most important elements of the Goal-based strategic model. Goals should be accomplished in accordance with timing constraints. Usually, the first goals described are to be achieved in the long-term (e.g., five years from 'now'). They should be aligned with enterprise's mission and vision. Further, it is common that intermediate goals or milestones are described, as well as short-term goals (e.g., one year or less). Each of these goals can be related to other goals, usually in some sort of hierarchical view, in which goals are defined at lower-levels in order to facilitate the achievement of higher-level goals.

Further, goals might have a precedence order or might need to be accomplished before or after a certain date. Additionally, goals might require a time window in which they should be addressed and achieved (e.g., because of regulatory compliance; in the case of perishable products).

Goals might also be treated by the enterprise individually or in a bundle and might influence one another. Particularly, it should be assessed whether goals being planned are compatible with previously defined goals. In case a goal contradicts a previously defined goal, one of them should be revised. Goals can

3 The models described here are mainly based on descriptions in (McNamara, 2001), (Mintzberg, Ahlstrand and Lampel, 1998) and (Bryson, 2011). 
be the responsibility of specific departments, of individuals or the whole enterprise.

In addition, enterprises plan how their goals are to be achieved. For shortterm goals, it might be relevant to the enterprise to describe which are the operations required to realize the goals. It also might be relevant to describe the capabilities and resources required to achieve the goals. For mid-term and longterm goals, although the same approach can be applied, the enterprise might prefer not to detail how to perform the achievement of the goal, or might choose to refer only to the capabilities and resources required for achievement, in a strategy as capability-based planning (Stirna et al., 2012).

In some organizations, strategic planning is separately performed by different departments as well as different management levels, in which each department and management level has different responsibilities on the strategic planning. For example, high-level managers may describe the strategic part of the strategic plan and release it to lower-level managers, who refine the plan and describe how that plan should be implemented.

Thus, a requirement to an approach that aims to incorporate enterprise strategic plans into enterprise architecture is to have elements that encompass the goal-based strategic model.

\subsubsection{Other Strategic Planning Models}

The Issue-based strategic planning model (McNamara, 2001) defines how to overcome issues the enterprise is facing, instead of defining and planning on a future state in terms of goals. The issue-based model is concerned with a shorter period of time (e.g., a one-year plan) and is usually performed when the enterprise faces difficulties. To express the Issue-based model, it is necessary to express the perceived issues as well as their solution requirements.

The Alignment model is useful for enterprises that need to find out why their strategies are not working (McNamara, 2001). The overall steps of this model consist of: (i) outlining the enterprise's mission, programs and resources; (ii) identifying what is working well and what needs adjustment; (iii) identifying how these adjustments should be made and; (iv) including these adjustments in the strategic plan.

The Scenario Planning model (Bryson, 2011) is usually used in conjunction with other strategic planning models to improve strategic thinking. It assists in identifying strategic issues and goals using different views. Scenario planning consists of selecting several external forces and devising changes related with each of them, which might influence the organization (e.g., change in regulations, competition, new products or services included in the market). For each force, different future organizational scenarios (usually best, worst and reasonable cases) 
are discussed, in which they might result from a change. Then, potential strategies to each of these scenarios are identified. With that information, enterprises usually detect common strategies that can be employed to respond to multiple possible scenarios. The review of the worst cases usually identifies enterprise's weaknesses and motivates changes to avoid such cases.

The issue-based strategic planning model, the alignment strategic planning model and the scenario planning model are not considered in this thesis as strict requirements for incorporating enterprise strategic plans into EA. Nevertheless, we argue that the issue-based strategic planning model is similar in its conceptualization to the goalbased strategic planning model, if we consider "solving an issue" as a goal and that the alignment strategic planning model can be regarded as a mix of the goal-based strategic planning model and the issue-based strategic planning model.

The scenario planning model, in its turn, deals with treating possible different enterprise realities over time. Scenarios could be perceived as different EA instances. However, a full introduction of this approach would require relating the various EA instances, or EA version. We consider this outside the scope of the present thesis.

\subsection{Resources and Capabilities in the Enterprise}

A primary objective of strategic planning is to obtain and preserve superior enterprise performance (Miller and Cardinal, 1994) (Song et al., 2011) (AlShammari and Hussein, 2007). Management literature has aimed at understanding the origins of enterprise performance and how a superior enterprise performance can be maintained. Theoretical and empirical research indicates that enterprises' resources and capabilities are key elements that interfere in enterprises' performance (Barney, 1991) (Leiblein, 2011) (Ray, Barney and Muhanna, 2004) (Barroero, Motta and Pignatelli, 2010) (Teece, Pisano and Shuen, 1997) (Lee, 2001) (Kogut and Zander, 1992) (Barreto, 2009). This has inspired resource-based and capabilities-based theories in the management literature.

\subsubsection{Resource-based Theories}

In resource-based theories, "resources include all assets, capabilities, organizational processes, firm attributes, information, knowledge, etc.; controlled by a firm that enable the firm to conceive of and implement strategies that improve its efficiency and effectiveness" (Barney, 1991). In the language of traditional strategic analysis, enterprise resources are strengths the enterprise can use to conceive of and implement their strategies (Barney, 1991). Not all aspects 
of an enterprise's physical capital, human capital, and organizational capital are strategically relevant resources. Some of these enterprise attributes may prevent an enterprise from conceiving of and implementing valuable strategies (Barney, 1991). Still others may have no impact on an enterprise's strategizing processes. However, those attributes of an enterprise's physical, human, and organizational capital that do enable an enterprise to conceive of and implement strategies that improve its efficiency and effectiveness are considered enterprise resources (Wernerfelt, 1984).

The Resource-based theories state that in order to have a sustainable competitive advantage, firms must have resources that are valuable, rare, imperfectly imitable and that there are no other resources strategically equivalent to these. Otherwise, the competitive advantage is not sustainable. Resourcebased theories suggest that enterprises' resources can only be a source of competitive advantage or sustainable competitive advantage when they are valuable. "Resources are valuable when they enable a firm to conceive of or implement strategies that improve its efficiency and effectiveness [...]. Firm attributes may have the other characteristics that could qualify them as sources of competitive advantage (e.g., rareness, inimitability, non-substitutability), but these attributes only become resources when they exploit opportunities or neutralize threats in a firm's environment" (Barney, 1991).

Since the introduction of the resource-based theories, several major limitations have been identified. Amongst these, the most relevant are that valuable, rare, inimitable, and non-substitutable resources (Barney, 1991) are not necessarily sufficient for sustaining competitive advantage in a dynamic environment (Kraaijenbrink, Spender and Groen, 2010). While Barney's definition of "resources" alludes to "capabilities" and "organizational processes" as possible resources, the focus of resource-based theories has been on resources such as physical and human assets. (Henceforth, we use the term "resources" to refer to assets of these kinds.) However, resources by themselves are not useful unless they are correctly employed (Penrose, 1959) (Eisenhardt and Martin, 2000) (Kraaijenbrink, Spender and Groen, 2010). The way resources are used defines the outcome: (Penrose, 1959) stated that "exactly the same resources when used for different purposes or in different ways and in combination with different types or amounts of other resources provide a different service or set of services". Especially in situations of rapid and unpredictable change, "the rationale is that RBV [resource-based view] has not adequately explained how and why certain firms have competitive advantage" (Eisenhardt and Martin, 2000). 


\subsubsection{Capability-based Theories}

To cope with limitations of resource-based theories, capability-based theories have been defined (Eisenhardt and Martin, 2000). Capabilities include the local abilities and competencies that are fundamental to the competitive advantage of an enterprise, such as skills in molecular biology for biotech enterprises or in advertising for consumer product enterprises. Different authors have emphasized different aspects of capabilities, identifying special types. We, however, are interested in the capability concept as a whole, encompassing these special types of capabilities. Dynamic capabilities are " $[\mathrm{t}]$ he firms processes that use resources - specifically the processes to integrate, reconfigure, gain and release resources to match and even create market change. Dynamic capabilities thus are the organizational and strategic routines by which firms achieve new resource configurations as markets emerge, collide, split, evolve, and die" (Eisenhardt and Martin, 2000). This definition is similar to other definitions, such as Kogut and Zander (1992) which describes "organizational processes by which firms synthesize and acquire knowledge resources, and generate new applications from those resources' as combinative capabilities". Teece et al. (1997) understand that these capabilities are the drivers behind the creation, evolution, and recombination of other resources into new sources of competitive advantage.

The intrinsic relation between resources and capabilities has been further researched in the work presented in (McKelvie and Davidsson, 2009). Many organizations have been analyzed in order to answer the question "to what extent do access and changes to resource bases influence the development of dynamic capabilities in new firms?". The work provides statistical evidence for the relationship between organizational resources and the subsequent capabilities of the organization. According to the capability-based theories, the enterprise needs to know the capabilities it wants to leverage in order to use and plan to acquire resources in an intended manner. The capability-based theories can be used in conjunction with resource-based theories. In this sense, the enterprise needs to understand the capabilities it wants to leverage. Further, the enterprise is required to plan on how to acquire those capabilities, including the acquisition (or training of) the required resources in order to accomplish enterprise's intentions.

\subsection{Conclusions}

In this Chapter, we have revised the two main strategic planning theories, the prescriptive and descriptive theories. We have further revised the main strategic 
planning models, in which its concepts are required to be incorporated in an approach to incorporate strategic planning into EA.

We also discuss the capability-based and resource-based theories, which are used in both management and strategic planning. Research in management literature indicates that capabilities and resources are key to account for enterprise performance. Thus, we conclude that an approach to incorporate strategic plans into EA should allow enterprises to express its capabilities and resources, supporting enterprises' usage of capabilities and resource theories. 


\section{Enterprise Architecture}

In this chapter we introduce Enterprise Architecture as a discipline, in section 3.1 , then focuses on requirements to incorporate strategic plans and strategic concerns into this discipline, in section 3.2. We identify requirements concerning the representation of strategic plans and their relation to operational aspects of the enterprise. Further, we give a summary of a number of prominent EA frameworks and discuss their support to the identified requirements in section 3.3. Finally, we conclude the chapter in section 3.4.

\subsection{Introduction}

Enterprise Architecture can be traced to Information Planning, in the 80's (Boynton and Zmud, 1987). With software applications becoming larger and with various business processes sharing information, people became aware that the development of information technology (IT) should be done in conjunction with the development of the context in which it was used (Op 't Land et al., 2009).

When the IT industry got confronted with complex structures and decisions, the idea of architecture was introduced as a means to foster alignment in the enterprise. Architecture is defined by the ISO/IEC/IEEE 42010 recommendation (ISO, IEC and IEEE, 2011) as "fundamental concepts or properties of a system in its environment embodied in its elements, relationships, and in the principles of its design and evolution”.

In an enterprise architecture, the enterprise is the system, and the architecture is focused on the design, relationships and evolution of the enterprise-related components, such as its organizational structure, business processes, services, products, IT assets and infrastructure (IEEE, 2000). Enterprise architecture is used as a means to manage the combination of enterprise elements and its complex relationships. 
In order to support the design, modeling and management of the different components (or parts) of an enterprise and its interaction, Enterprise Architecture Frameworks have been proposed. According to the ISO/IEC/IEEE 42010, "[a]n architecture framework establishes a common practice for creating, interpreting, analyzing and using architecture descriptions within a particular domain of application or stakeholder community" (2011). An Architecture Description is "a work product used to express the Architecture of some System Of Interest.[...] An Architecture Description may take the form of a document, a set of models, a model repository, or some other form" (2011).

An Enterprise Architecture Framework (EAF) provides principles and practices for creating, managing and using the architectural description of an enterprise. It provides means to verify enterprise architecture completeness, in terms of scope and level of detail, to give insight into interrelationships of the enterprise architecture and to enable the traceability of decisions and their impact (Op 't Land et al., 2009). The EAF common approach is to separate the enterprise into different parts (hereby called aspects), each of which with a specific focus, covering a specific viewpoint of the enterprise. For example, the Business Layer, in The Open Group Architecture Framework (TOGAF) "focuses on products and services offered to external customers".

EA frameworks also support enterprise governance. Governance is "the activity of [...] controlling a company or an organization" (Oxford, 2005). Enterprise architecture aims at improving the governance of an enterprise and to support its transformations. EAF provides models, tools and/or approaches to design, model and manage (i.e., to control) the enterprise.

Ideally, enterprise architecture plays a key role in the continuous improvement of an enterprise (Op 't Land et al., 2009). In this sense, one can assume that enterprise architecture discipline and EA frameworks supports enterprises' strategic plans. However, most enterprise architecture frameworks are still struggling with goal modeling and often lack expressiveness for concerns at higher levels of abstraction, such as enterprise strategy and strategic plans. In the remainder of this Chapter we discuss enterprise architecture support for enterprises' strategic plans, including the support by EA frameworks.

\subsection{Requirements for Strategic Plan Support in EA}

This section discusses requirements for the enterprise architecture discipline to support and incorporate strategic plans into $\mathrm{EA}^{4}$. We take into account the

\footnotetext{
${ }^{4}$ This section main work has been published in (Carlos L B Azevedo, Van Sinderen, et al., 2015)
} 
theories and models discussed in Chapter 2. We discuss four major lines of requirements in order for enterprise architecture to support strategic plans.

\subsubsection{Description of Strategic-level Concerns}

As described in Chapter 2, in order to support strategic plans, EA should ideally support descriptive and prescriptive theories (Mintzberg, Ahlstrand and Lampel, 1998) (Trainer, 2004). In order to support these theories, EA must support the model which enterprises uses to describe its strategic plan. The GoalBased strategic model ${ }^{5}$ is believed to be the most used model in strategic planning (McNamara, 2001). This model is well-used in the industry and is based on the mix of prescriptive and emerging theories (McNamara, 2001) (Bryson, 2011). This model expresses enterprises intentions and how the enterprise aims at fulfilling these intentions ${ }^{6}$.

According to the description and description theories, and further, according to the Goal-Based strategic model, in order to support describing enterprises intentions, the EA must support describing enterprises' mission, vision and its planned goals. Additionally, it should support describing goal's individual properties, such as the time window in which it goal should be accomplish (e.g., two years after implementation), as stated in Chapter 2. Further, EA must be able to describe goals relations, as goals can be related to other goals, including a sort of hierarchical view (in which new goals are defined to facilitate achievement of higher-level goals), as well as in precedence order.

In addition, an EA approach to support enterprise strategic plans should also be concerned with encompassing other strategic planning models that are usually used with the goal-based strategic planning model. As described in section 2.2.2, The Scenario Planning model intends to enhance strategic thinking. It consists of selecting external forces and devising changes which might influence the organization (e.g., change in regulations, competition, new products or services included in the market). Then, different future organizational scenarios (usually best, worst and reasonable cases) are discussed and potential strategies to each of these scenarios are identified. These potential strategies are acquired using enterprises' favorite strategic planning model, usually in a less extended approach. As described in section 2.2.2, full support of the Scenario Planning model would require different EA instances to be related. Due to this fact, Scenario Planning is not considered as a requirement in this thesis. However, the requirements defined in this thesis cover the strategies devised in each scenario planned using the Scenario Planning model.

\footnotetext{
${ }^{5}$ Also called Vision-Based strategic model.

${ }^{6}$ For a full detail of the Goal-Based Strategic Model description requirements we refer the reader to Section 2.2.1.
} 


\subsubsection{Capabilities and Resources for Handling Enterprise Strategic Level Concerns}

The enterprise architecture must deal with how the enterprise approaches its concerns. In enterprises, goals might be treated by the enterprise individually or in a bundle. Goals might also influence one another. The responsibility of achieving goals also need to be described. Goals can be the responsibility of specific departments, of individuals or the whole enterprise. The EA approach must allow strategic plans to be described with different responsibilities for different management levels.

In addition, enterprises plan how their goals are to be achieved. The EA approach should be able to describe and support how to realize these plans. In fact, since capabilities and resources are regarded as key factors for enterprise's superior performance (Barney, 1991), (Teece and Pisano, 1994), (Eisenhardt and Martin, 2000) (as discussed in Chapter 2) an EA approach should be able to describe the required capabilities and resources in order to achieve enterprise goals.

\subsubsection{Traceability of Strategic Plans to Operational Aspects}

In order to proper introduce strategic plans into EA, being able to trace the strategic decisions to the EA operational level is a requirement. An EA approach must introduce or use concepts to relate the current strategic plan to the current enterprise architecture. The EA can facilitate a traceability between the strategic decisions and how they are actually being implemented, working as a middle ground between enterprise's operations and enterprise's strategic plan. Further, tracing strategic plans to EA operational level can support the enterprise in its planning phase, in change impacts analysis and in change management analysis. The traceability could also support analysis on enterprise's strategic planning achievement monitoring.

\subsubsection{Coherent Architectural Descriptions}

A main challenge to EA to support strategic plans is in the identification of a precise conceptualization for the strategic notions. Precise semantic definitions for the strategic concepts and its consequently modeling elements in EA is key, otherwise inaccurate or ambiguous conceptualizations can occur. This could lead to modeling and communication problems (Guarino, 1998). In particular, we point out that strategic decisions are to impact the whole enterprise and, thus, a problem such as the false agreement (Guarino, 1998), deeply impacts the enterprise. The false agreement happens when model users have different 
interpretations of the same model, but believe they have a shared interpretation. This is an example of the consequences of constructs semantic problems ${ }^{7}$.

In the next section, we introduce enterprise architecture frameworks and present a panorama of their support for strategic concerns of enterprises, focusing specifically on strategic plan elements.

\subsection{Current Support for Strategic Plans in EA Frameworks}

In this section, we consider the support for strategic plans in a number of $E_{A F}^{8}$. We focus on those frameworks that are prescribed in standards and that cover some strategic or motivational aspect. Although strictly not a standard, we also include here the Zachman framework given its seminal role in the enterprise architecture discipline. We give extra attention to their relation to enterprise strategic plans and objectives.

Most enterprise architecture frameworks, if not all, use the idea of dividing the enterprise into logical blocks (also termed perspectives, aspects or views), as postulated by Zachman (Zachman, 1987). This idea has been widely adopted by the enterprise architecture community and is incorporated into most enterprise architecture frameworks. As such, we start our description of EAF with the Zachman framework.

\subsubsection{The Zachman Framework for Enterprise Architecture}

The Zachman framework was introduced by John Zachman in his seminal work (1987), and is considered to be one of the first frameworks for EA. The main contributions of the Zachman framework was the goal of architecting the enterprise in some logical blocks and managing the enterprise with respect to those blocks. The Zachman Framework has six perspectives or views: Scope, Enterprise Model, System Model, Technology Model, Detailed Representation, and Functioning System. Each of these perspectives is contrasted with a second dimension, in order to answer Zachman's six basic questions: (i) what: what is done, expected results; (ii) how: how the what is performed; (iii) where: physical or logical location it is performed; (iv) who: who is responsible or allocated for the performance; (v) when: timing requirements; and (vi) why: motivation (Kappelman and Zachman, 2013). This creates a matrix in which each cell is an

\footnotetext{
${ }^{7}$ Discussed in more details in Chapter 4.

8 The enterprise architecture frameworks descriptions are based on, and has parts of text extracted from the frameworks documentation.
} 
outcome of an architecture activity based on both perspectives. Figure 5 illustrates the framework.

\begin{tabular}{|c|c|c|c|c|c|c|}
\hline & $\begin{array}{l}\text { What } \\
\text { (Data) }\end{array}$ & $\begin{array}{c}\text { How } \\
\text { (Function) } \\
\end{array}$ & $\begin{array}{c}\text { Where } \\
\text { (Locations) } \\
\end{array}$ & $\begin{array}{c}\text { Who } \\
\text { (People) } \\
\end{array}$ & $\begin{array}{l}\text { When } \\
\text { (Time) } \\
\end{array}$ & $\begin{array}{c}\text { Why } \\
\text { (Motivation) }\end{array}$ \\
\hline $\begin{array}{c}\text { Scope }\{\text { contextual\} } \\
\text { Planner }\end{array}$ & $\begin{array}{c}\text { List of things } \\
\text { important to the } \\
\text { business }\end{array}$ & $\begin{array}{c}\text { List of } \\
\text { processes that } \\
\text { the business } \\
\text { performs }\end{array}$ & $\begin{array}{c}\text { List of locations } \\
\text { in which the } \\
\text { business } \\
\text { operatses }\end{array}$ & $\begin{array}{c}\text { List of } \\
\text { organizations } \\
\text { important to } \\
\text { the business }\end{array}$ & $\begin{array}{c}\text { List of } \\
\text { events/cycles } \\
\text { important to } \\
\text { the business }\end{array}$ & $\begin{array}{l}\text { List of business } \\
\text { goals/strategies }\end{array}$ \\
\hline $\begin{array}{c}\text { Enterprise Model } \\
\text { \{conceptual\} } \\
\text { Business Owner }\end{array}$ & $\begin{array}{l}\text { e.g. Semantic } \\
\text { Model }\end{array}$ & $\begin{array}{c}\text { e.g. Business } \\
\text { Process Model }\end{array}$ & \begin{tabular}{|c|} 
e.g. Business \\
Logistics System
\end{tabular} & $\begin{array}{l}\text { e.g. Workflow } \\
\text { Model }\end{array}$ & $\begin{array}{l}\text { e.g. Master } \\
\text { Schedule }\end{array}$ & e.g. Business Plan \\
\hline $\begin{array}{c}\text { System Model } \\
\{\text { logical\} Designer }\end{array}$ & $\begin{array}{c}\text { e.g. Logical Data } \\
\text { Model }\end{array}$ & $\begin{array}{l}\text { e.g. Application } \\
\text { Architecture }\end{array}$ & $\begin{array}{l}\text { e.g. Distributed } \\
\text { System } \\
\text { Architecture }\end{array}$ & $\begin{array}{l}\text { e.g. Human } \\
\text { Interface } \\
\text { Architecture }\end{array}$ & $\begin{array}{l}\text { e.g. Process } \\
\text { Structure }\end{array}$ & $\begin{array}{c}\text { e.g. Business Rule } \\
\text { Model }\end{array}$ \\
\hline $\begin{array}{c}\text { Technology Model } \\
\text { \{physical\} } \\
\text { Implementer }\end{array}$ & $\begin{array}{c}\text { e.g. Physical Data } \\
\text { Model }\end{array}$ & $\begin{array}{l}\text { e.g. System } \\
\text { Design }\end{array}$ & $\begin{array}{l}\text { e.g. Technology } \\
\text { Architecture }\end{array}$ & $\begin{array}{c}\text { e.g. } \\
\text { Presentation } \\
\text { Architecture }\end{array}$ & $\begin{array}{l}\text { e.g. Control } \\
\text { Structure }\end{array}$ & e.g. Rule Design \\
\hline $\begin{array}{c}\text { Detailed } \\
\text { Representation \{out } \\
\text { of-context\} } \\
\text { Subcontractor }\end{array}$ & $\begin{array}{l}\text { e.g. Data } \\
\text { Definition }\end{array}$ & e.g. Program & $\begin{array}{l}\text { e.g. Network } \\
\text { Architecture }\end{array}$ & $\begin{array}{l}\text { e.g. Security } \\
\text { Architecture }\end{array}$ & $\begin{array}{l}\text { e.g. Timing } \\
\text { Definition }\end{array}$ & $\begin{array}{l}\text { e.g. Rule } \\
\text { Definition }\end{array}$ \\
\hline Functioning System & e.g. Data & e.g. Function & e.g. Network & $\begin{array}{c}\text { e.g. } \\
\text { Organization }\end{array}$ & e.g. Schedule & e.g. Strategy \\
\hline
\end{tabular}

Figure 5 - The Zachman Framework

Zachman realized the need to use some logical form to manage the enterprise, which he later called architecture. "[T]he increased scope of design and levels of complexity of information systems implementations are forcing the use of some logical construct (or architecture)". The Zachman framework suggests the dimensions and exemplifies the types of models that should be in each cell. However, the Zachman framework provides no actual support to the enterprise in how to perform the framework recommendations. The framework only provides brief descriptions of architectural outcomes and no description of the architectural processes. As to the description of motivational aspects, as a general framework Zachman does not further elaborate on a language for representation of his "why" column.

However termed as a framework by Zachman, the Zachman framework is more of a taxonomy than an architectural framework. The framework does not "establish a common practice for creating, interpreting, analyzing and using architecture descriptions", as required to be an architectural framework according to the IEEE (ISO, IEC and IEEE, 2011). According to the American Heritage Dictionary, a taxonomy is defined as " $[\mathrm{t}]$ he classification of organisms in an ordered system that indicates natural relationships; The science, laws, or

9 "taxonomy". The American Heritage Dictionary of the English Language. Fourth Edition. Boston, MA: Houghton Mifflin Company, 2006. 
principles of classification; systematics; Division into ordered groups or categories".

\subsubsection{The ISO Reference Model for Open Distributed Processing (ISO RM-ODP)}

The ISO Reference Model for Open Distributed Processing (ISO RM-ODP) is a reference model in computer science, which provides a coordinating framework for the standardization of open distributed processing (ODP). The ISO RM-ODP aims to provide a framework for specifying and building large or complex systems. The ISO RM-ODP Standards is a set of international standards composed of four parts. Part 1 (ISO 10746-1/ITU-T X.901) provides an overview and a guide to the use of the reference model. Part 2 and Part 3 (ISO 10746-2/ITU-T X.902 and ISO 10746-3/ITU-T X.903) provide a foundation of concepts and prescribe concepts, rules and functions for the modeling of ODP systems. Part 4 (ISO 10746-4/ITU- T X.904) is the architectural semantics which provides a formal description technique for Part 2 and Part 3. The primary objective is to allow the benefits of distribution of information processing services to be realized in an environment of heterogeneous IT resources and multiple organization domains.

The RM-ODP defines a framework, but not a methodology. It gives the designer a way of thinking about the system, and structuring its specification, but does not constrain the order in which the design steps should be carried out. The RM-ODP is defined in five separate viewpoints. Each of these viewpoints satisfies an audience with interest in a particular set of aspects of the system. Associated with each viewpoint is a viewpoint language that optimizes the vocabulary and presentation for the audience of that viewpoint. Among the five RM-ODP viewpoints, the most relevant viewpoint for this thesis is the enterprise viewpoint $^{10}$. We briefly introduce the five viewpoints below:

- The enterprise viewpoint focuses on the organizational situation in which the design activity is to take place. It concentrates on the objectives, business rules and policies that need to be supported by the system being designed. The stakeholders to be satisfied are therefore the owners of the business processes being supported and the managers responsible for the setting of operational policies. The emphasis is on business and social units and their interdependencies;

- The information viewpoint concentrates on the modeling of the shared information manipulated within the enterprise of interest.

10 Viewpoints description adapted from: (Linington et al., 2011) 
- The computational viewpoint is concerned with the development of the high-level design of the processes and applications supporting the enterprise activities.

- The engineering viewpoint tackles the problem of diversity in infrastructure provision;

- The technology viewpoint is concerned with managing real-world constraints, such as restrictions on the hardware available to implement the systems.

The enterprise viewpoint is based on the concept of community, which is a part of the enterprise that shares common objectives. The community defines its objectives and define a way to pursue and achieve those objectives, usually in terms of business processes (Linington et al., 2011). In the ISO RM-ODP, an objective can be refined into other objectives. This concept can be related to process, community or roles. Possible relations are that a community has an objective, which might represent ownership, and refined goals can be assigned to both processes or roles. In this sense, the language allows the modeler to define the business objects and roles which are required for achieving the objectives. The business objects usually represent resources.

Although there are objectives, which can be refined and assigned to roles and processes, there is a limited support for expressing goal relationships, such as requirements for goals. There is also no support for context modeling or different scenarios. Additionally, there is no support to represent enterprise mission, vision and there is no support to represent different strategies. Thus, the RM-ODP EA framework provides limited support for using and representing strategic plans.

\subsubsection{Department of Defense Architecture Framework (DoDAF)}

The Department of Defense Architecture Framework (DoDAF) is an architecture framework for the use of the United States Department of Defense. It aims at "enabling the development of architectures to facilitate the ability of [United States] Department of Defense (DoD) managers to make key decisions more effectively through organized information sharing across the Department, Joint Capability Areas (JCAs), Mission, Component, and Program boundaries”. The DoDAF serves supporting the Department of Defense Chief Information Officer in his responsibilities for development and maintenance of architectures. DoDAF is prescribed for the use and development of Architectural Descriptions. It also provides guidance on the development of architectures supporting the adoption and execution of Net-centric services within the Department of Defense.

The DoDAF framework is comprised of eight viewpoints: the capability viewpoint, the data and information viewpoint, the operational viewpoint, the 
project viewpoint, the services viewpoint, the standards viewpoint, the systems viewpoint and the all viewpoint, which comprises overarching aspects of the architecture, such as the ones related to enterprise goals. The most important viewpoints in the scope of this thesis are the all viewpoint and the capability viewpoint.

The all viewpoint is used to capture the scope of the architecture. It provides information pertinent to the entire Architectural Description rather than representing a distinct viewpoint. It provides the purpose and perspective of the architecture, its context, assumptions and constraints.

The all viewpoint is, actually, used as an executive summary. On the motivational part of the architecture, the all viewpoint is expected ${ }^{11}$ to have the "mission, doctrine, relevant goals and vision statements, concepts of operation, scenarios, information assurance context (e.g., types of system or service data to be protected, such as classified or sensitive but unclassified, and expected information threat environment), other threats and environmental conditions". Although termed as a viewpoint and described by the DoDAF framework such as that, the all viewpoint is expected to be a textual description and has no models exclusively associated with it. In fact, the DoDAF metamodel does not include concepts as goal and mission. However, it is worth mentioning that DoDAF has a concept termed desired effect, which is to be used in a similar way as a goal concept would. The existent relations are to represent that vision is realized by desired effect. There is also an activity concept, used to relate the desired effect to activities, in which a desired effect directs an activity.

The capability viewpoint has been introduced into DoDAF in 2009, in its 2.0 version. The viewpoint is intended to "address the concerns of Capability Portfolio Managers. In particular, the Capability Models describe capability taxonomy and capability evolution". It has been motivated on the (US) Department of Defense need to provide visualizations of the evolving capabilities, to provide the synchronization for introduction of capability increments and to capture the relationships between interdependent projects and capabilities, especially on benefit-driven projects. According to the DoDAF descriptions, it is used to support managing the risks of complex procurements, including military situations.

In the DoDAF documentation, the required capabilities should be mapped to the operational activities that those capabilities support. Capabilities should be planned and are associated with different sub-viewpoints: (i) the capability phasing, which provides the planned achievement of capability at different points in time or during specific periods of time; (ii) the capability dependencies, which provide the dependencies between planned capabilities and the definition of

11 expected, but not mandatory. 
logical groupings of capabilities; (iii) the capability to organizational development mapping, which provides the fulfillment of capability requirements and show the planned capability deployment and its interconnection for a particular Capability Phase; (iv) the capability to operational activities mapping, which provides a mapping between the capabilities and the operational activities that those capabilities support; and (v) the capability to services mapping, which provides a mapping between the capabilities and the services that these capabilities enable, respectively.

In DoDAF models, the capabilities are present both as a type and as a type of types (IndividualTypeType). They can be related with Performer, Activity, Capability Type and Resource, and can be associated with Desired Effects.

DoDAF has an increasing support for the usage of capabilities and aims to map capabilities to operations and services. However, there is limited support to express the motivational part in DoDAF, goals (desired effects) and its relationships, such as requirements for desired effects, and refinements and decompositions of desired effects. At the strategic level, there is a limited support for the usage of capabilities, since there is no map of capabilities to desired effects, the DoDAF concept that resembles goals. Further, it would not be possible to trace from enterprises mission and vision to the operational part of the enterprise. The approach to use desired effects direct related to processes and services resembles an approach in which the desired effect is not strategic, since it cannot be related to other desired effects, nor be composed in order to compose a higher-level desired effect. This notion is further suggested by the name of the concept, desired effect, resembling something more palpable than goals or objectives (e.g., soft goals from goal modeling, strategic goals from management area). Thus, we conclude that there is limited support for the planning of different scenarios and the description of what strategy to follow in which scenario; Limited support for linking strategy with the EA; Limited support for relating strategic plan goals to enterprise architecture elements, since there is no connection between the enterprise mission and vision to other goals. We conclude that there is limited support to use DoDAF as to adequately introduce and relate strategic plans to EA.

\subsubsection{MODAF}

The Ministry of Defence Framework (MODAF) is an enterprise architecture framework developed by the British Ministry of Defence to support defense planning and change management activities. It aims to enable "the capture and presentation of information in a rigorous, coherent and comprehensive way that aids the understanding of complex issues". The MODAF has been developed based on 
DoDAF version 1.0 and it is similar to it. MODAF is divided into 7 view categories:

i. Strategic views ( $\mathrm{StVs}$ ) define the desired business outcome, and what capabilities are required to achieve it.

ii. Operational views (OVs) define (in abstract rather than physical terms) the processes, information and entities needed to fulfil the capability requirements.

iii. Service oriented views (SOVs) describe the services, (i.e. units of work supplied by providers to consumers), required to support the processes described in the operational views.

iv. Systems views (SVs) describe the physical implementation of the operational and service orientated views and, thereby, define the solution.

v. Acquisition views (AcVs) describe the dependencies and timelines of the projects that will deliver the solution.

vi. Technical views (TVs) define the standards that are to be applied to the solution.

vii. All views (AVs) provide a description and glossary of the contents of the architecture.

The motivational part in MODAF is mainly covered by the Strategic Views. In these views, aiming to cover the strategic part of the enterprise, MODAF has the concepts of Enterprise Vision, Vision statement and the concept of goal. MODAF also has the concept of capability, which can be indirectly related with the Enterprise Vision relating both concepts to enterprise task. Goals can only be related to the Enterprise Vision. Figure 6 presents a fragment of MoDAF metamodel (as is), concerned with capabilities, goals and vision.

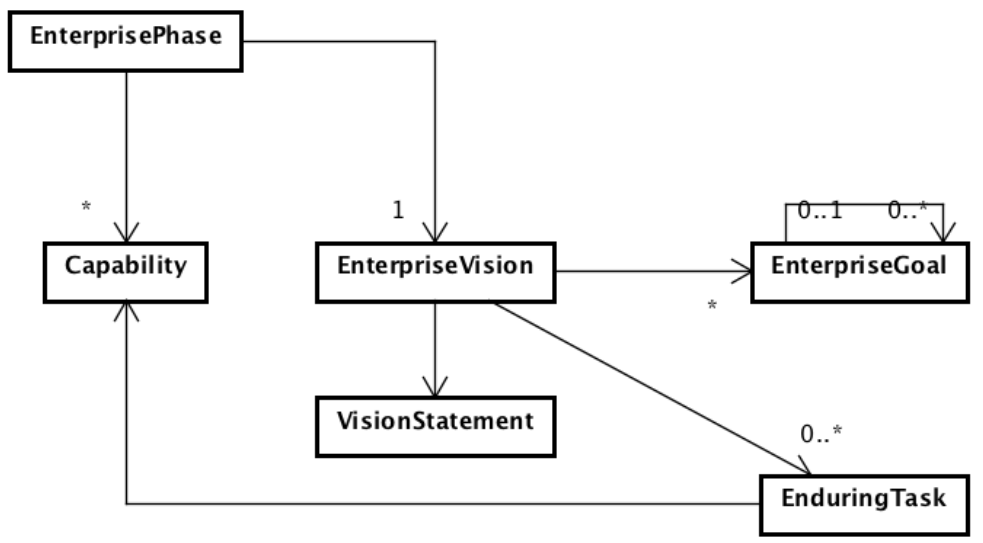

Figure 6 - MODAF metamodel fragment - adapted from (Ministry of Defence 2013) 
However, MODAF has concepts related to mission (not expressed in Figure $6)$, vision, goals and capabilities. The relation between these concepts, as shown in Figure 6 does not allow one to relate the goals with the required capabilities to perform those goals. The same is applicable to enterprise vision. At first, it seems naïve to believe that one is able to specify the required tasks to achieve the enterprise vision by the time this is defined. Further, MODAF lacks the notions of refinement or decomposition of goals, thus the enterprise is not able to state which are its higher level goals and its lower level goals. We conclude that there is: Limited support for relating the strategy with the EA; Limited support to relate strategic planning goals to enterprise architecture elements, allowing the specification of required elements for each goal; Limited support for the planning of different scenarios and the description of what strategy to follow in which scenario. Thus, we believe there is a limited support to represent enterprise strategy and its strategic plan and to relate it to the EA in MODAF.

\subsubsection{OMG Business Motivation Model (BMM)}

The Business Motivation Model (BMM) aims at providing "a scheme or structure for developing, communicating, and managing business plans in an organized manner" (OMG, 2010). Specifically, the Business Motivation Model aims at:

- Identifying factors that motivate the establishing of business plans.

- Identifying and defining the elements of business plans.

- Indicating how all these factors and elements inter-relate.

The BMM also provide governance for and guidance to the business. There are two major areas of the Business Motivation Model:

- The first is the Ends and Means of business plans. Among the Ends are things the enterprise wishes to achieve (for example, Goals and Objectives). Among the Means are things the enterprise will employ to achieve those Ends (for example, Strategies, Tactics, Business Policies, and Business Rules).

- The second is the Influencers that shape the elements of the business plans, and the Assessments made about the impacts of such Influencers on Ends and Means (i.e., Strengths, Weaknesses, Opportunities, and Threats).

The Ends, Means, and Influencers are related to each other in order to answer the following questions:

- What is needed to achieve? What the enterprise wishes to achieve? These questions are answered by laying out the particular elements of the business plans (in other words, the Means necessary to achieve the desired Ends). 
- Why does each element of the business plan exist? This question is answered by identifying the particular Ends that each of the Means serves, and the Influencers that underlie the choices made in this regard.

The elements of the Business Motivation Model are developed from a business perspective. The basic idea is to develop a business model for the elements of the business plans, before system design or technical development has begun. In this manner, the business plans should become a foundation for these activities.

The Business Motivation Model is not a full business model. It is not concerned with, for example: Business Processes, Workflows nor Business Vocabulary. The Business Motivation Model is not a methodology. It is neutral with respect to methodology or particular approach, with only some general exceptions. It might not be considered an Enterprise Architecture, due to its enterprise coverage. However, it is mentioned in this section due to its relevance to the motivational part of enterprise architectures.

The OMG BMM framework is primarily divided into Ends and Means. An End is "something the business seeks to accomplish". It includes concepts such as vision, goals and objectives. Mean represents elements "that may be called upon, activated, or enforced to achieve Ends". Means are further specialized into Courses of Action (Strategy and Tactics) and Directives. Although the BMM framework introduces concepts that appear to be aligned with strategic planning, the framework lacks important notions for strategic planning. The framework higher-level elements (e.g., goals, strategies) can't be related with those responsible for achieving it (only to whom have established it) or with required resources to achieve it, without getting into details of how to perform the element execution. For example, it is not possible to define who is responsible for achieving a strategy or a goal in the framework without defining a business process and, then, who is to perform it. This is especially relevant for cases in which more than one business process are executed and there are different actors responsible for executing each process. Further, resources that are required in order to achieve a goal (or strategy) are to be defined in its usage, for example at the business process level. Thus, however at a first glance the BMM appears to have proper concepts, the framework lacks possibilities for modeling strategic planning in the level required by higher-level managers, which are interested in capturing what is to be achieved and, only further, and in a high level of abstraction, the 'how', frequently in an open delegation (in which the how is left for the responsible for it to define). Further, the BMM framework would not be completely suitable for enterprises that pursue the 'umbrella strategy' (Mintzberg, Ahlstrand and Lampel, 1998).

Additionally, the BMM framework (Object Management Group, 2014) has no proper concept to represent timing constraints. Timing constraints can only be 
represented if instructed in the label of the timed constrained model element (e.g., in the goal label). Thus, it becomes impractical to plan on what is required for the EA to support the required capabilities, resources, products and services the enterprise is to deliver with adequate timing. We argue this is one of the most important benefits allowed by the introduction of strategic plans into EA approaches. Summarizing, we argue that there is: limited support for linking strategy with the EA since BMM does not focus on EA aspects; No support for stating when a goal or milestone should be achieved, including precedence between goals; Limited support for using strategic plans to plan on the EA in its short, mid, and long-term and; Limited support for the planning of different scenarios and the description of what strategy to follow in which scenario. Thus, we conclude BMM is still not suitable for representing strategic plans in EA and relating EA to enterprise strategic plans.

\subsubsection{The Open Group Architecture Framework (TOGAF)}

The Open Group Architecture Framework is an enterprise architecture framework, which provides methods and tools for assisting the acceptance, production, use, and maintenance of an enterprise architecture. It is based on an iterative process model and a re-usable set of existing architecture assets.

TOGAF provides a method, the Architecture Development Method (ADM), which is mainly based on guidelines for developing an enterprise architecture. The method is based on eight phases, which are then further developed into steps. Figure 7 shows the ADM phases.

The method is based on eight phases, labeled from A to $\mathrm{H}$ in Figure 7. The phase dedicated to enterprise strategy and strategic plans is considered a preliminary phase and is not completely covered by the ADM method (at the top of Figure 7). This preliminary phase is understood to be performed in prior to the TOGAF phases. TOGAF is not concerned with how to do the preliminary phase nor with documenting it. In case this preliminary phase has not been performed in prior, TOGAF advises it to be performed using any method and then, the TOGAF ADM method should be started. No guidelines to perform it are given and no documentation of the enterprise strategy is modeled in TOGAF. 


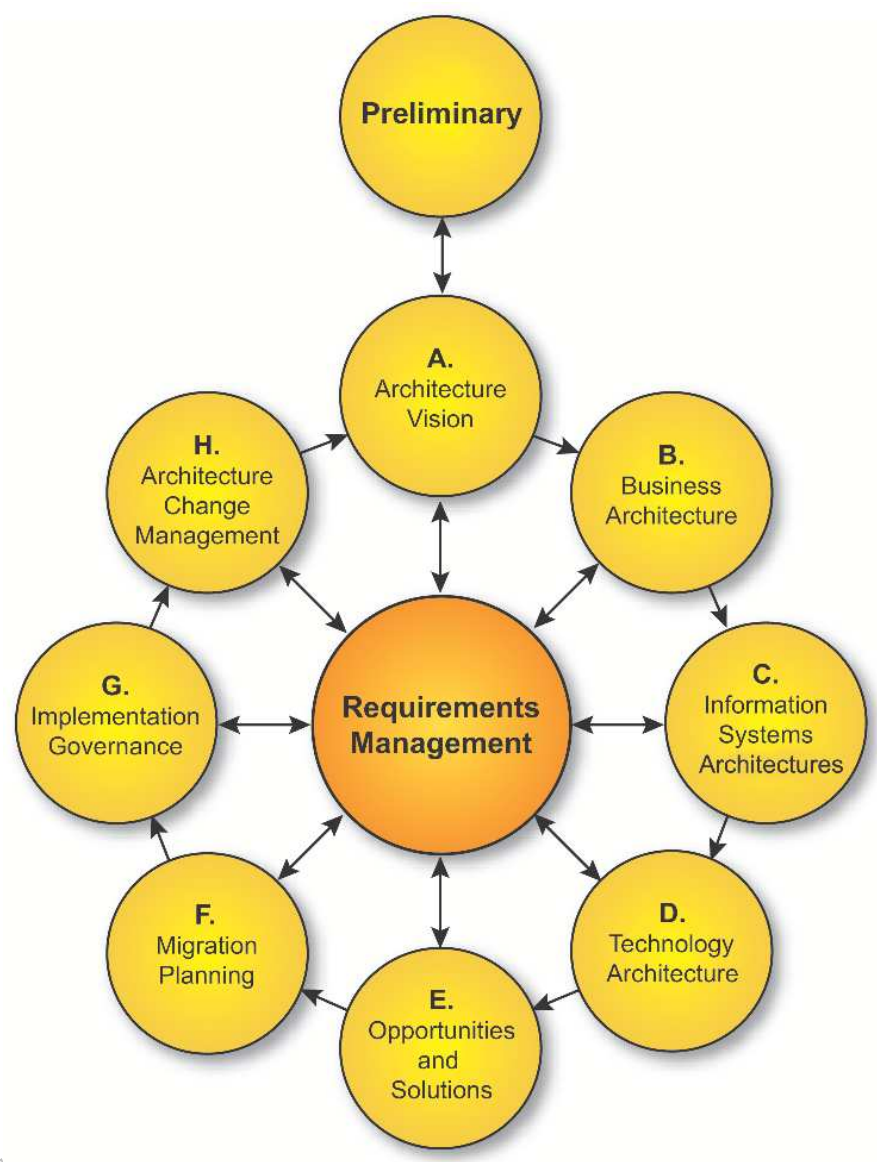

Figure 7 - TOGAF ADM Method

Another part of the method that is related to the motivational part of enterprises is the ArchiMate modeling language, which is suggested to be used in conjunction with TOGAF. The ArchiMate modeling language has a motivation extension, which adds the ability to model motivational elements to the language. The idea of the original motivation extension is that enterprise goals should be translated into requirements and that those requirements should be addressed by the enterprise architecture. Figure 8 presents an ArchiMate metamodel fragment related to the motivation extension, as in its version $2.1^{12}$.

12 By the time of development of this thesis, ArchiMate version 2.1 was the current ArchiMate version. By the time of the writing of this thesis, ArchiMate released its version 3.0. 


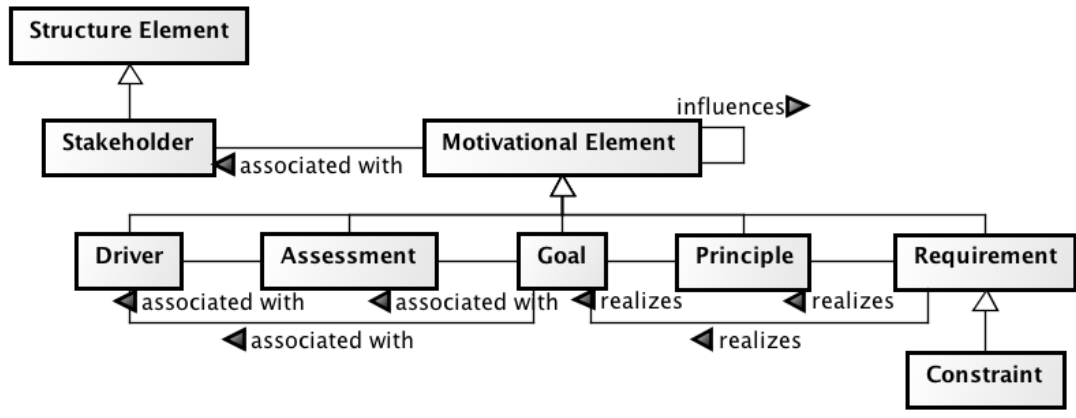

Figure 8 - ArchiMate Motivation Extension metamodel fragment (The Open Group, 2012)

As the other EAF and EA languages, ArchiMate lacks important distinctions in order to represent strategic plans. There is no support to express enterprise mission and vision. Further, there is no support to relate the enterprise strategy with the EA. There is also no support for capabilities modeling, context modeling and how capabilities and context can affect strategic planning and long-term EA ${ }^{13}$. Thus, we conclude that the ArchiMate, as in its 2.1 specification, would not be suitable to represent strategic plans.

\subsubsection{Summary}

Based on the sections above, we conclude that none of the compared frameworks supports the explicit representation of strategic plans concepts and its relations. We summarize the limitations found in the list below:

(i) Limited support for expressing goal relationships as stated in Chapter 2, specifically in Section 2.2 ;

(ii) Limited support for partial planning of the enterprise strategy, leaving details to emerge;

(iii) Limited support for relating strategic concerns with operational aspects of the EA;

(iv) Limited support for enterprises to model their capabilities and resources;

(v) Limited support for relating strategic plan goals to enterprise architecture elements, allowing the specification of required elements for each goal;

(vi) No support for stating when a goal or milestone should be achieved, including precedence between goals;

13 The ArchiMate concept of driver might be used to represent external factors, however, the language would not introduce how this can affect the enterprise strategic plan and the EA in its long-term. 
(vii)Limited support for the planning of different scenarios and the description of what strategy to follow in which scenario;

\subsection{Discussions}

In this Chapter, we have presented general requirements towards the extension of enterprise architecture frameworks to incorporate strategic plans into EA. We have introduced enterprise architecture frameworks and argued that there is a limited support for describing enterprise's strategic plans in EA. We also argue that the usage of EA in conjunction with strategic plans should be mutually beneficial to the practices of strategic planning and EA.

We listed several limitations of the current frameworks. In particular, we state that EA frameworks coverage of strategic planning concepts is incipient. We have also outlined that EA can be used as a bridge to achieve an end-to-end traceability between strategic plans and enterprise's operations. Nevertheless, we also focus on how EA can improve enterprise's strategic plans monitoring and management. EA can be used as a middle ground between enterprise's operations and enterprise's strategic planning supporting the strategic plan operationalization. EA can also be used for strategic planning on design time for the verification of change impact.

In summary, although the need for relating enterprise strategy and strategic plans to EA exist, none of the reviewed enterprise architecture frameworks satisfactorily addressed this topic. Most of the EA frameworks have some incipient coverage on the motivation part of the enterprise and would not be appropriated choices to express strategic plans.

In the remainder of this thesis, we outline a proposal to incorporate strategic plans into EA, focusing on proposing an adequate theoretical foundation, and further, in its practical application, extending the ArchiMate EA modeling language. Chapter 5 of this thesis presents a proposal to capture strategy and strategic plans in EA and Chapter 6 presents a proposal to relate enterprise strategic plans to the enterprise architecture operational level using capabilities and resources. In order to base our proposal, we make use of an ontological basis. Our ontological basis is presented in the next Chapter, Chapter 4. 



\section{Ontological Basis}

In this chapter we present the ontological basis we use in order to propose our theoretical foundation. In section 4.1, we present a brief introduction to our ontological basis, highlighting its importance for semantic clarity. In section 4.2, we present the Unified Foundational Ontology (UFO), and the reasons why we have chosen to use UFO as our foundational ontology. In section 4.3, we present Bratman's intention, plans and practical reasoning theory, which we use to complement UFO with respect to plans, in order to improve the understanding and representation of strategic plans in EA. Sections 4.2 and 4.3 are the core of our ontological basis. Then, in section 4.4 , we present the ontological analysis approach we use in our proposal.

\subsection{Introduction}

Since the 80 's there has been a growing interest in the use of foundational ontologies for evaluating and reengineering modeling languages and methodologies, as in (Wand and Weber, 1989) and (Wand and Weber, 1990). Empirical evidence ((Bodart et al., 2001) (Gemino and Wand, 2005) (Shanks et al., 2008) (Recker et al., 2011)) has corroborated the hypothesis that a suitable conceptual modeling language should comprise modeling elements that reflect conceptual modeling categories and relations defined in a foundational ontology. A foundational ontology defines a system of domain-independent categories and their ties, which can be used to articulate the conceptualizations of reality (Guizzardi, 2005). The use of foundational ontologies aims to ensure ontological correctness of the language and of the models described with the language.

Concerning enterprise modeling approaches, a noteworthy number of them have been subject to ontology-based analysis in recent years, e.g., (Azevedo et al., 2011), (Santos Jr et al., 2013), (Davies, Rosemann and Green, 2000), (Gailly, Geerts and Poels, 2009), (Green and Rosemann, 2005), (Rosemann, 
Green and Indulska, 2004), (Guizzardi et al. 2007), (Laurier and Poels, 2009a), and (Laurier and Poels, 2009b). These ontological analyses showed ontological and practical deficiencies in current languages and pointed to solutions. In (Azevedo et al., 2011), for example, the analysis of a whitepaper (Quartel, Engelsman and Jonkers, 2010) influenced the to-be standard, in which a number of the work's recommendations, as a result of the ontological analysis, were later incorporated in the ArchiMate standard, in its version 2.0. As highlighted in section 3.2.4, without a precise conceptualization, modeling and communication problems may arise (Guarino 1998), resulting in enterprise architecture models that are not suitable as tools for proper communication between stakeholders. This decreases the value of enterprise architecture models in the pursuit of informed decision-making.

A key challenge of incorporating the notions from strategic management, as strategic plans, capabilities and resources in the enterprise architecture discipline resides in using a precise conceptualization for these notions. In particular, strategic notions affect the whole enterprise and address subjective aspects in the enterprise. In the next sections we present the ontological basis we use for semantic clarity.

\subsection{The Unified Foundational Ontology (UFO)}

In this section, we present the Unified Foundational Ontology (UFO), reasoning why we have chosen to use UFO as our foundational ontology.

UFO has been developed based on theories from Formal Ontology, Philosophical Logics, Philosophy of Language, Linguistics and Cognitive Psychology (Guizzardi, 2005). Like other foundational ontologies, such as DOLCE (Gangemi et al., 2002) and GFO (General Formalized Ontology) (Herre et al., 2006), it has the firm ontological grounding of the so-called Aristotelian Square (or Four-Category Ontology) (Lowe, 2006). This allows for the construction of an ontology that is founded on a parsimonious set of essential ontological categories, while still being able to account both for natural science as well as linguistic and cognitive phenomena (Guizzardi, 2005).

UFO is used in this work in order to address the notions that are involved in the strategic planning domain with a sound conceptual basis. More specifically, the UFO fragment for intentional and social agents defines key notions for our analysis, from general notions (e.g., to explain objects, properties, events) to more specific ones (e.g., to explain agents, actions and intentional phenomena). Further, UFO presents a treatment of dispositions (and their systematic connection to events and situations), which allows us to properly address many of the issues that are germane to the purposes of this thesis (G. Guizzardi et al., 
2013). This treatment is in line with Molnar's Powers theory (Molnar, 2006), which greatly affected our approach to deal with enterprise's capabilities.

Additionally, UFO has been employed in many semantic analyses, including the analysis of ARIS EPCs (Santos Jr et al., 2010), i*/TROPOS (Guizzardi and Guizzardi, 2011), goals and business processes models (Cardoso et al., 2010) and role-related concepts in EA (Almeida, Guizzardi and Santos Jr, 2009). In particular, UFO has been previously used to analyze and interpret the semantics of the ArchiMate motivational concepts, having led to recommendations of that proposal that have been incorporated in the ArchiMate specification (Azevedo et al., 2011).

UFO is structured in three main parts: UFO-A, which is the core of the ontology and is concerned with endurants (e.g., entities such as objects and their properties); UFO-B, which is an ontology of events and, as such, makes a distinction between enduring and perduring individuals and elaborates on the possible connections between these two fundamental types of entities and; UFO$\mathrm{C}$, which is built on top of UFO-A and UFO-B and focuses on social aspects of reality by dealing with notions such as plans, goals, agents, commitments and normative descriptions.

For a more detailed discussion of the development and applications of UFO we refer to (Guizzardi, 2005), (Guizzardi, Falbo and Guizzardi, 2008), (Almeida and Guizzardi, 2013) and (G. Guizzardi et al., 2013).

\subsubsection{Endurants}

A fundamental distinction in UFO is between the categories of individuals and universals. Universals are predicative terms that can be applied to a multitude of individuals, capturing their general aspects. Individuals are entities that exist in reality possessing a unique identity and that can instantiate one or more universals.

\section{Individuals}

Further, UFO makes a distinction between the concepts of endurants and events. Endurants are individuals that persist in time while keeping their identity, in the sense that if we say that in circumstance $c 1$ an endurant $e$ has a property $p 1$ and in circumstance $c 2$ a property $p 2$ (possibly incompatible with $p 1$ ), $e$ is the same endurant in each of these situations. Examples can include a particular person (say Peter) weighting $70 \mathrm{~kg}$ in one circumstance and $78 \mathrm{~kg}$ in a different circumstance, while being the same individual (Peter) in these two circumstances. Other examples include organizations (the University of Twente, the Federal University of Espírito Santo, etc.) and everyday objects (a ball, an apple, etc.). Events, in contrast, are individuals composed of temporal parts and 
they happen in time, in the sense that they extend in time and accumulate temporal parts. Examples include a particular execution of a business process, a meeting or a soccer game. Whenever an event occurs, it is not the case that all of its temporal parts are simultaneously present. For instance, if we consider a business process "Buy a Product" at different time instants, at each time instant only some of its temporal parts are occurring.

A substantial is an endurant that does not depend existentially on any other individual, what is usually referred to by the common sense term "object". In contrast with substantials, moments (also known as 'abstract particulars' and 'tropes' (Lowe, 2006), (Heil, 2003)) are existentially dependent entities, i.e., for a moment $x$ to exist, another individual must exist, named its bearer. Examples of moments include an apple's color, John and Mary's marriage, an electric charge on a conductor, etc. Moments in UFO include both qualities (e.g., color, weight, temperature) and dispositions (e.g., the fragility of a glass, the disposition of a magnet to attract metallic material) (Guizzardi et al. 2013). In the philosophical jargon, the category of dispositions typically subsumes properties such as powers, tendencies, potentials, capacities, capabilities, affordances, liabilities and propensities. In general, these properties have in common that they endow their bearers with the potential of exhibiting some behavior or bringing about a certain effect under certain conditions. Dispositions are only manifested in particular situations, but they can also fail to be manifested. When manifested, they do so through the occurrence of events. Take, for example, the disposition of a magnet $m$ to attract metallic material. The object $m$ has this disposition even if it is never manifested, for example, because $m$ was never close to any magnetic material. Nonetheless, $m$ can certainly be said to possess that intrinsic property (Heil, 2003), (Molnar, 2006), (Mumford, 2003), which may be manifested by attracting iron $^{14}$.

Existential dependence can be used to differentiate intrinsic and relational moments. Intrinsic moments are dependent on a single individual, while relational moments (also called relators) depend on a plurality of individuals. Examples of the first include an apple's weight and color, while examples of the latter include John and Mary's marriage, John's enrollment at the University of Twente - being the relator that particular marriage and other relator that particular enrollment. A relator is the truth maker of a material relation.

\footnotetext{
14 While this is an example of physical disposition, dispositions are also important in the enterprise to account for the notion of capability of persons and organizational units (Carlos L. B. Azevedo et al., 2015).
} 


\section{Universals}

A universal is rigid if it applies necessarily to its instances, i.e., if it applies to its instances in every possible world (e.g., Apple, Person). A kind is the rigid substantial universal that supplies a principle of identity for the substantial individuals that instantiate them. Every substantial individual must be an instance of exactly one kind. In contrast to rigid universals, a universal is non-rigid if it does not apply necessarily to all its instances and is anti-rigid if it applies contingently to its instances. Roles are anti-rigid and relationally-dependent universals (e.g., Student, Husband). This means that roles are instantiated by a substantial in a relational context, i.e., the role player is connected by a relator to other individuals in the context of a relation;

Whenever entities of different kinds have similar properties they may be classified by substantial universals termed Mixin universals. Rigid Mixin Universals subsuming different Kinds are termed categories (e.g., Physical Object, Living Entity). Some Mixin Universals are anti-rigid and represent abstractions of common properties of roles. These are termed role mixins. An example of role mixin is 'customer', which can be played by 'persons' (i.e., entities of the kind Person) and 'organizations' (i.e., entities of the kind Organization). In any case, 'customer' is an anti-rigid and relationally dependent type for all its players.

\subsubsection{Intentional and Social Elements}

Agents are substantial individuals capable of bearing intentional moments. These include mental states, such as individual beliefs, desires and intentions. Intentionality in UFO should not be understood as the notion of "intending to do something", but as the capacity to refer to possible situations of reality (Searle, 1983). Every intentional moment has an associated proposition that is called the propositional content of the moment. In general, the propositional content of an intentional moment can be satisfied (in the logical sense) by situations in reality. Every intentional moment has a type (belief, desire or intention). The propositional content of a belief is what an agent holds as true. Examples include one's belief that the Eiffel Tower is in Paris and that the Earth orbits around the Sun. A desire expresses the will of an agent towards a possible situation (e.g., a desire that Brazil wins the next World Cup), while an intention expresses desired states of affairs for which the agent commits to pursuing (internal commitment) (e.g., John's intention of going to Paris to see the Eiffel Tower).

Actions are intentional events, i.e., events with the specific purpose of satisfying (the propositional content of) some intention of an agent. The propositional content of an intention is termed a goal. Only agents are said to 
perform actions (Guizzardi, Falbo and Guizzardi, 2008), as opposed to nonagentive objects that participate (non-intentionally) in events.

Agents can be further specialized into physical agents (e.g., a person) and social agents (e.g., an organization). Social agents are further specialized into institutional agents and collective social agents. Institutional agents are composed of other agents, each one contributing to the functionality (or behavior) of the institution, also termed functional complex (Guizzardi, 2005). In addition to institutional agents, UFO acknowledges the existence of collective social agents, which are distinguished from institutional agents in that all its members play the same role in the collective.

Similarly to agents, non-agentive objects can be specialized into physical objects and social objects. A category of social objects of particular interest to us here is that of normative descriptions. Normative descriptions are social objects that create social entities recognized in that context. Examples of normative descriptions include a company's regulations and public laws. Examples of social entities that can be defined by normative descriptions include social roles (e.g., president, manager, sales representative), social role mixins (whose instances are played by entities of different kinds, e.g., customer, which can be played by persons and organizations), social agent universals (e.g., that of political party, education institution), social agents (e.g., the Brazilian Labour Party, the University of Twente), social object universals (e.g., currency) and other social objects (e.g., the US dollar) or even other normative descriptions (e.g., a piece of legislation). Normative descriptions are recognized by at least one social agent. Figure 9 shows a fragment of the specializations of individuals in UFO. 


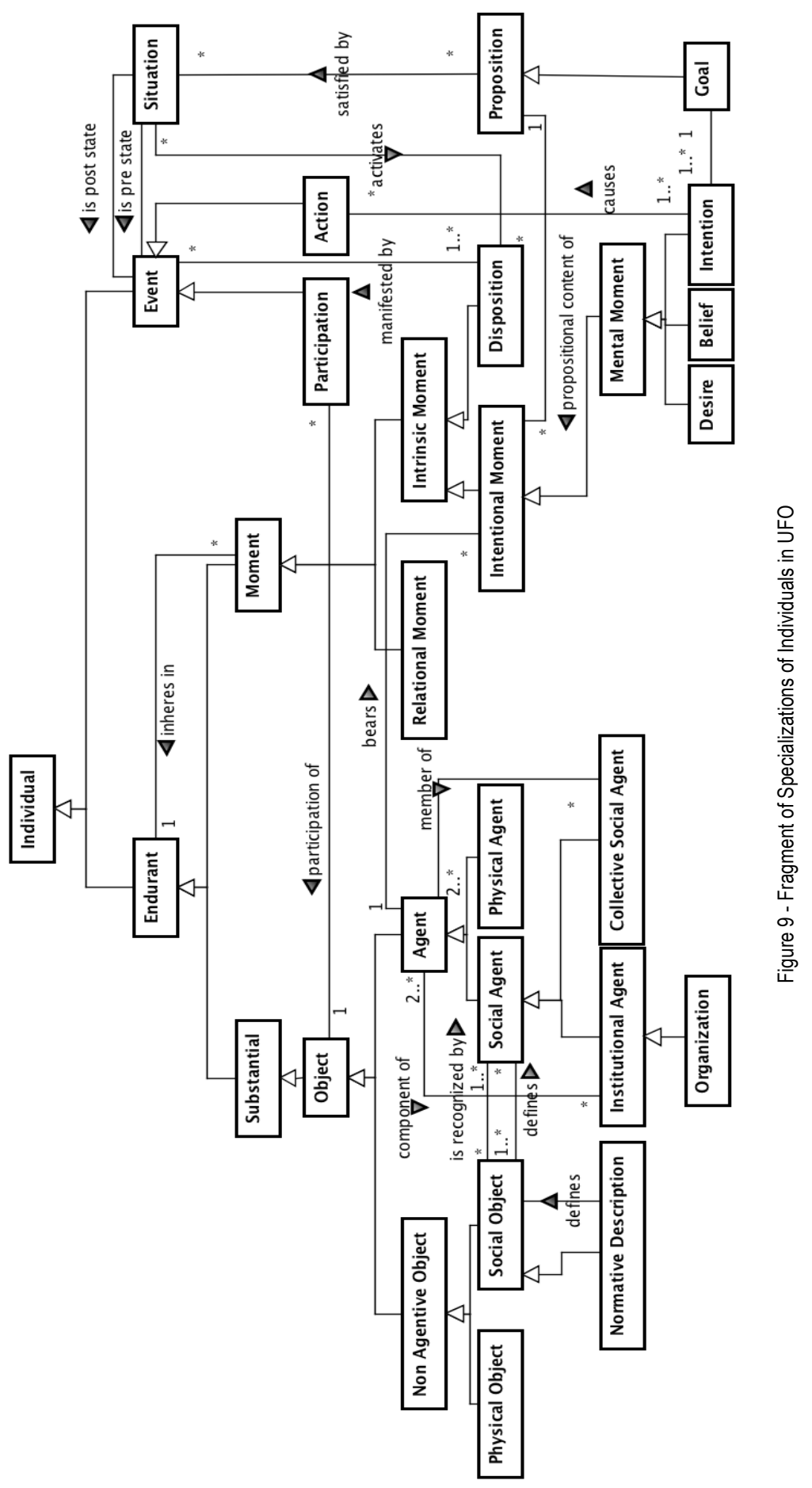


A category of social element of particular importance in organizations is a social relator between agents (e.g., a marriage, an employment, an agreement). Social relators entail commitments and claims by the related agents, and depend on a normative description or speech act valid in the social context (e.g., a written contract, a verbal agreement). Delegation occurs when two agents (namely delegator and delegatee) are related through a special kind of social relator (termed delegatum) (Guizzardi and Guizzardi, 2011). The foundation of this relation is the social relator (i.e. a bundle of commitment/claim pairs) established between the two agents involved in this delegation. Commitments are classified in open and closed. In an open commitment, the agents responsible for fulfilling the commitment are free to define how they will fulfill it. In a closed commitment, the agent must fulfill the commitment by performing actions that are instances of the actions (type) defined by another agent.

The temporal properties of events have their values (their qualia) taken by projecting these properties into a quality structure (Guizzardi, 2005) (Bringuente, Falbo and Guizzardi, 2010). UFO takes the time conceptual space to be a structure "composed of" Time Intervals. Time intervals themselves are "composed of" Time Points. UFO admits: (i) intervals that are delimited by begin and end points as well as open intervals; (ii) continuous and non-continuous intervals; (iii) intervals with and without duration (instants). In particular, it allows a diversity of temporal structures such as linear, branching, parallel and circular time. Figure 10 shows a fragment of the specializations of individuals and intentions in UFO that are relevant to this thesis. 


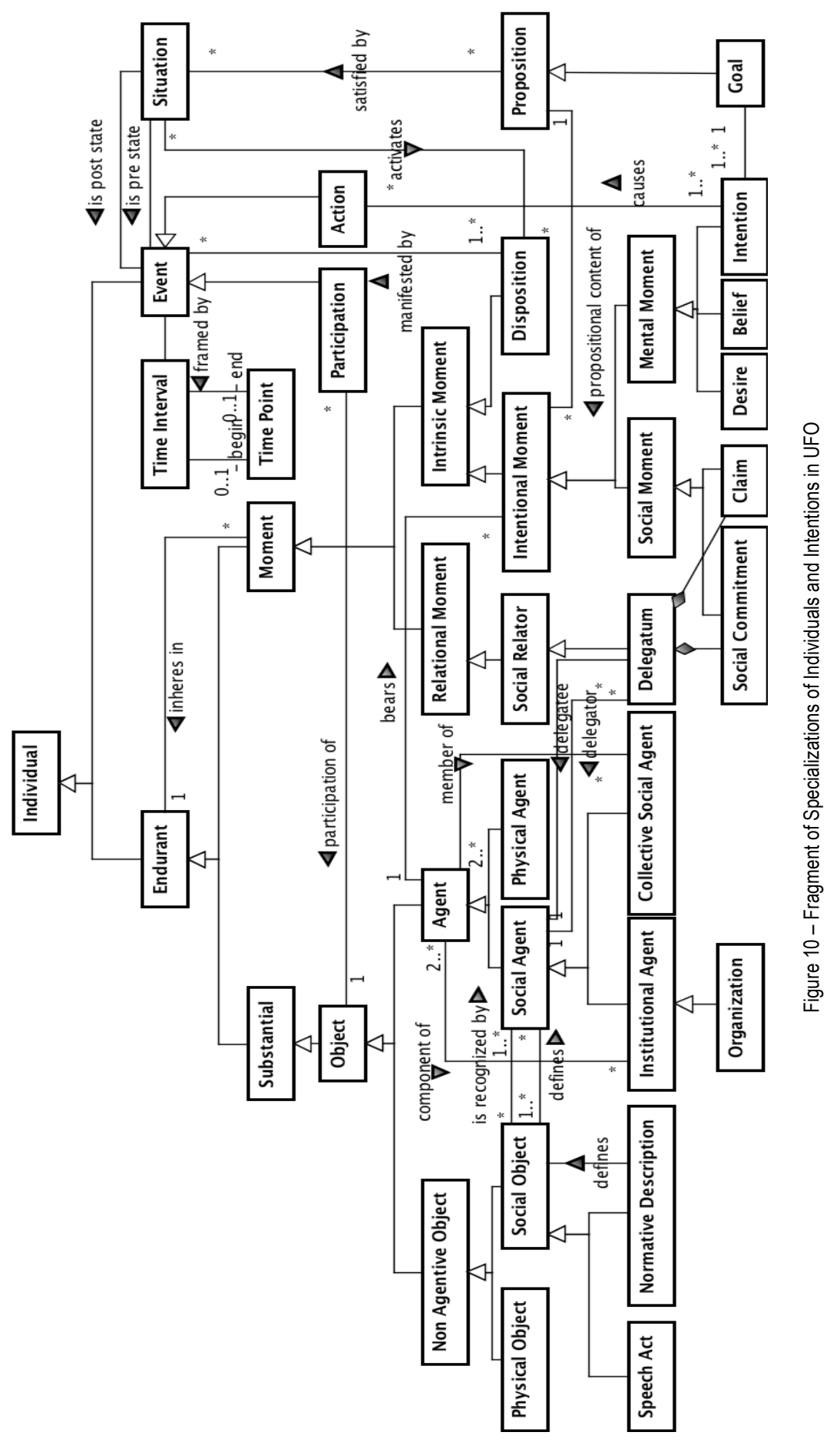




\subsection{Bratman's Intention, Plans and Practical Reasoning Theory}

In order to further cover enterprise's strategic plans, we complement UFO with notions explored by Bratman in his theory of intentions, plans and practical reasoning (Michael E. Bratman, 1999). UFO notions of intentionality can be traced to Bratman's belief-desire-intention model (Michael E. Bratman, 1999). In this section, we further detail plans and planning based on Bratman's theory.

Bratman discusses that what makes an action intentional is that it "stands in an appropriated relation" to the agent's relevant desires and beliefs. In this sense, he explains the source of intentions, as a background of "desire-beliefs reasons for action". He clarifies the distinction between desires and intentions by stating that desires are potential influencers of actions, while intentions are conduct-controlling pro-attitudes. An intention involves thus a kind of choice or special commitment to (future) action that desires do not involve. Intentions play a role in practical reasoning in that prior intentions constrain further intentions. An intention involves certain characteristic of reasoning-centered dispositions: "a disposition to retain the intention without reconsideration, a disposition to reason from this retained intention to yet further intentions, and to constrain other intentions in the light of this intention."

Bratman also discusses that plans share properties of intentions, but, because of their increased complexity, plans reveal other properties: partiality and having a hierarchical structure. Plans are partial in that they can be filled in later as required, with specifications of means, preliminary steps, and more specific courses of action. They are hierarchical in that a more general intention may be fixed while deliberating about how more specifically to realize it. Plans must satisfy certain constraints if they are to support coordination and deliberation on later conduct; they need to be internally consistent and consistent with the agent's beliefs, and they need to be "means-end coherent" (i.e., filled with specifications that are as detailed as needed for their eventual successful execution).

In this thesis, Bratman's planning theory plays an important role. The discussion of plans and their roles as inputs to further practical reasoning, including how it constrains further plans and intentions had specially contributed to explain and propose how to consider enterprises' strategic plans in EA, in Chapter 5. Bratman's discussions on partiality and hierarchical structure of plans play an important role for describing real-world strategic plans, since most strategic plans, as discussed in Section 2.1, deliberate about the general guidelines 
and left details to be deliberated later in the process (Mintzberg, Ahlstrand and Lampel, 1998).

\subsection{Ontological Analysis Approach}

In this section we discuss the ontological analysis approach we use. We apply ontological analysis in chapters 5 and 6 .

Ontological analysis is performed by considering a mapping between language modeling constructs and the concepts in an ontology. In ontological analysis, each modeling element is interpreted using the ontological theory as a semantic domain, i.e., the meaning of each modeling element is interpreted based on the concepts of the ontological theory. In this work, we make use of our ontological basis to propose our theoretical foundation, which is described in chapters 5 and 6. Our theoretical foundation is then used for ontological analysis purposes as an ontological theory. The performance of ontological analysis further stresses the relevance of the theoretical foundation, as well as the relevance of its correctness and expressiveness ${ }^{15}$.

Further, concepts of the domain of discourse (captured in the theoretical foundation) should be represented by modeling elements of the language being considered (Weber, 1997) (Moody, 2009). When this is not the case, the modeler is not able to represent some part of the domain of discourse. According to (Weber, 1997), there should be a one-to-one correspondence between the concepts in the ontology and the language modeling elements. When this correspondence cannot be obtained, the following language problems can be identified $^{16}$, as illustrated in Figure 11:

15 The ontological analysis is not used to enforce any claim on the theoretical foundation correctness. However, we disclaim that correctness and expressiveness is relevant in the theoretical foundation since the theoretical foundation is used in this thesis for ontological analysis, serving as an ontological theory.

16 Adapted from (Santos Jr et al., 2013) 


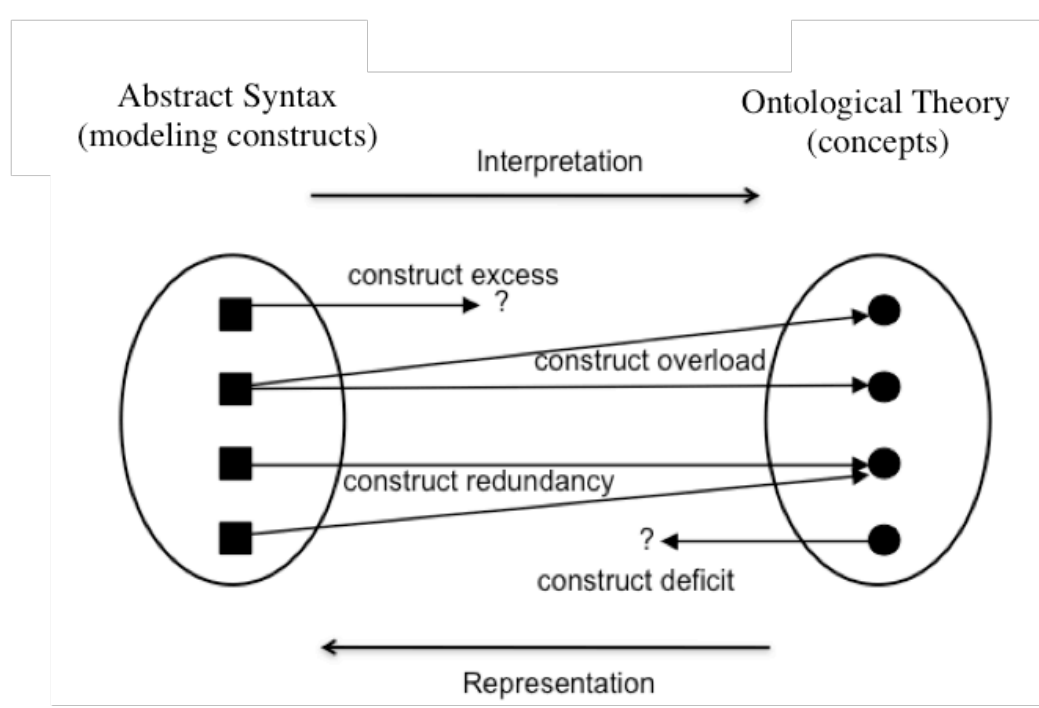

Figure 11 - Issues uncovered by ontological analysis - adapted from (Moody, 2009)

- Construct excess: exists when a modeling construct does not correspond to any ontological concept. Since no mapping is defined for the exceeding construct, its meaning becomes uncertain, hence, undermining the clarity of the specification produced using the language. According to (Wand and Weber, 1990), users of a modeling language must be able to make a clear link between a modeling construct and its interpretation in terms of domain concepts. Otherwise they will be unable to articulate precisely the meaning of the unclear construct and, consequently, the specifications ${ }^{17}$ they generate using the language. Therefore, a modeling language should not contain construct excess and every instance of its modeling constructs must represent an individual in the domain.

- Construct overload: exists when a single modeling construct can represent multiple ontological concepts. Construct overload impacts language clarity negatively. Construct overload is considered as an undesirable property of a modeling language since it causes ambiguity and, hence, undermines clarity. When a construct overload exists, users have to bring additional knowledge not contained in the specification to understand the phenomena which are being represented.

- Construct redundancy: exists when multiple modeling constructs can be used to represent a single ontological concept. Construct redundancy is a

${ }^{17}$ Specification is used as specified model, the user defined model. 
violation of parsimony. In (Wand and Weber, 1990), the authors claims that construct redundancy "adds unnecessarily to the complexity of the modeling language" and that "unless users have in-depth knowledge of the grammar, they may be confused by the redundant construct. They might assume for example that the construct somehow stands for some other type of phenomenon." Therefore, construct redundancy can also be considered to undermine representation clarity.

- Construct deficit: exists when there is no construct in the modeling language that corresponds to a particular ontological concept. Construct deficit entails lack of expressivity of the modeling language, i.e., there are relevant phenomena in the considered domain (according to a domain conceptualization) that cannot be represented by the language. Alternatively, users of the language can choose to overload an existing construct, thus, undermining clarity.

In this work, we argue that a one-to-one mapping is too restrictive and agree with (Carvalho, Almeida and Guizzardi, 2014), which argues that patterns of modeling elements in the language could also be considered for the mapping correspondence. Some concepts in the domain of discourse might be too complex to be covered by a single modeling element. In this case, these domain of discourse concepts might be represented by a pattern of modeling elements in the modeling language. In this sense, patterns of elements (i.e., a subset of language elements that are to be used together) should also be target for ontological analysis. Further, we also account that, for the sake of simplicity, it might be of the interest of language creators that a single modeling element might represent a pattern on the domain of discourse. We also analyze language modeling elements with respect to patterns of concepts in the domain of discourse.

To conclude, we argue that modeling languages aiming at wide adoption, such as ArchiMate, which is analyzed in the upcoming chapters, should avoid ontological deficiencies. Evidences from empirical studies reported that users of modeling languages perceive when ontological deficiencies exist and that these deficiency perceptions are negatively associated with usefulness and ease of use of languages (Recker et al., 2011). In the next chapter we discuss strategic planning and propose a conceptual model for representing strategic plans in line with both the management literature and with the ontological analysis method described in this section. 



\section{Capturing Strategic Plans in EA}

In this chapter ${ }^{18}$ we further discuss strategic plans with regards to EA and propose a conceptual model for introducing strategic plans in EA. We make use of our ontological basis to state the conceptual model intended semantics. In section 5.1 , we present our conceptual model, which is in line with the management literature. The conceptual model is then used to propose an extension to ArchiMate in order to enable the modeling of strategic plans in EA, which we present in section 5.2. Our modeling choices reflect our objective to incorporate strategic plans into enterprise architecture. In section 5.3, we present related works and, in section 5.4, we conclude the chapter.

\subsection{A Conceptual Model for Strategic Plans}

The conceptual model described here is mainly-based on the goal-based strategic model (Mintzberg, Ahlstrand and Lampel, 1998), (Bryson, 2011) and (McNamara, 2001). Further, as discussed in Chapter 2, the model supports what is called 'umbrella strategy', in which there is a mix of deliberate and emergent strategies (Mintzberg, Ahlstrand and Lampel, 1998).

To describe the goal-based strategic model, it is necessary to express enterprises' goals, which can be achieved in long-term, mid-term or short-term.

\subsubsection{Strategic Plan Goals}

The enterprise goals are among the most important elements of the goal-based strategic model (Bryson, 2011) (McNamara, 2001). Usually, the first goals described are to be achieved in the long-term (e.g., five years from 'now'). They encompass the enterprise's mission and vision. Further, it is common that

18 This chapter main content was published in (Carlos L B Azevedo, Almeida, et al., 2015). 
intermediate goals or milestones are described, as well as short-term goals (e.g., one year or less). Usually, goals in strategic plans are to be accomplished with timing constraints. Each of these goals can be related to other goals, in a decomposition, refinement or contribution type of relation.

The enterprise mission is a statement of purpose (Levin, 2000). Effective mission statements commonly define what business the organization is in, its beliefs about how business should be conducted, the markets and customers it serves, and the unique value it contributes to society at large (Bart, Bontis and Taggar, 2001) (Levin, 2000). Mission statements rarely change significantly over time, although sometimes they may be extended or modified to reflect shifts in business focus (Bart, Bontis and Taggar, 2001). Mission statements are regarded as the critical starting point for almost every major strategic initiative (Bart, Bontis and Taggar, 2001) (The Open Group, 2009) (Levin, 2000). In addition, mission statements are intended to motivate (and in so doing, control) the behaviors of organizational members toward common organizational goals (Bart, Bontis and Taggar, 2001). Mission statements can be idealistic rather than simply matter of fact (Levin, 2000). For example, a health-care organization such as a hospital may have as mission "to improve people's lives through high-quality affordable healthcare". Vision statements, while still partial, should be futureoriented, compelling, bold, aspiring, and inspiring, but yet believable and achievable (Levin, 2000). Effective visions describe a future that is more attractive than the present, it is the vision of where and how the enterprise would be in the defined number of years (Levin, 2000). An example of a vision is "to be one of the largest European health-care providers within 5 years".

In the conceptual model in Figure 12 we introduce the concept of strategic plan goal, which is specialized into a strategic goal or a planned goal. A strategic goal is either a Mission or a Vision. The strategic plan goal concept is interpreted in UFO as an agent's intention. Thus, every strategic plan goal should be related to an agent, which bears the intention. The agent is an individual, which can represent a person, who might play roles in the organization (e.g., Chief-Executive Officer), the organization itself, or a unit of an organization. As discussed by Bratman (1999), mission and vision must be consistent since they are intentions of the same agent. 


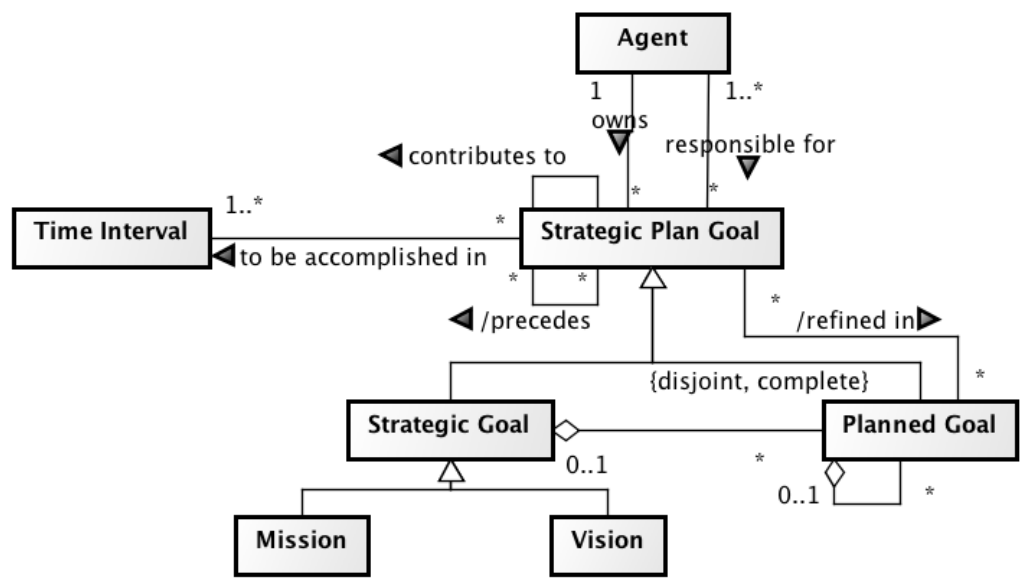

Figure 12 - Fragment of the Conceptual Model Depicting Specializations of Strategic Plan Goals

\subsubsection{Refinement and Decomposition Between Goals}

In order to achieve its higher-level goal, it is common that enterprises decompose (or refine) its higher-level goal into lower-level goals. The general idea is that by achieving lower-level goals enables the enterprise to achieve its higher level goal.

Our conceptual model distinguishes between the decomposition and the refinement relations between strategic plan goals.

The goal decomposition is understood as a whole-part relation in which the goals resulting from the decomposition, whenever achieved entail the achievement of the original goal. In this sense the decomposition does not provide us with a plan, but rather with the sufficient conditions under which we consider that the overall goal is satisfied. For example, the health-care organization may decompose its vision into "having 30\% of the European market share within 5 years" and "being present in the largest European member states within 5 years". This means that it will consider these conditions as sufficient to reach its vision of "being one of the largest European health-care providers within 5 years". Taken as intentions in UFO, we can understand decomposition as a logic relation between the propositional contents of the intentions in the decomposition. The decomposition relation is present in most goal modeling languages (Cardoso, Almeida and Guizzardi, 2010) (often with conjunctive and disjunctive variants). This is not the case for the refinement relation we introduce here, which is key to strategic planning.

The refinement relation encompasses partiality and reflects the preparation for some future, in line with Bratman's notion of plan. If in a given state of the enterprise a refined goal is derived from an original goal, then reaching the 
refined goal brings the enterprise closer to reaching the original goal. However, other actions might still be required.

Whenever a refinement is performed, the agent decides on pursuing new goals, motivated by his intention of achieving his original goal. The agent believes that when achieving his newly defined goals, his original goal would be easier to achieve (i.e., the agent believes that when achieving those goals he will be 'closer to' achieving his original goal). However, achieving these goals does not entail that his original goal is achieved. It is still possible that the agent achieves his newly defined goals and still does not achieve his original goal. The intentions that are created motivated by the original intention have a special type of 'bond' that 'glue' those intentions together (and not other intentions). The intention to pursue new goals is, in itself, a new intention. So, the agent had his original intention, which motivated him to have a new intention: to pursue other goals in order to achieve the original intention. This intermediate intention 'glues' the other intentions together. For that, we say that the agent has defined a way, i.e., a strategy of how to achieve his original goal.

\subsubsection{Strategy}

Strategy is defined in our conceptual model as an intention in UFO, whose creation has been motivated with the purpose of achieving one or more goals. The strategy is an intention, composed of a collection of intentions, which can be intentions - to perform actions, achieve desired situations, acquire desired capabilities or control resources. Regarding our scope, this model of strategy is aligned with definitions from the management field. Porter states that corporate strategy is: "a combination of the ends (goals) for which the firm is striving and the means (policies) by which it is seeking to get there" (1980). Mintzberg and Quinn states that: "strategy is the pattern or plan that integrates an organization's major goals, policies and action sequences into a cohesive whole" (2003). We generalize Mintzberg and Quinn's definition in our approach by not constraining strategy to only 'major' goals, especially since we do not intend to define what are enterprise's major goals. Our modeling is also aligned with Kenneth Andrews' definition of corporate strategy: "Corporate strategy is the pattern of decisions in a company that determines and reveals its objectives, purposes, or goals, produces the principal policies and plans for achieving those goals, and defines the range of business the company is to pursue [...]" (Andrews, 1997).

Figure 13 introduces the strategy concept in our model. Additionally, each of the goals might have one or more possible decompositions or refinements, and the usage of one decomposition or refinement does not entail that other decompositions or refinements might not be possible as different ways to achieve the same goal; usually to increase the probability of success or decrease risks 
during strategy implementation (McNamara, 2001). The conceptual model does not allow a regular goal to be refined into an enterprise mission or vision (Bryson, 2011) (McNamara, 2001), defining thus a hierarchy between strategic goals and planned goals. In the conceptual model represented, the refinement between Strategic Plan Goals and Planned Goals is derived via the Strategy concept. The Planned Goal incomplete generalization represents some different types of goals the enterprise may pursue that are expressively relevant in strategic plan contexts - to perform actions, acquire desired capabilities, control resources or achieve desired situations - all of which are captured by the UFO concept of intention.

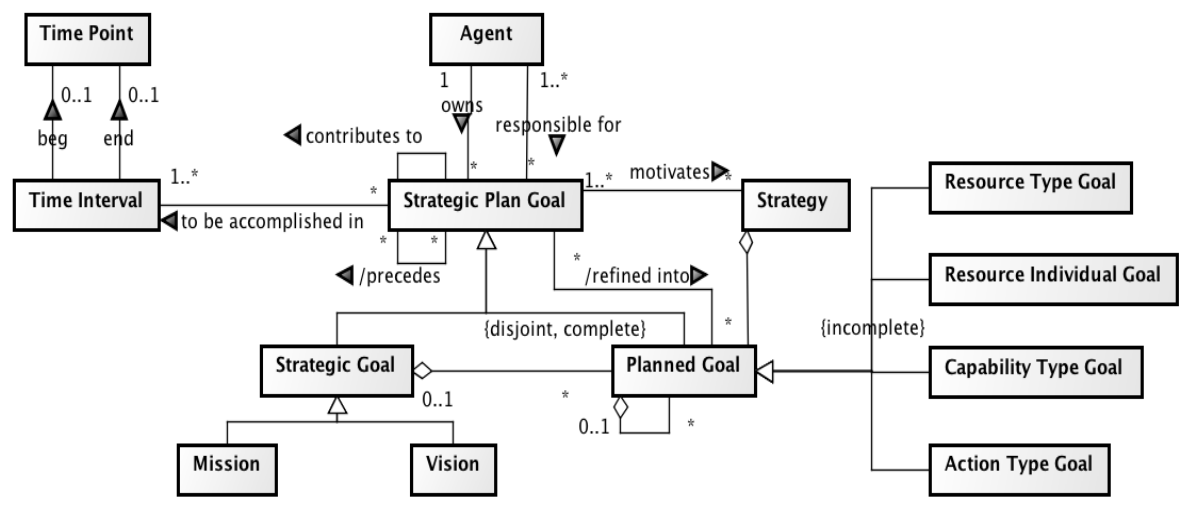

Figure 13 - Conceptual Model on Strategy and Strategic Planning

\subsubsection{Timing Constraints}

Strategic plan goals usually are to be accomplished in timing constraints (Bryson, 2011) (McNamara, 2001). Goals might have a precedence order or might need to be accomplished before or after a certain date (McNamara, 2001). Additionally, goals might require a time window in which they should be addressed and achieved (e.g., because of regulatory compliance; in the case of perishable products). These are represented in the conceptual model in Figure 13 as the precedes relation and the Time Interval and Time Point concepts. Precedence between goals is interpreted in UFO as that the situation that satisfies the preceding goal has events that are pre-state of the situations that satisfy the succeeding goal. Time Interval and Time Point point to the homonymous concepts in Section 4.2.2 and in detail in (Bringuente, Falbo and Guizzardi, 2010). However, we restrict our conceptual model to forbid end Time Points that are supposed to 'happen' before begin Time Points in the same Time Interval, thus not enabling time to be set backwards. 


\subsubsection{Responsibility for Goal Achievement and Delegation}

Goals might also be treated by the enterprise individually or in a bundle, and might influence one another (Mintzberg, Ahlstrand and Lampel, 1998) (Mylopoulos, Castro and Kolp, 2013) (Van Lamsweerde, 2009). Particularly, goals being planned should be compatible with previously defined goals, in accordance with Bratman's conducting-controlling-pro-attitudes (Michael E. Bratman, 1999). In case a goal contradicts a previously defined goal, one of them should be redefined.

In some organizations, strategic planning is separately performed in different departments as well as at different management levels, in which each department and management level has different responsibilities regarding the strategic planning. For example, high-level managers may describe the strategic part of the strategic planning and release it to lower-level managers, who further describe how that plan should be implemented. Goals can be the responsibility of specific departments, of individuals or the whole enterprise. In the conceptual model presented in Figure 13, this is represented by the agent concept and its relations of owns and responsible for a goal. This comprises the cases in which an agent has a goal and delegates it to another agent, which is actually responsible for the goal achievement. This is interpreted in UFO as the delegation social relation (Guizzardi and Guizzardi, 2011), in which the agent that owns the goal can delegate it to a different agent and, as such, can perform claims and the delegated agent has a social commitment to the first agent.

\subsubsection{Further Goal Achievement Details}

In addition, organizations need to plan how their goals should be achieved. For short-term goals, it might be relevant to describe the operations required to realize them (Bryson, 2011) (McNamara, 2001). It also might be relevant to describe their required capabilities and resources (Stirna et al., 2012). For midterm and long-term goals, although the same approach can be applied, enterprise's might prefer not to detail the achievement of the goal (Mintzberg, Ahlstrand and Lampel, 1998), or might choose to refer only to the capabilities and resources required for achievement, in a strategy as capability-based planning (Carlos L B Azevedo, Van Sinderen, et al., 2015) (Stirna et al., 2012). This is represented in the conceptual model on Figure 13 as the (incomplete) specializations of planned goals.

A strategic plan is treated as an enterprise plan that defines a strategy in order to achieve some goal. The model represents the strategic plan, as a result of strategic planning. As such, a specific concept to represent strategic plan is not suitable in this scenario. 


\subsection{Modeling Strategic Plans in EA}

In this section we propose an extension to ArchiMate in order to model strategic planning and strategy. The metamodel proposed in this section is based on the conceptual model developed in Section 5.1. Among the reasons to choose ArchiMate, we highlight its efforts to address two important concerns, viz. motivational concerns and versioning concerns. Motivational concerns and versioning concerns are addressed in the Motivation Extension and the Implementation and Migration Extension, respectively, both incorporated in the ArchiMate standard (The Open Group, 2012). Further, the ArchiMate language has been the target of ontological analysis, such as in (Azevedo et al., 2011) (Azevedo et al., 2013) (Nardi, Falbo and Almeida, 2014), which facilitates a semantic integration of the proposal with the language.

The ArchiMate ME has been introduced in (The Open Group, 2012). As stated in the ArchiMate specification, "[m]otivational concepts are used to model the motivations, or reasons, that underlie the design or change of some enterprise architecture. These motivations influence, guide, and constrain the design" (The Open Group, 2012). The addition of strategic planning elements to the language appears to be a step further towards the stated intention to keep track of the reasons "that underlie the design or change of some enterprise architecture".

\subsubsection{The Current ArchiMate Motivation Extension}

Figure 14 presents the ArchiMate ME metamodel. The definitions of concepts and relationships presented below are extracted 'as is' from the ArchiMate specification (The Open Group, 2012):

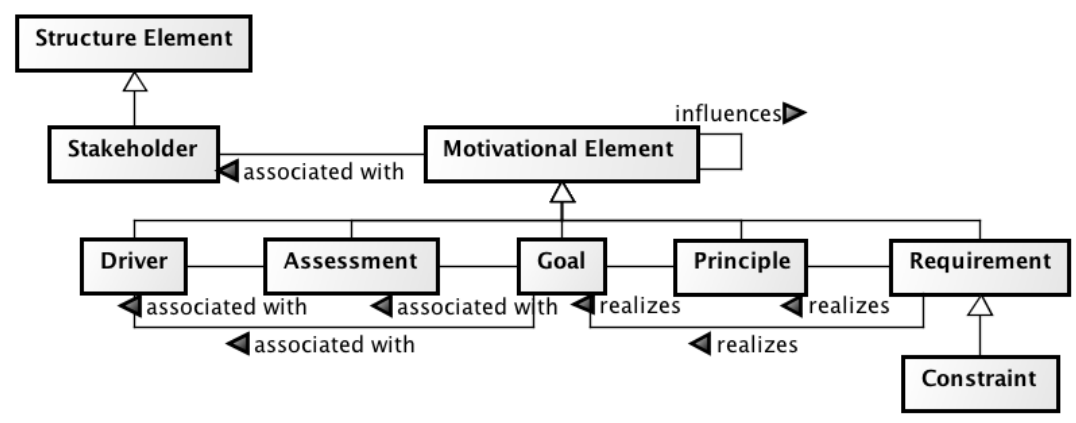

Figure 14 - Current ArchiMate Motivation Extension Metamodel

- A stakeholder is defined as the role of an individual, team, or organization (or classes thereof) that represents their interests in, or concerns relative to, the outcome of the architecture. 
- A driver is defined as something that creates, motivates, and fuels the change in an organization.

- An assessment is defined as the outcome of some analysis of some driver.

- A goal is defined as an end state that a stakeholder intends to achieve.

- A requirement is defined as a statement of need that must be realized by a system.

- A constraint is defined as a restriction on the way in which a system is realized.

- A principle is defined as a normative property of all systems in a given context, or the way in which they are realized.

- The aggregation relation models that some intention is divided into multiple intentions.

- The realization relation models that some end is realized by some means.

- The influence relation models that some motivational element has a positive or negative influence on another motivational element.

In the current ArchiMate framework it is not possible to distinguish mission, vision and other kinds of goal. Further, the relations concerning goals, such as precedence, representation of time constraints for goal achievement, the delegation of a goal to another agent (to differentiate between the agent who owns a goal and the agent responsible for it) or the differences between partial and complete decompositions, and thus, sufficient and necessary conditions cannot be represented in the ArchiMate language. The only element to capture some notion of strategy is the realizes relation.

\subsubsection{Proposed Extension for Modeling Strategic Plans in ArchiMate}

In this section we propose improvements to the ArchiMate ME metamodel in order to represent strategic planning. We use as a basis the ArchiMate ME metamodel and follow the semantic analysis performed in (Azevedo et al., 2011). We strive to reuse the existing language concepts and to introduce as few additional concepts as possible. Note that the notation proposed here was based on ArchiMate version 2.1 and predates the current version 3.0 of the ArchiMate language.

Figure 15 presents our proposed metamodel extension for ArchiMate. The highlighted elements (in blue) are the elements introduced to the language in the metamodel. Unnamed associations are explained in its related concepts sections. 


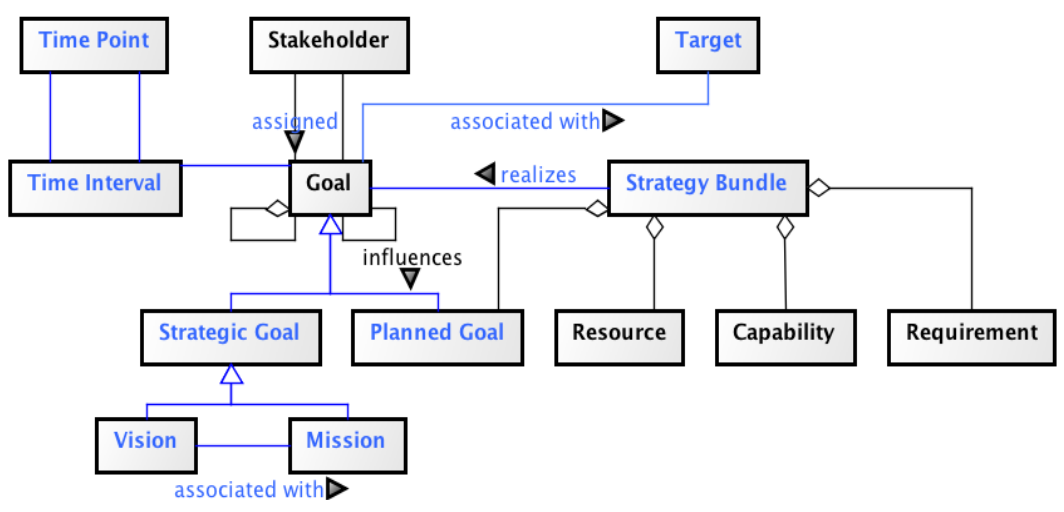

Figure 15 - Proposed Extension for Modeling Strategic Plans in ArchiMate

Figure 16 presents a proposed concrete syntax, in order to represent the newly introduced constructs.

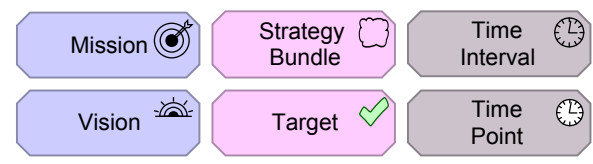

Figure 16 - Concrete Syntax

\section{Goal and Stakeholder}

The concepts of Goal, Stakeholder and Requirement have been previously analyzed in (Azevedo et al., 2011). Thus, a brief description is given here and the reader should refer to (Azevedo et al., 2011) for a full discussion on the semantics of these concepts.

A goal in the metamodel is interpreted as a goal of an agent in UFO. A goal is the propositional content of an agent's intention. The agent that has a goal (or any other motivational element) is represented in the ArchiMate current metamodel in Figure 4 by the association between the motivational element superclass and the stakeholder in which that motivational element inheres. The stakeholder concept, in turn, is interpreted as an agent or as a universal that can be instantiated by agents.

The Types of Goals defined in the proposed extension are Strategic Goal, Mission, Vision and Planned Goal. The mission concept has been interpreted as an agent's intention in UFO, in which its propositional content refers to an intended desirable future, however not easily or readably achievable. The vision concept has also been interpreted as an agent's intention in UFO. The propositional content, in turn, refers to an intended and achievable future. 
The concept of planned goal has been introduced in the language to properly address concerns from the literature on strategic planning ((Bart, Bontis and Taggar, 2001) (Porter, 1980) (Porter, 1991) (Bryson, 2011) (McNamara, 2001) (Levin, 2000)), not allowing undesired representations, such as a goal being realized by the enterprise's mission or vision. As such, goal is defined as an abstract concept in the metamodel, so that the modeler needs to reveal its intended meaning (mission, vision or planned goal). The concrete syntax for planned goal is the same as the original syntax of a goal in ArchiMate. In Figure 17 we present the Mission and Vision of a pension fund.

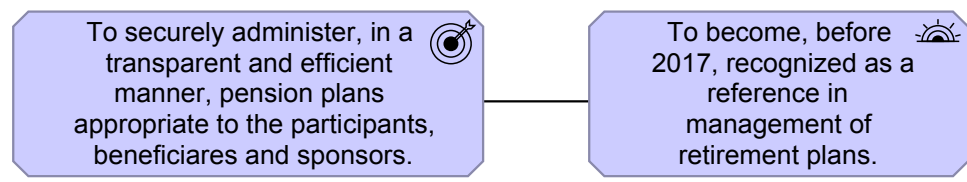

Figure 17 - Mission and Vision

\section{The Strategy Bundle Concept}

The Strategy concept from our conceptual model has been interpreted in UFO as an intention, whose creation is motivated with the purpose of achieving one or more goals. Strategy is composed of a collection of intentions. The strategy bundle construct in the ArchiMate concrete syntax is intended to represent this. We should interpret the strategy bundle in the pattern strategy realizes a goal. This is interpreted in UFO as an intention, whose creation is motivated with the purpose of achieving one or more goals, represented by the goal construct. The part-whole relation in the conceptual model, thus, is represented in the ArchiMate concrete syntax as the aggregation relations between the strategy and the planned goal, resource, capability and requirement. The presence of the planned goal, resource, capability or requirement in a strategy bundle is intended to represent the intentions to achieve a situation specified by a specific intention, to control individual resources or resources of a specific type, to acquire desired capabilities and to achieve the situations specified in the requirement. As discussed in Section 5.1, the agent believes the strategy is satisfied in situations from which less effort would be required to reach the motivated goal ${ }^{19}$, but other actions might still be required to reach the motivated goal.

Figure 18 shows the representation of strategies to achieve the pension fund goals 'Adequate administrative costs', 'Model Current Business Processes' and 'Model Remaining processes', which are part of different strategies to ultimately achieve the goal of 'Adequate administrative costs' and the mission and vision of

${ }^{19}$ Compared to a situation in which the strategy is not satisfied. 
the pension fund (represented in Figure 17). The strategy bundle concept allows the enterprise to model its strategies to achieve each goal. It shows the 'bond' between the different goals and what they aim at achieving. The refinement relations are represented in a pattern involving: (i) realization of a goal by a strategy bundle and (ii) aggregation relations between the bundle and its elements, represented graphically as containment. The aggregation relation between goals representing decomposition is also presented in Figure 18 showing that the enterprise believes that achieving the goals on the aggregation relation entails the achievement of the aggregated goal, e.g., those are the sufficient conditions to achieve the 'Model remaining processes' goal. The derived realization relation between the goals in the strategy bundle and the goal the bundle is supposed to realize presents the enterprise with the possibility of tracing which goals in fact contribute to each of its 'higher-level' goals. It could further provide the enterprise with the possibility of assessing the core elements that are related with the 'higher-level' goals achievement, whenever they are related with the 'lower-level' goals achievement, facilitating the applicability of a capability-based approach, as in (Carlos L B Azevedo, Van Sinderen, et al., 2015) (Stirna et al., 2012).

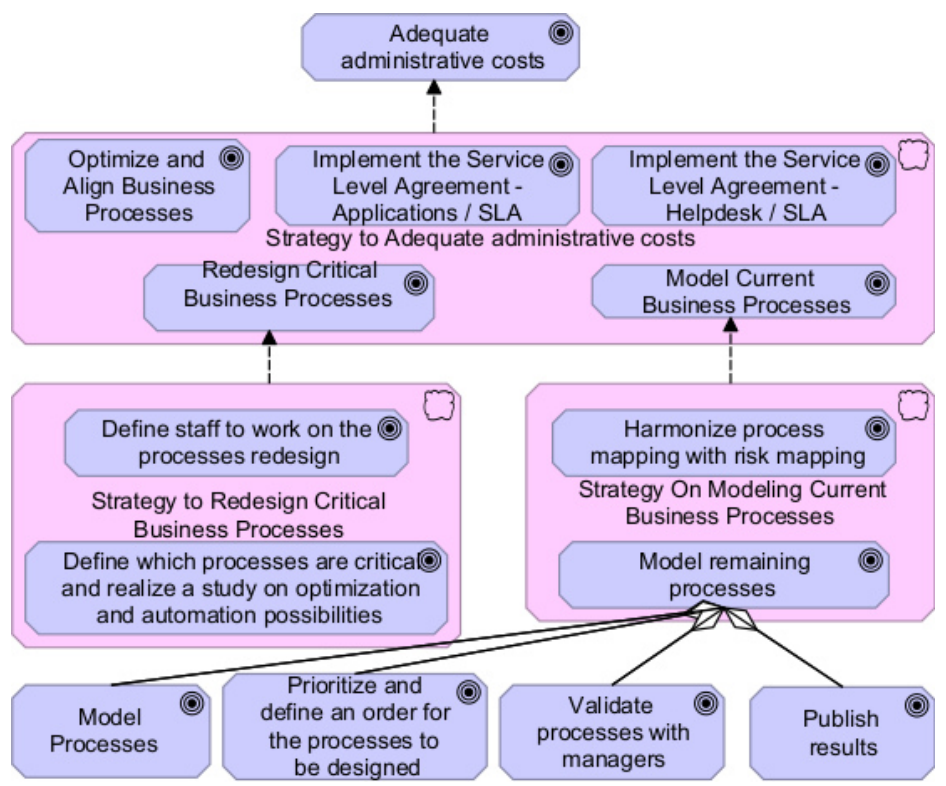

Figure 18 - Strategy and Decomposition 


\section{Time Point, Time Interval and Target}

The Time Interval and Time Point concepts are defined in the metamodel in order for ArchiMate to be able to define timing constraints on goals. The two associations between Time Interval and Time Point represent the begin and end Time Points of the Time Interval. The reification of the concepts is required since the language does not allow the introduction of these conceptualizations in any other way. However, in practice tools might instantiate these as properties of affected concepts. Time might also be important for other aspects of ArchiMate, such as its Implementation and Migration Extension (The Open Group, 2012). However, it is out of scope of this work to review the whole ArchiMate language.

The Target concept has been introduced to represent the idea of measurable targets associated with goals. The interpretation of defining a measurable target in UFO is understood to be a new (or further) specification of the intention's proposition, and, as such, it is a redefinition of the agent's intention. The agent redefines its goal, stating sufficient (objective) conditions to consider its intention achieved. However, the ArchiMate language does not have any element that could represent this further definition of the agent's intention. Thus, our proposal introduces the target concept to represent this notion. Figure 19 presents a fragment of the strategic plan of the pension fund in which there is the assignment of the stakeholder responsible for goal achievement and the sufficient targets defined for considering that the goals have been achieved.

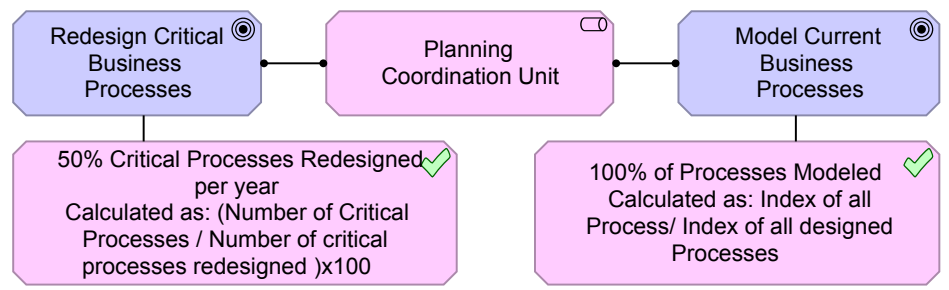

Figure 19 - Responsible and Target

\section{Capability, Resource, Requirement and Common Relationships}

The capability concept represents the power to bring about a desired outcome. This power is understood in a broad sense, as, for example, a mug has the power of constraining coffee, which is the desired outcome. Capabilities can be used to state a broad range of behaviors, ranging from simple ones as a mug's behavior, to complex behaviors, such as 'design business process' that can be assumed to inhere in an organization. Capabilities are interpreted as UFO dispositions (Azevedo et al., 2013) (Carlos L. B. Azevedo et al., 2015). This interpretation allows the organization to model the capabilities it can "socially 
perform”. This is applicable for a variety of cases that use delegation, such as, for example, cases in which an organization hires a different company to bring about some desired outcome and needs to state that the original (hiring) organization has the capability of bringing about that desired outcome (because it has the capability of delegating it (Bringuente, Falbo and Guizzardi, 2010) (Guizzardi and Guizzardi, 2011)).

The resource concept in UFO represents a role or a role mixin that objects may play in particular contexts of usage. 'Being controlled by an organization' is understood as 'being available for the organization' (e.g., by an employment contract between employers and employees, or by having the right/ownership over a certain object) (Azevedo et al., 2013) (Carlos L. B. Azevedo et al., 2015).

A requirement is interpreted as a desire, in which its propositional content (representing the requirement) is formulated as a normative description that states that if a system is to exist, then it must satisfy the requirement's proposition (Azevedo et al., 2011). Ideally, the desire would lead to the adoption of intentions to satisfy the requirement, for example, by committing to actions to develop systems that satisfy the requirement. Nevertheless, this may not be the case for requirements with a low priority or requirements whose realization may not be worthwhile (in which case the stakeholder will not commit to the actions that pursue requirements satisfaction).

We now focus on common relationships, such as the influence and the aggregation relations that apply to all motivational elements. The influence relationship models that "some motivational element has a positive or negative influence on another motivational element". In a positive influence, less effort is required to reach a situation that satisfies the propositional content of $\mathrm{B}$ from the situation that satisfies the propositional content of A. In a negative influence, more effort is required to reach a situation that satisfies the propositional content of B from the situation that satisfies the propositional content of A (Azevedo et al., 2011).

In the aggregation ontological interpretation presented in (Azevedo et al., 2011), the relationship has been defined as a logic relation between propositions. More specifically, the propositional content $P_{i}$ of each of the $n$ fine-grained model elements appears as a term in the propositional content $P$ of the composed model element, formally, $\left.\left(P \leftrightarrow P_{1} \bullet_{1} P_{2} \bullet_{2} \ldots \bullet_{n-1} P_{n} \bullet{ }_{n} Z\right)\right)$, where $\bullet_{i}$ represents either the disjunction or the conjunction operator and an optional term $Z$ represents any other proposition that may be used to derive $P$ and is not explicitly modeled in the aggregation. $Z$ captures the ambiguity regarding the notion of incompleteness that is associated with the aggregation concept. In the proposal presented in this thesis, the optional term is not necessary for the Goal concept, since the ambiguity on the partiality for this concept is covered, to explicit express if the aggregation is complete or incomplete. The ability to model an incomplete 
aggregation is particularly useful, since one may not be able to list all possible decompositions of a goal, many of which may be unknown at the time of modeling. Nevertheless, the optional term is necessary for the current ArchiMate specification.

\subsection{Related Work}

As discussed in Section 3.3, most EA approaches are still struggling with the goal domain and its modeling. In this section we analyze the frameworks: Zachman (Kappelman and Zachman, 2013), MoDAF (UK Ministry of Defense, 2013), DoDAF (Department of Defense Architecture Framework Working Group, 2007), ISO RM-ODP (ISO_-International Organization for Standardization, 2004), ARIS (Scheer, 2000) (Santos Jr et al., 2013) and the OMG BMM (Object Management Group, 2014) according to their strategic aspects concerns, with a special focus on representation aspects. We also analyze the goal modeling languages I*/Tropos (Mylopoulos, Castro and Kolp, 2013) and Kaos (Van Lamsweerde, 2009) according to their suitability to model strategic plans.

\subsubsection{Strategic Plans in Enterprise Architecture Frameworks}

In 1992, Zachman and Sowa introduced a "why" column in the Zachman framework. This column includes the concept of strategy, together with the concept of objective. The concepts can be related by means-ends-relations between objectives and strategies. There is also a conflict relation in the framework that can be used between objectives. No special attention is given to the semantics of the notion of strategy and the Zachman framework does not further elaborate on a language for representation of its "why" column.

The MoDAF and DoDAF frameworks support the concept of vision and relate it to desired effects and goals, respectively. The MoDAF framework states that Enterprise Phase has Enterprise Vision and Enterprise Vision has Enterprise Tasks. It states that vision can have tasks. DoDAF, however represents that vision is realized by desired effect. Desired effect can be related to activities, in which a desired effect directs an activity. However, other strategic planning conceptualizations are not represented in these frameworks.

The concept of goal, sometimes called objective, which is a crucial concept for strategic planning, also appears in the ARIS and the ISO RM-ODP frameworks. In the ARIS framework, an objective can belong to another objective and might be supported by a function. The semantics of this notion is unclear (Cardoso et al., 2010). In the ISO RM-ODP, an objective can be refined into other objectives. This 
concept can be related to process, community or roles. Possible relations are that a community has an objective, which might represent ownership, and refined goals can be assigned to both processes or roles. However, these frameworks do not represent the other strategic planning concepts.

The OMG BMM framework is primarily divided into Ends and Means. An End is "something the business seeks to accomplish". It includes concepts such as vision, goals and objectives. Means represents elements "that may be called upon, activated, or enforced to achieve Ends". Means are further specialized into Courses of Action (Strategy and Tactics) and Directives. Although the BMM framework introduces concepts that appear to be aligned with strategic planning, the framework lacks important notions for strategic planning. The framework higher-level elements (e.g., goals, strategies) cannot be related with the individual responsible for achieving it (only to whom have established it). For example, it is not possible to define who is responsible for achieving a strategy or a goal in the framework without defining a business process and, then, who is to perform it. This is especially relevant for cases in which multiple business processes are executed and there are different individuals responsible for executing each process. Further, resources that are required in order to achieve a goal (or strategy) are to be defined in its usage, for example, at the business process level. Additionally, in the BMM framework there is no proper concept to represent timing constraints, which are only represented in the label of the timed constrained model element (e.g., on the goal label).

Thus, however on a first glance the BMM appears to support the proper concepts, the framework lacks capabilities for modeling strategic planning at the level required by high-level managers, which are interested in capturing what is to be achieved and how it should be achieved only in a high level of abstraction, frequently in an open delegation (in which the responsible agent is to define how it should be achieved). Further, it would be difficult to plan on the delivery of required capabilities, resources, products and services for the enterprise with controlled effort and adequate timing using BMM.

\subsubsection{Strategic Planning on Goal Modeling Languages}

In this subsection we analyze the main goal modeling languages Kaos and $I^{*} /$ Tropos with respect to their suitability for modeling strategic planning.

The Kaos goals modeling language was designed to support the discovery and realization of system requirements (Van Lamsweerde, 2009). The underlying idea is that goals are to be refined until they are realized by some actor, which could be the system to be, an internal actor or an external actor. The I*/Tropos language, in its turn, was designed for requirements engineering (Mylopoulos, Castro and Kolp, 2013). 
Both languages lack concepts to represent timing. There is no conceptualization for when, in time, the goals are to be realized. Indeed, it is not possible to state if a goal is to be accomplished in a short-term, mid-term or longterm. The modeler is also not able to capture precedence between goals, except the implicit one on refinements of the same goal in Kaos or decomposition in I*/Tropos.

On the partiality of goals decomposition or refinement and goal achievement, the Kaos language has no conceptualization to represent a contribution between goals, as well as no partiality of goal achievement. The models are supposedly complete, so, if goals resulting from a refinement are achieved, the refined goal is therefore achieved. The problem of this approach is that the organization cannot model something that facilitates achieving the desired result, but it is not guaranteed to deliver the desired result without other unknown or nonrepresented efforts, which frequently exists in strategic plans. The I*/Tropos language, otherwise, understands that the model is partial. However, the opposite can not be expressed, i.e., that a specific model or part of it is complete. None of the goal modeling languages allows the modeler to state both complete and partial models. This is unfortunate, since complete and partial models may be of interest to the enterprise in different times.

Goals, in I*/Tropos can be decomposed into other goals (partial decomposition). The conceptualization of 'contribution' between goals is possible for goals, plans and resources (the plan concept is a plan on tasks and cannot be used in a similar way as the strategy concept represented in Section 5.1.3). The means-end relation can be related from a task, resource or plan to a goal and cannot be used as a relation between goals. In the Kaos language, it is also not possible to direct relate goals with capabilities, neither with the resources that might be required to achieve that goal.

Thus, we conclude that none of the compared frameworks and goal modeling languages support the explicit representation of strategic plans concepts.

\subsection{Conclusions}

In this Chapter, we have presented an approach to capture strategic plans in EA. We have presented a conceptual model for strategic plans and extended ArchiMate to support the representation of the concepts in the model.

The strategic planning conceptual model is aligned with the strategic management literature, as well as with the requirements presented in in Section 3.2 and in (Carlos L B Azevedo, Van Sinderen, et al., 2015), which assessed strategic planning and identified requirements to incorporate it in EA. The use of a foundational ontology and of Bratman's planning theory (1999) have been 
instrumental in clarifying the semantics of various notions in the strategic management literature.

The introduction and usage of strategic planning into EA should improve the traceability between an enterprise's strategic planning and EA choices. Further, we believe that the planning of EA transformations could be enhanced if aligned with strategic plans (Ross, Weill and Robertson, 2006). Nevertheless, we also believe that EA can improve enterprises' to monitor and manage strategic plans achievement. EA can be used as a middle ground between an enterprise's operations and its strategic plans. EA can also be used for strategic planning at design time for the verification of change impact. The analysis can be relevant to decision-making.

Additionally, we have also outlined an initial approach for extending EA to achieve end-to-end traceability between strategic plans and EA operationalization, which we continue in Chapter 6. 

Chapter

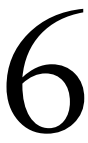

\section{Relating Strategic and Operational Aspects of EA using Capabilities and Resources}

Our objective in this Chapter ${ }^{20}$ is to address the challenge of incorporating the strategic management notions of capabilities and resources in EA descriptions, resulting ultimately in a well-founded approach to capture capabilities and resources in enterprise architecture descriptions. To accomplish that, we analyze the semantics of the Business Strategy and Valuation Concepts (BSVC) extension to ArchiMate (Iacob, Quartel and Jonkers, 2012), building up on this work. We identify issues with the original proposal, by interpreting it in terms of the UFO foundational ontology. We then introduce a new ontologically well-founded version of the BSVC metamodel that addresses the identified issues. The novelty of our approach resides in the strong relation of enterprise architecture modeling to these concepts as introduced in strategic management, and, most importantly, in the clear semantics we provide for the proposed modeling elements through ontological analysis. We aim at addressing the strategic management level, allowing capability-based planning and better decision making.

One of the main advantages of using capability-based planning, in the context of EA, is to provide enterprise architects with a common ground to initiate discussions with business leaders in terms of business outcomes (increased output, better quality, lower costs, revenue growth or improved market share) instead of projects, processes and applications (Scott, 2009). The problem is that processes are too detailed, applications are too technical and projects focus on short term results, usually having little strategic value.

20 The content of this Chapter has been adapted from author publications (Carlos L. B. Azevedo et al., 2015) and (Azevedo et al., 2013). 
We argue that modeling resources and capabilities for decision making purposes at strategic level must simplify models and hide the complexity of architecture models which is of no relevance at that abstraction level. Decision makers are mostly interested in means (i.e., resources \& capabilities) and goals (i.e., motivation). This is due to the fact that both capabilities and resources can be used as abstractions of complex behavior and architectural structure, respectively. This is also why important benefits to be reaped from modeling resources and capabilities are at the strategic level, while carrying out activities such as strategic alignment, capability-based planning, capability portfolio management, etc. Further, resources and capabilities can be linked to the architecture fragments they are abstracted from, then enabling an end-to-end traceability from strategic decisions to implementation and architecture change.

\subsection{Current Support for Modeling Capabilities and Resources}

Organizational resources and capabilities are key factors for organizational success. Our goal is to enable modelers to capture capabilities, resources and competences in an enterprise architecture modeling language. We use ArchiMate as a starting point.

Despite the relevance of capabilities and resources to the success of enterprises, little attention has been given to integrate these notions of capability and resource in enterprise architecture descriptions. A notable exception is the work discussed in (Iacob, Quartel and Jonkers, 2012), which extends the ArchiMate language (The Open Group, 2012) with constructs to represent capabilities and resources, integrating these new constructs with those used to represent other aspects of an enterprise architecture (such as active structure and behavior). The objective is to empower enterprise architects to use these important notions in coherent enterprise architecture descriptions. The Business Strategy and Valuation Concepts extension was based on the analysis and review of relevant business strategy and portfolio management literature. For this reason, many concepts present in other approaches, such as (Gordijn and Akkermans, 2001) and (Zandi and Tavana, 2010) have been incorporated in the proposed extension.

Similarly to other earlier ArchiMate extension proposals (e.g., the motivation extension presented in (Quartel, Engelsman and Jonkers, 2010) the initial development of the BSVC has been conducted without a rigorous definition of the semantics of the proposed modeling elements (Azevedo et al., 2011). The absence of such definitions could lead to several modeling and communication problems. Further, this would result in enterprise architecture models that 
cannot serve their purpose as tools for communication between stakeholders, and would decrease the enterprise architecture value in the pursuit of informed decision-making.

The BSVC introduces to ArchiMate the concepts of resource, capability, competence and risk. We focus on the resource, capability and competence concepts. The definitions and concrete syntax for the modeling elements introduced by the extension are shown in Table 1 . In this section we have preserved the definitions as they were originally provided in (Iacob, Quartel and Jonkers, 2012). These are the objects of analysis in Sections 6.2, 6.3 and 6.4.

Table 1 - Concrete syntax and definitions for Resource, Capability and Competence as provided in the BSVC

\begin{tabular}{|c|c|c|}
\hline Modeling element & \multicolumn{1}{|c|}{ Definition } & Concrete syntax \\
\hline Resource & $\begin{array}{l}\text { "an asset owned or controlled by an } \\
\text { individual or organization" }\end{array}$ \\
\hline Capability & $\begin{array}{l}\text { "the ability (of a static structure element, } \\
\text { e.g., actor, application component, etc.) to } \\
\text { employ resources to achieve some goal" }\end{array}$ \\
\hline Competence & $\begin{array}{l}\text { "the definition of competence [...] is } \\
\text { almost identical with that of personnel-based } \\
\text { resources". }\end{array}$ & Resource \\
\hline
\end{tabular}

Figure 20 shows the metamodel fragment, as proposed in (Iacob, Quartel and Jonkers, 2012) , for the integration of the BSVC with the ArchiMate core metamodel and its extensions.

${ }^{21}$ The competence element has no individual concrete syntax and is represented by the resource concrete syntax in (Iacob, Quartel and Jonkers, 2012). 


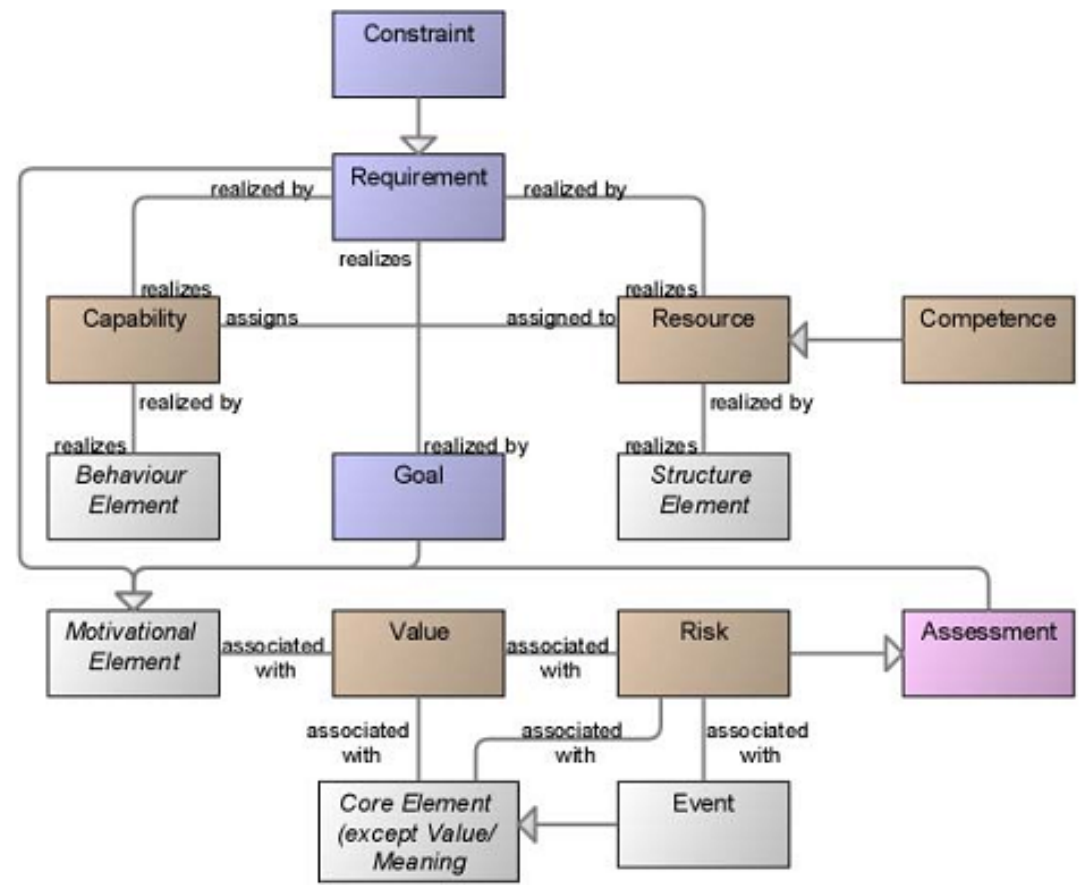

Figure 20 - BSVC Metamodel fragment (IACOB; QUARTEL; JONKERS, 2012)

The resource concept is prominently present in most valuation techniques, in business modeling approaches, and in constraint optimization models in which they are mathematically defined and constrained. This supports the importance given to the resource concept in the management literature (Iacob, Quartel and Jonkers, 2012) .

A resource represents an asset owned or controlled by an individual or organization. Resources are related to the motivation extension, in particular to requirements and goals, through the realization relation. The argument for this relationship is that goal achievement assumes availability and (constrained) consumption of certain resources. This view is based on the mathematical formulation of constrained optimization models, in which a goal function is minimized/maximized subject to a system of constraints (expressed as inequalities) imposed on the resources to be consumed for the achievement of the goal. Thus, a resource may satisfy a requirement, which in turn, may realize a goal. Furthermore, a resource is realized by structure elements, and is regarded in (Iacob, Quartel and Jonkers, 2012) as an abstraction of these elements.

Capability is defined as the ability of a static structure element (e.g., actor, application component, etc.) to employ resources to achieve some goal. Similarly to resource, capability is regarded in (Iacob, Quartel and Jonkers, 2012) as an 
abstraction of some behavior. The assignment relationship between resource and capability expresses the ability to employ (i.e., configure, integrate, etc.) resources.

The competence concept is introduced in (Iacob, Quartel and Jonkers, 2012) as a specialization of resource, based on the definition of competence proposed by (Prahalad and Hamel, 1990), which equates competence to personnel-based resources.

Figure 21 shows an ArchiMate model that was defined before the ontological analysis to reflect the range of elements and relations used to represent capabilities and resources in the proposed ArchiMate extension. The example focuses on the ArchiSurance company and its 'Insuring Capability'. The example shows other capabilities that are associated to the 'Insuring Capability' ('Claim Handling Capability', 'Selling Capability', 'Damage Assessment Expertise Capability' etc.). The example also reviews the resources assigned to the capabilities ('Damage Assessment Resources', 'Money', 'Authorized Garage', etc.). The example reflects that capabilities can be decomposed into other capabilities, and can be realized by some behavior elements (as in the case of 'Insuring Capability' and 'Claim Handling Capability' being realized by the 'Assess claim' business process, by the 'Financial administration' business function and by the 'Claim registration' application service). Similarly, resources can be realized by structure elements and resources can be assigned to capabilities (as in the 'Car Damage Assessment Resource' and 'Claim Handling Capability' case). 


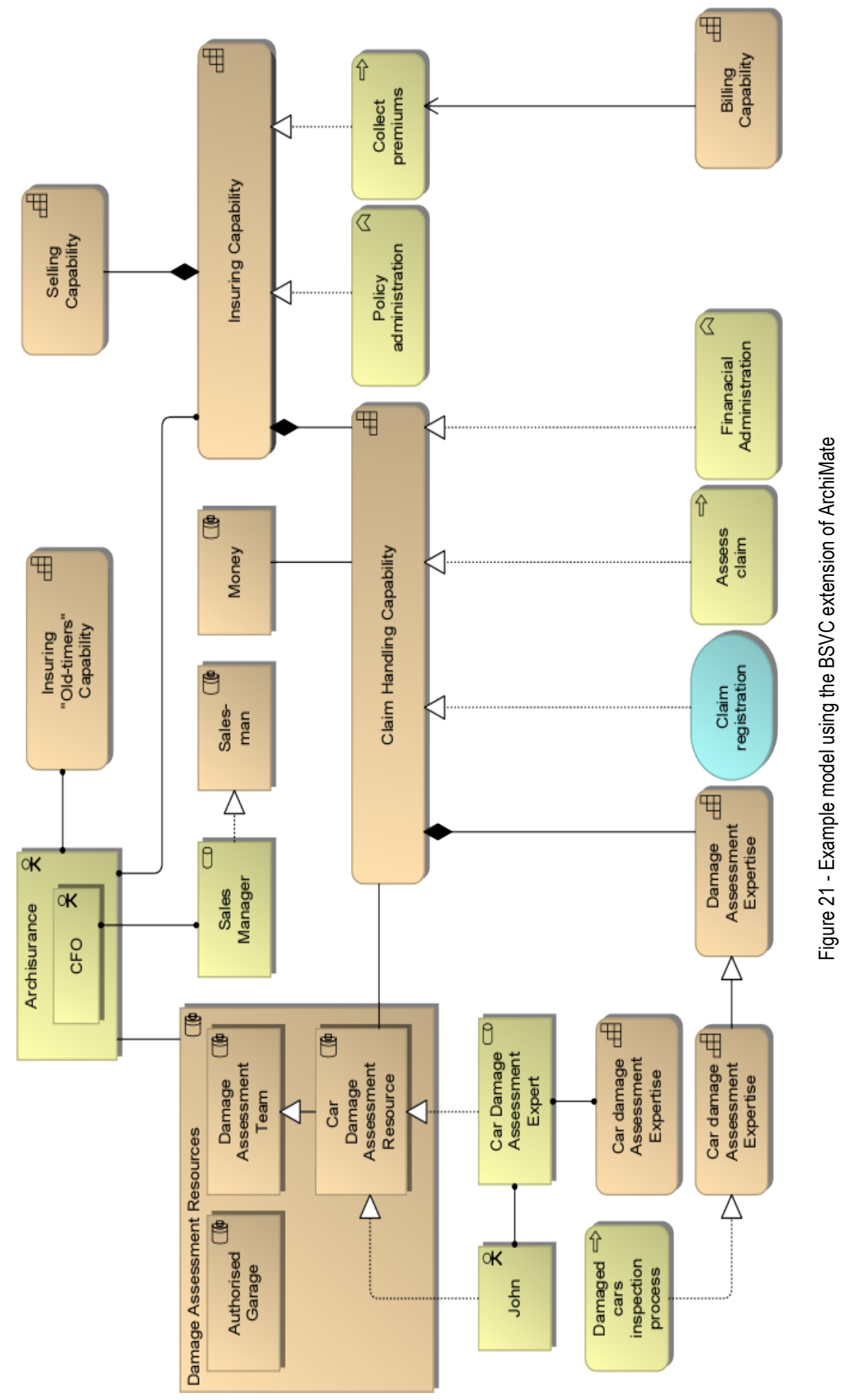




\subsection{Ontological Analysis of Resource}

In this section we discuss the ontological analysis and interpretation of the resource modeling element introduced in (Iacob, Quartel and Jonkers, 2012). We discuss possible interpretations in terms of UFO and consider the consequences of the various interpretations on the usage of the language. We make a thorough analysis, and the section is structured according to six problems that have been revealed in this analysis, which for convenience are named R1 to R6 (summarized in a table at the end of the section). The analysis of the revealed problems leads to the recommendations presented in Section 6.5.

\subsubsection{Resource Context of Usage (R1)}

The Oxford Dictionary defines resource as "a stock or supply of money, materials, staff, and other assets that can be drawn on by a person or organization in order to function effectively". In (Iacob, Quartel and Jonkers, 2012), a similar intuition is put forward when motivating the resource element in the BSVC extension: "the achievement of a goal assumes the availability and (constrained) consumption of certain resources". Further, resources are also characterized as "assets owned or controlled by an organization".

Since "assets" are (valuable) things, in a first examination, this characterization seems to suggest that resources represent specific individuals, such as business actors (e.g., in case of staff as resource) or business objects (agentive objects (agents) or non-agentive objects). Nevertheless, this interpretation would show a clear case of construct redundancy (Guizzardi, 2005), as the additional resource modeling element would serve no purpose, being supplanted by the previously existing structure elements of the language (such as business actor and business object). We must conclude this is not the intention of the designers of the extension, which indicate further that a resource is "an abstraction of structure elements" and include a "realizes" relation that may be used to connect structure elements to the resources they "realize". This suggests that it is not the specific structure element that is represented using a resource, but some more abstract notion, which reveals the dependence on a structure element with certain characteristics without specifying the particular element involved. In other words, we understand that the resource element defines some type of structure element (a universal), and that the structure element that realizes the resource instantiates this type. An example of this would be a model that includes a business actor 'John' that realizes a resource called 'Car Damage Assessment Resource'. 
If we further consider that resources are used in the scope of the efforts to achieve goals, we can understand that a resource refers to the role an object (agentive or non-agentive) plays when employed in the scope of these efforts. In the example above, 'John' functions as a 'Car Damage Assessment Resource' in some context of the organization (for example, that of the process of assessing damages).

Further, in order to play a particular role, an object may be required to instantiate some particular type (what is called an "allowed type" in (Bock and Odell, 1998)). For example, any 'Car Damage Assessment Resource' may need to possess specific damage assessment skills, and thus instantiate some specific universal that is characterized by these skills.

Thus, an intermediate conclusion is that resource represents an externally dependent universal (either a role or role mixin) that may be instantiated by objects of a particular allowed type. The fact that resource models both the role an object plays in a particular context of usage as well as its allowed type has some consequences to the terms used in the label of a resource. In some cases, such as 'Car Damage Assessment Resource', the context of usage is emphasized, focusing thus on the role or role mixin that is instantiated when the resource is used; in other cases, such as 'Money', the allowed type required for role playing is emphasized in the label.

An insight that comes out of this interpretation is that, as a role (mixin), a resource should have a context of usage, which in UFO is defined in the scope of a material relation (or in the scope of an event). This means some asset is a resource in a defined context, but not in others. For example, the 'Car Damage Assessments Expert' is a resource in the 'Damaged cars inspection process' because of the 'Car Damage Assessment Expertise', but it should not be considered a resource for the 'Collect premiums' process. This cannot be directly represented with the BSVC metamodel, because there is no notion of 'use' of resources. We label this as problem 'R1'.

\subsubsection{Resources Control (R2) and Agentive Resource vs Non- Agentive Resource (R3)}

The resource concept is also defined as "an asset owned or controlled by an individual or organization". Being "owned or controlled" is understood as being available for the organization, e.g., by an employment contract between employers and employees, or by having the right/ownership over a certain object. For the cases in which the resource is an agentive element (agent) we understand the 'controlling' in the context of the social relator that bounds the particular individual or organization with the first, e.g., the employment contract. A controls $B$ means that there is a (possibly a set of) meta- 
commitment(s) of $B$ towards $A$. In other words, $A$ has meta-claims over $B$ and, hence, the ability to delegate to $B$ and, consequently to increase its social ability (Bringuente, Falbo and Guizzardi, 2010). For the interpretations in which the resource is a non-agentive object, we understand "the control or owning of the asset" as the ability to have that element to participate in an event of interest, in which the organization $A$ has a certain right with respect to the object $O$ (for example, a right to use, to consume, to destroy, to sell, etc.). The current metamodel does not allow the modeler to identify who controls the resource, aside from the use of the very general and abstract associated with relation, which has no specific semantics and can be applied between any constructs in the language. This could be an issue when there are multiple business actors (different organizations, business departments) that could control this resource. For example, the model user would not be able to know which organization controls the resource modeled, and as such, could not distinguish if that resource is or is not available at his organization. We call the lack of expressiveness of control relations 'R2'.

Furthermore, the extension does not distinguish between resources potentially played by agents from those potentially played by non-agentive objects. We call this lack of expressiveness 'R3'. Further, R3 has an impact on R2, since nonagentive resources are to be controlled by someone, and, as importantly, should not control any other element.

\subsubsection{Resources Properties and Instances}

Other examples of usage indicate that not only business actors and objects may realize a resource, but also that business roles may be said to realize a resource. In our example, the 'Car Damage Assessment Expert' business role realizes the 'Car Damage Assessment Resource'. In this case, we should understand that whichever object instantiates the role represented by the business role may also instantiate the role (mixin) represented by the resource. Intuitively in the example, not only 'John' but also any other damage assessment expert is a 'Car Damage Assessment Resource'. For these cases, the language does not determine whether one or more individuals instantiating the role (mixin) represented by the resource are required, used or controlled in the particular context. In other words, it is not possible to express whether all the instances of that type are required, used or controlled, if just one instance of that type is required, used or controlled or if an arbitrary set of instances of that type are required, used or controlled. We label this as problem 'R4'.

Further, the current ArchiMate language does not address the cases in which the resources are objects of interest or raw materials (e.g., 'Money' as in the running example, or gold, diamond, gas), i.e., passive non-agentive elements. 
We believe the language designers have tried to cover this by stretching the resource element, and using it directly to represent such objects. However, these would be resources that do not have any structure element to realize them, since there are no structure elements that can represent these types of objects in ArchiMate (the passive structure of ArchiMate focuses primarily on information objects). Also, in these cases, the resources are role (mixins) and the language is not able to express if the same instance is to be considered a resource in various contexts (e.g., usage of the same amount of money in different contexts). Also, it is not possible to express any property associated to the element itself (e.g., quantity of money, gold carats). We label this as problem ' $\mathrm{R} 5$ '.

The resource concept is related to the motivation extension through the realization relation, in which a 'resource realizes a requirement'. According to (Azevedo et al., 2011), a requirement corresponds to a normative description, which states that if a system (in a broad sense) is to exist, then it must satisfy a particular proposition. In this case, we understand that proposition refers to the object (or objects) playing the resource role. Any instance of the role (mixin) represented by the resource must satisfy the requirement's proposition. To put it simply, a requirement adds characteristics to a resource's allowed type.

The proposal also states that "the achievement of a goal assumes the availability and (constrained) consumption of certain resources". However, goals are not associated directly to resources, and the proposal is silent on the issue of resource consumption. Resources and goals are only indirectly related through the 'goal is realized by requirement' and the 'requirement is realized by resource' relations. At this point, no interpretation can be given to the textual definition, and further language documentation would be required on the topic of resources availability and consumption.

\subsubsection{Lack of Clarity on Required Resources}

Now we focus on the common ArchiMate relationships that apply to the resource concept (specialization and aggregation). We interpret the specialization relation between resources as subsumption between the roles or (role mixins) represented by the resources. The aggregation relation between resources suggests some sort of whole-part relationship, since aggregation in ArchiMate may be represented by containment (see in Figure 21 the relation between 'Damage Assessment Resources' as a whole, and 'Authorized Garage', 'Damage Assessment Team' and 'Car Damage Assessment Resource' as parts). Since resources may represent both agentive and non-agentive objects, it would be possible to combine these with aggregation. We interpret this as a very general sort of whole-part relation known as mereological sum. However, there is no distinction between AND or OR resource aggregations in ArchiMate. Thus, when 
resources are aggregated, it is unclear whether all the aggregated resources are required/used, or whether one or any arbitrary number of them is required. We label this as problem 'R6'.

Table 2 summarizes the problems found by the ontological analysis of the BSVC resource concept.

Table 2 - Summary of problems found by the ontological analysis of the BSVC resource concept

\begin{tabular}{|c|c|c|}
\hline Problem & Context Information & Implies in \\
\hline R1 & $\begin{array}{l}\text { There is no context of usage for } \\
\text { resources in the language. }\end{array}$ & $\begin{array}{l}\text { Some asset is a resource in a defined } \\
\text { context, but not in others. For example, the } \\
\text { 'Car Damage Assessments Expert' is a } \\
\text { resource in the 'Damaged cars inspection } \\
\text { process' because of the 'Car Damage } \\
\text { Assessment Expertise', but it should not be } \\
\text { considered a resource for the 'Collect } \\
\text { premiums' process. }\end{array}$ \\
\hline R2 & $\begin{array}{l}\text { There is no relation in the } \\
\text { language to state who controls a } \\
\text { resource }\end{array}$ & $\begin{array}{l}\text { This could be an issue when there are } \\
\text { multiple business actors (different } \\
\text { organizations, business departments) that } \\
\text { could control this resource. For example, the } \\
\text { model user would not be able to know which } \\
\text { organization controls the resource modeled, } \\
\text { and as such, could not distinguish if that } \\
\text { resource is or is not available at his } \\
\text { organization. }\end{array}$ \\
\hline R3 & $\begin{array}{l}\text { The language does not } \\
\text { distinguish resources played by } \\
\text { agents and non-agentive } \\
\text { resources }\end{array}$ & $\begin{array}{l}\text { Non-agentive resources are to be controlled } \\
\text { by someone, and, as importantly, should not } \\
\text { control any other element. }\end{array}$ \\
\hline R4 & $\begin{array}{l}\text { The language does not } \\
\text { determine whether one or more } \\
\text { individuals instantiating the role } \\
\text { (mixin) represented by the } \\
\text { resource are required, used or } \\
\text { controlled in the particular } \\
\text { context. }\end{array}$ & $\begin{array}{l}\text { It is not possible to express whether all the } \\
\text { instances of that type are required, used or } \\
\text { controlled, if just one instance of that type is } \\
\text { required, used or controlled or if an arbitrary } \\
\text { set of instances of that type are required, } \\
\text { used or controlled. }\end{array}$ \\
\hline R5 & $\begin{array}{l}\text { The language does not address } \\
\text { the cases in which the resources } \\
\text { are objects of interest or raw } \\
\text { materials (e.g., money, gold, } \\
\text { diamond, gas), i.e., passive non- } \\
\text { agentive elements. }\end{array}$ & $\begin{array}{l}\text { The language is not able to express if the } \\
\text { same instance is to be considered a } \\
\text { resource in various contexts (e.g., usage of } \\
\text { the same amount of money in different } \\
\text { contexts). Also, it is not possible to express } \\
\text { any property associated to the element itself } \\
\text { (e.g., quantity of money, gold carats) }\end{array}$ \\
\hline
\end{tabular}




\begin{tabular}{|l|l|l|}
\hline R6 & $\begin{array}{l}\text { There is no distinction between } \\
\text { AND or OR resource } \\
\text { aggregations in ArchiMate }\end{array}$ & $\begin{array}{l}\text { When resources are aggregated, it is unclear } \\
\text { whether all the aggregated resources are } \\
\text { required/used, or whether one or any } \\
\text { arbitrary number of them is required. }\end{array}$ \\
\hline
\end{tabular}

\subsection{Ontological Analysis of Capability}

In this section we discuss the ontological analysis and interpretation of the capability modeling element introduced in (Iacob, Quartel and Jonkers, 2012). This section discusses the 5 problems revealed by the ontological analysis, named $\mathrm{C} 1$ to $\mathrm{C} 5$, although the ontological analysis is continued throughout the subsections. The revealed problems inspired the recommendations in Section 6.5 .

\subsubsection{Individual vs Type of Individuals}

The BSVC proposal defined capability as "the ability (of a static structure element, e.g., actor, application component, etc.) to employ resources to achieve some goal. [...] Also capability assumes the ability to employ (i.e., configure, integrate, etc.) resources". The definition also states that "capability (similarly to resource) can be seen as an abstraction of some behavior of the static structure element".

We intuitively understand that a capability is attributed to some agent and gives that agent its power to bring about some behavior in order to achieve a desired outcome. From the excerpt "of a static structure element, e.g., actor, application component, etc.", the capability appears to belong to the specific individual that is to bring about the desired outcome. This would lead us to interpret that capabilities are dispositions in UFO (dispositions, i.e., moments that are only manifested in particular situations and that can also fail to be manifested). However, carefully examining the "abstraction of some behavior" fragment, and considering the same pattern that was employed by the language designers with respect to resources (as "abstractions of structural elements"), we understand that capabilities should be interpreted as types of dispositions (disposition universals in UFO).

Often a capability represents a general disposition type. For example, the 'car damage assessment expertise' capability is a general disposition type that is implicitly specialized into a more specific type (e.g., the capabilities to assess car damage produced by fire, to assess car damage caused by flood, and to assess car damage after a crash).

This dispositional account is also applicable for cases in which some organization might hire a different organization to perform processes that realize 
a capability, and still state to have that capability, in this case because it has the disposition of delegating the capability (Guizzardi and Guizzardi, 2011), (Bringuente, Falbo and Guizzardi, 2010)). This is related to the idea of what an organization can "socially perform". If $A$ has a meta-commitment from $B$ to execute $S$, then $A$ (socially) can do $S$. An object can have dispositions which arise from its parts, or from the network of its delegation relations (Bringuente, Falbo and Guizzardi, 2010).

Preferably, the language should allow us to infer which individuals bear the dispositions that are related to that capability. However, the original metamodel does not include relations between the capabilities and the structure elements that are said to have the capabilities, such as a business actor or business role. As a consequence, the language does not allow one to identify the individuals or types of individuals that bear dispositions of the type presented by the capability, aside from using the generic and semantically-neutral association of ArchiMate. In other words, it is not possible to express in the language which structure element has a capability, including the capabilities an organization has, unless the capability is realized by some behavior element. We label this as 'problem $\mathrm{C} 1$ '.

For the case of resources, these are assigned to a capability, in the sense that they are used in order to leverage capabilities), but resources themselves do not have capabilities in the original extension. This is represented in Figure 21, in which the organization has not assigned the 'selling capability' to any resource. Since the language cannot express which are the capabilities inhering in the 'Salesman' resource and the 'Sales Manager' structure element (business role), the organization is not able to know which resource or structure element has the required 'selling capability' to properly assign its performance.

\subsubsection{Diverse Interpretations and Unknown Capabilities}

The capability concept has three defined relationships, according to the original metamodel. We now focus on "capability realizes requirement". Again, according to (Azevedo et al., 2011), a requirement corresponds to a normative description, which states that if a system (in a broad sense) is to exist, then it must satisfy a particular proposition. In this case, we understand that proposition refers to the dispositions that instantiate the disposition universal represented by the capability. The dispositions must be in accordance with the requirement, in order to satisfy its proposition.

We now focus on the relations 'capability realized by behavior element' and 'resource assigned to capability'. We understand that the first needs to be considered also with the participation of the resource (via the 'resource assigned to capability' relationship). We understand that this pattern of relations can have two different interpretations. We label this as 'problem C2'. A first one is that 
the resource object has a disposition that instantiates the disposition universal represented by the capability, and that the participation of the resource manifesting its disposition is required in order to perform the behavior element (an event universal). For example, the 'Car damage Assessment Expertise' capability on Figure 21 is to be manifested in the 'Damaged cars inspection process' business process in order for the organization to perform that process. The second possible interpretation is that the capability is acquired (by the resource) with the performance of the behavior element (Molnar, 2006), i.e., the resource acquires a capability after the process is performed. For example, the 'Car damage Assessment Expertise' capability is acquired with the occurrence of the 'Damaged cars inspection process' process. In UFO, this can be interpreted as follows: $s$ is a situation in which the object has the disposition $d, e$ is an event representing the behavior element, and $e$ is a pre-state of $s$. If no resource is represented, the object that is acquiring or manifesting the capability is unknown. We label this as 'problem C3'. In this case, one can argue that it is an organization's capability, but it is not possible to clearly define it without relating it to the object, and the specification does not define this case. Even when related to the resource concept, since the resource that is acquiring the disposition represents a universal, a type element, the actual object that is acquiring the disposition is undetermined. The language is not expressive enough to state if one individual, all the individuals that instantiates the universal or an arbitrary combination of individuals instantiating the universal are acquiring the disposition. In none of these interpretations it is possible to know in advance if it is one individual, all the individuals that instantiates that universal or an arbitrary combination of them that are related to the disposition. In the first interpretation, is not possible to know how many objects are to manifest their dispositions in the event represented by the behavior element. In the later, it is not possible to know which object is to acquire the disposition. We label this as 'problem C4'.

\subsubsection{Lack of Clarity on Manifested Capabilities}

Now we focus on the common ArchiMate relations that apply to the capability concept. The specialization relation between capabilities should mean that a disposition universal (type) subsumes other disposition universal, and the aggregation relation between capabilities is interpreted as (complex) dispositions, which are dispositions based on other dispositions (Molnar, 2006). However, there is no distinction between AND or OR capability aggregations in ArchiMate, i.e., it is not clear whether the "aggregated" capabilities are all required or whether there are optional capabilities. The language also lacks expressiveness to state if all the capabilities associated to a behavior element are acquired or 
manifested, if just one of them is acquired or manifested, or if an arbitrary number of them are acquired or manifested. We label this as 'problem C5'.

Table 3 summarizes the problems found by the ontological analysis in the BSVC capability concept.

Table 3 - Summary of the problems found by the ontological analysis of the BSVC capability concept

\begin{tabular}{|c|c|c|}
\hline Problem & Context Information & Implies in \\
\hline $\mathrm{C} 1$ & $\begin{array}{l}\text { The language does not allow } \\
\text { one to identify the individuals } \\
\text { or types of individuals that } \\
\text { bear dispositions of the type } \\
\text { presented by the capability }\end{array}$ & $\begin{array}{l}\text { It is not possible to express in the language } \\
\text { which structure element has a capability, } \\
\text { including the capabilities an organization has, } \\
\text { unless the capability is realized by some } \\
\text { behavior element. Since the language cannot } \\
\text { express which are the capabilities inhering in } \\
\text { the 'Salesman' resource and the 'Sales } \\
\text { Manager' structure element (business role), } \\
\text { the organization is not able to know which } \\
\text { resource or structure element has the required } \\
\text { 'selling capability' to properly assign its } \\
\text { performance. }\end{array}$ \\
\hline $\mathrm{C} 2$ & $\begin{array}{l}\text { The relations 'capability realized } \\
\text { by behavior element' and } \\
\text { 'resource assigned to capability' } \\
\text { can have two different } \\
\text { interpretations. }\end{array}$ & $\begin{array}{l}\text { It is not possible to clearly interpret if the } \\
\text { capability is required in order to perform a } \\
\text { behavior element (e.g., 'Car damage } \\
\text { Assessment Expertise' capability on Figure } 18 \\
\text { is to be manifested in the 'Damaged cars } \\
\text { inspection process' business process in order } \\
\text { for the organization to perform that process) or } \\
\text { if the capability is acquired (by the resource) } \\
\text { with the performance of the behavior element } \\
\text { (MOLNAR, 2006), i.e., the resource acquires a } \\
\text { capability after the process is performed (e.g., } \\
\text { 'Car damage Assessment Expertise' capability } \\
\text { is acquired with the occurrence of the } \\
\text { 'Damaged cars inspection process' process). }\end{array}$ \\
\hline C3 & $\begin{array}{l}\text { If no resource is represented, } \\
\text { the object that is acquiring or } \\
\text { manifesting the capability is } \\
\text { unknown. }\end{array}$ & $\begin{array}{l}\text { It is not possible to know the object which } \\
\text { performs or acquires capabilities if no resource } \\
\text { is represented. }\end{array}$ \\
\hline C4 & $\begin{array}{l}\text { The language is not expressive } \\
\text { enough to state if one } \\
\text { individual, all the } \\
\text { individuals that instantiates } \\
\text { the universal or an arbitrary } \\
\text { combination of individuals } \\
\text { instantiating the universal are } \\
\text { acquiring the disposition. }\end{array}$ & $\begin{array}{l}\text { In the first interpretation, it is not possible to } \\
\text { know how many objects are to manifest their } \\
\text { capabilities in the event represented by the } \\
\text { behavior element. In the later, it is not possible } \\
\text { to know which object is to acquire the } \\
\text { capability. }\end{array}$ \\
\hline
\end{tabular}




\begin{tabular}{|l|l|l|}
\hline C5 & $\begin{array}{l}\text { There is no distinction between } \\
\text { AND or OR capability } \\
\text { aggregations in ArchiMate }\end{array}$ & $\begin{array}{l}\text { It is not clear whether the "aggregated" } \\
\text { capabilities are all required or whether there } \\
\text { are optional capabilities. The language also } \\
\text { lacks expressiveness to state if all the } \\
\text { capabilities associated to a behavior element } \\
\text { are acquired or manifested, if just one of them } \\
\text { is acquired or manifested, or if an arbitrary } \\
\text { number of them are acquired or manifested. }\end{array}$ \\
\hline
\end{tabular}

\subsection{Ontological Analysis of Competence}

In this section we discuss the ontological analysis and interpretation of the competence modeling element introduced in (Iacob, Quartel and Jonkers, 2012). This section discusses the 3 problems revealed by the ontological analysis, named $\mathrm{C} 1.1, \mathrm{C} 2.1$ and C6, although the ontological analysis is continued throughout the subsections. The revealed problems inspired the recommendations in Section 6.5 .

\subsubsection{Diverse Interpretations and Unknown Object}

The competence concept was introduced in (Iacob, Quartel and Jonkers, 2012) as a "specialization of resource (intangible or personnel-based)". The proposal states that "a core competence is a particular strength of an organization. Core competences are the collective learning in organizations, and involve how to coordinate diverse production skills and integrate multiple streams of technologies. Examples of core competences include technical/subject matter know-how, a reliable process and/or close relationships with customers and suppliers". This was "based on the fact that the definition of competence [...] is almost identical with that of personnel-based resources". Personnel-based resources have been exemplified as "technical know-how, other knowledge assets including organizational culture, employee training, [...]".

Based on the aforementioned statements regarding competence, we understand that a competence is something that an element, when provoked, is able to do, or to perform. It addresses the element's capacity of performing an activity. At a first examination, this characterization seems to suggest that competence is to be applied to specific individuals, and that it would be a disposition that inheres in the individual. However, the original metamodel shows that competence is a resource, i.e., a universal. Based on the resource interpretation as a universal, we conclude that the competence also represents a universal, which would be a disposition type, whose instances inhere in the objects that play the role represented by a resource. 
Since a competence is a specialization of resource in the BSVC, it inherits the resource's relations. We now focus on the 'competence realizes requirement'. According to requirement interpretation (Azevedo et al., 2011), we interpret this relation as 'the disposition of the object satisfies the requirement's proposition'. We understand that the competence is of the same disposition type as of the capability that is manifested (or acquired depending on the given interpretation) with the performance of the behavior element (event). The interpretation varies according to the interpretation given to the capability relationship. We label this as 'problem C2.1', since it is a consequence of C2. This can be interpreted as that: (i) by being able of executing a certain behavior element (an event universal), the resource object has a disposition $\mathrm{d}$ (of the competence defined type) that instantiates the type represented by the capability or that; (ii) $\mathrm{s}$ is a situation in which the object has the disposition $\mathrm{d}$ and $\mathrm{e}$ is an event representing the behavior element, e is a pre-state of $\mathrm{s}$, in which the $\mathrm{d}$ is an instance of the competence. The relation 'competence is realized by structure element' relates the dispositions to the elements that bears them. This is interpreted in UFO as that the object that represents the structure element bears a disposition of that disposition type. This is desirable, however, since it is not enforced by the language, we label the lack of the knowledge on which object bears the disposition as 'problem C1.1', since it is associated to $\mathrm{C} 1$.

\subsubsection{Construct Redundancy}

The interpretation of the competence concept points to the same ontological construct as the interpretation of the capability concept. We label this as 'problem C6'. The competence concept appears to have been introduced to fill the gap in the proposal that it is unknown which capabilities a resource (or structure element) has. This shows a case of construct redundancy in the language. According to (Weber, 1997), "construct redundancy occurs when more than one grammatical construct can be used to represent the same ontological construct". Our analysis confirms and explicates the informal suspicions raised in the original proposal text when it states that "depending on the (interpretation of the) definition of competence, one may argue that, for example it is more natural to introduce competence in the metamodel as a specialization of a capability" (Iacob, Quartel and Jonkers, 2012). The original proposal also states that "the semantic distance between competence, on one hand, and either resource or capability, on the other hand, is too small”.

Table 4 summarizes the problems found by the ontological analysis of the BSVC competence concept. 
Table 4 - Summary of the problems found by the ontological analysis of the BSVC competence concept

\begin{tabular}{|l|l|l|}
\hline Problem & \multicolumn{1}{|c|}{ Context Information } & \multicolumn{1}{|c|}{ Implies in } \\
\hline C1.1 & $\begin{array}{l}\text { Lack of knowledge on which object bears the } \\
\text { competence disposition. }\end{array}$ & $\begin{array}{l}\text { The structure element that } \\
\text { has a competence is } \\
\text { unknown. }\end{array}$ \\
\hline C2.2 & $\begin{array}{l}\text { The competence is of the same disposition } \\
\text { type as of the capability that is manifested (or } \\
\text { acquired depending on the given interpretation) } \\
\text { with the performance of the behavior element } \\
\text { (event). }\end{array}$ & $\begin{array}{l}\text { The interpretation varies } \\
\text { according to the interpretation } \\
\text { given to the capability } \\
\text { relationship (see problem } \\
\text { C2). }\end{array}$ \\
\hline C3 & $\begin{array}{l}\text { The interpretation of the competence concept } \\
\text { points to the same ontological construct as the } \\
\text { interpretation of the capability concept. }\end{array}$ & Construct excess \\
\hline
\end{tabular}

\subsection{Revisited Support for Modeling Capabilities and Resources}

In this section we propose improvements to the language based on the ontological analysis, the original intended meaning for the extension concepts and solutions to problems revealed in Sections 6.2, 6.3 and 6.4. We propose a revised metamodel to the language extension as part of the solution. We have attempted to preserve the original intended interpretations and original relations whenever possible, still addressing the semantic problems. Some additional expressiveness is made possible by using relations that were not initially employed in the BSVC metamodel, but most of which already existed in ArchiMate. We refrain from defining extensions to the ArchiMate core, focusing only on the BSVC capability and resource concepts and their relations. The competence construct was eliminated as a direct consequence of the ontological analysis.

Figure 22 presents a fragment of the revised metamodel. The constructs, relations and their semantics are discussed in the sequel. 


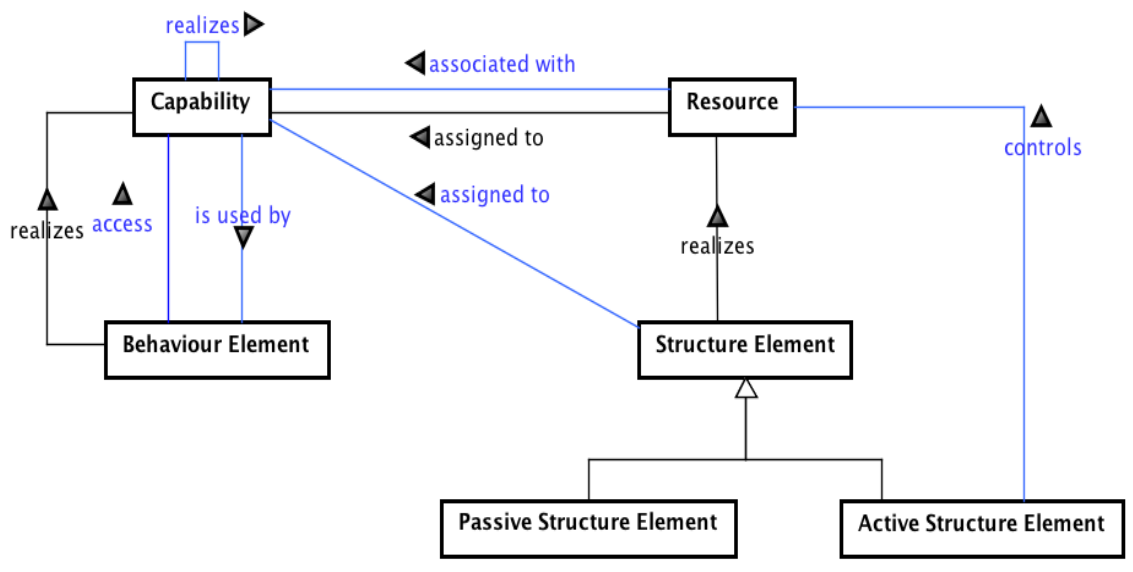

Figure 22 - Fragment of the proposed metamodel.

\subsubsection{Resource}

The resource concept in UFO represents a role or a role mixin that objects may play in particular contexts of usage. In Section 6.2, problem R1 stated that an element is a resource in a defined context, but it is not a resource in all situations, and that this was not enforced by the language. Thus, a resource should have a defined context.

The metamodel proposed here defines two relations between resources and capabilities, namely one that already existed in the extension (assigned to), and another due to the ArchiMate core (the generic associated with relation).

We propose that the associated with relationship between resource and capability should represent the context of usage of a resource. This relation should represent that a resource is allocated to perform the capability it is associated to, thus being the performance of that capability the context of usage of the element that is playing the resource role. This relation addresses problem R1.

Another relation involving resources is the assigned to relation, which we use to denote that a resource has that capability. It means that the object that instantiates the role represented by the resource has a disposition of the type represented by the capability. Combining the two aforementioned relations enables the modeler to represent the prescriptive capabilities that resources should have in order to perform a specific capability (e.g., to perform $c_{1}$ a resource $r$ should have $c_{a}, c_{b}$ and $c_{c}$ ). These relations address problems $\mathrm{C} 1, \mathrm{C} 1.1$, $\mathrm{C} 2$ and $\mathrm{C} 2.1$, partially contributing to their solutions.

The metamodel also introduces a controls relation between resources and structure elements. The controls relation defines that a resource is controlled by an 
active structure element. Being controlled is understood as being available for the organization (e.g., by an employment contract between employers and employees, or by having the right/ownership over a certain object). Since the ArchiMate specification defines passive structure elements as "objects in which behavior is performed", usually denoting information and data elements, we understand that only active structure elements are to control resources. This relation addresses problem R2.

Problem R6 states that there is no distinction between AND or OR resource aggregations in ArchiMate and, as such, the language lacks the expressivity to state optional resources. Although ArchiMate does not distinguish between AND or OR aggregations, an extension allow the representation of optional resources is addressed and described in Section 6.5.5.

\subsubsection{Structure Element and Its Specializations}

The proposed metamodel further introduces the assigned to relation between structure element and capability. This relation defines that a structure element has a capability. It means that the object represented by the structure element has a disposition of the type represented by the capability. This relationship enables the organization to specify which capabilities it has, as a whole, and as a summary of the capabilities of its participating parts (organizational units, individual agents, etc.). This relation, in addition to the 'resource is assigned to capability relation', described in Section 6.5.1, solves problems C1 and C1.1.

The Structure Element realizes Resource relation means that a resource is realized/performed by the mentioned structure element. This enables the organization to be able to match the 'required' capabilities a resource should have, as in its prescriptive version, to the capabilities the organization's structure elements actually have.

Problem R4 stated that for the cases in which a resource is realized by a business role (a universal), the language does not determine whether one or more individuals that instantiate the role (mixin) represented by the resource are required in the context of usage. This limitation can be addressed by the addition of a replication attribute to the language, such as a cardinality constraint. However, this kind of extension is out of the scope of this work, since it deals with ArchiMate core. These limitations have been reported by industry, and some ArchiMate tools already implement a replication attribute for similar purposes, in which case R4 could be considered remediated.

The Structure Element is explicitly shown in the proposed metamodel with its specializations, Active Structure Element and Passive Structure Element. Problem R3 states that the language does not distinguish resources that are realized by agents from those realized by non-agentive objects. These limitations 
can be addressed by specializing the structure element concept to explicit agentive elements and non-agentive elements. The language is also originally unable to address the cases in which resources are passive non-agentive elements, which are objects of interest or raw material (e.g., 'Money', gold, diamond, gas), which corresponds to problem R5. This can be addressed by specializing the structure element concept to include these objects of interest and raw material. Both these proposals, however, are out of the scope of this work, since they deal with the ArchiMate core. The ArchiMate core language or an extension that deals with the core elements of ArchiMate should address these limitations.

\subsubsection{The Behavior Element Concept}

The behavior element realizes capability relation means that elements that are capable of performing the behavior element have the capabilities that the behavior element is said to realize. Another reasoning is that some behavior elements might be seen as the simple ability to perform the specified behavior, as a business process might reflect the ability to organize elements in a specified manner in order to produce a desired outcome.

The capability is used by behavior element relation specifies that a capability of that type is required to the successful execution of the behavior element. In other words, for a behavior element to be performed, one (or more) specific capability (or capabilities) is required. This allows the organization to structure its necessities in terms of capabilities and then to prescribe the necessary capabilities that its resources should have in order to be able to perform the behavior element. Further, this scenario would allow the organization to match the structure elements it has to the required capabilities for the behavior element it needs to perform, thus improving organizational planning. The planning improves the organizational management of its current and future structure elements. It also helps the organization understand the elements it needs to acquire according to its plan. This enables the organization to work aligned to the methods suggested in resource-based theories.

The behavior element access a capability relation specifies that a capability of that type is acquired with the behavior element performance. The element that acquires the capability is the one that is assigned to the capability. It means that the object assigned to the capability, represented by the structure element or the structure element that is playing the resource role, acquires a disposition of the type represented by the capability by performing the behavior element. This relationship allows the organization to specify which capabilities its resources and structure elements acquire and how they acquire that (e.g., through training). This relationship thus solves problem C2 (and as a consequence C2.1) in tandem with the following relations: 'resource assigned to capability' (section 6.5.1), 
'structure element assigned to capability' (section 6.5.2) and 'behavior element realizes capability relation'.

\subsubsection{The Capability Concept}

The capability concept is a central concept in this proposal. The capability concept represents the power to bring about a desired outcome. This power should be understood in broad sense, as, for example, a mug has the power of constraining coffee, which is the desired outcome. Capabilities can be used to state a broad range of behaviors, ranging from simple ones as mug's behavior, to complex behaviors, as the 'damage assessment expertise' (shown in Figure 21) that can be assumed to inhere in an organization as well as in a specific person.

Based on the UFO concept of disposition, this interpretation allows the organization to model the capabilities it can "socially perform". This is applicable for a variety of cases that uses delegation, such as, for example, cases in which an organization might hire a different company to bring about some desired outcome and needs to state that the original (hiring) organization has the capability of bringing about that desired outcome (in this case because it has the capability of delegating it (Guizzardi and Guizzardi, 2011), (Bringuente, Falbo and Guizzardi, 2010)). As stated in Section 6.3, "if $A$ has a meta-commitment from $B$ to execute $S$ then $A$ (socially) can do $S$. An object can have dispositions [capabilities] which arise from its parts (or from the network of its delegation relations)".

In the proposed metamodel, the Capability concept is related to the Resource, Structure Element and Behavior Element concepts, and with itself. The relations with the other elements have been explained in Sections 6.5.1, 6.5.2 and 6.5.3, respectively. We now focus on the capability realizes capability relation. Let us assume that $C_{2}$ realizes $C_{1}$. This relation means that $C_{2}$ enables $C_{1}$, in the sense that $\mathrm{C}_{2}$ partially realizes or is required for one to have capability $C_{1}$. As a capability can be enabled by multiple ways and might need different ('lowerlevel') capabilities to be enabled, the need for optional possibilities arises. The capability-enabling bundle concept is used to address this need.

\subsubsection{The Capability-enabling Bundle Concept}

The capability-enabling bundle concept is used to represent the diverse approaches that can be used to enable a desired capability. The bundle is used to represent optional enabling approaches to a specific capability. This concept solves the lack of expressivity stated in problem R6, as well as the lack of expressivity stated in problem $\mathrm{C} 5$. When no bundle is used, we assume a conjunction, i.e., that all elements are required. When more than one bundle that explicitly realize the same capability is modeled, each bundle is considered as 
an alternative. Figure 23 presents the metamodel fragment that shows the Capability-enabling Bundle concept and its relations to the other elements of the metamodel.

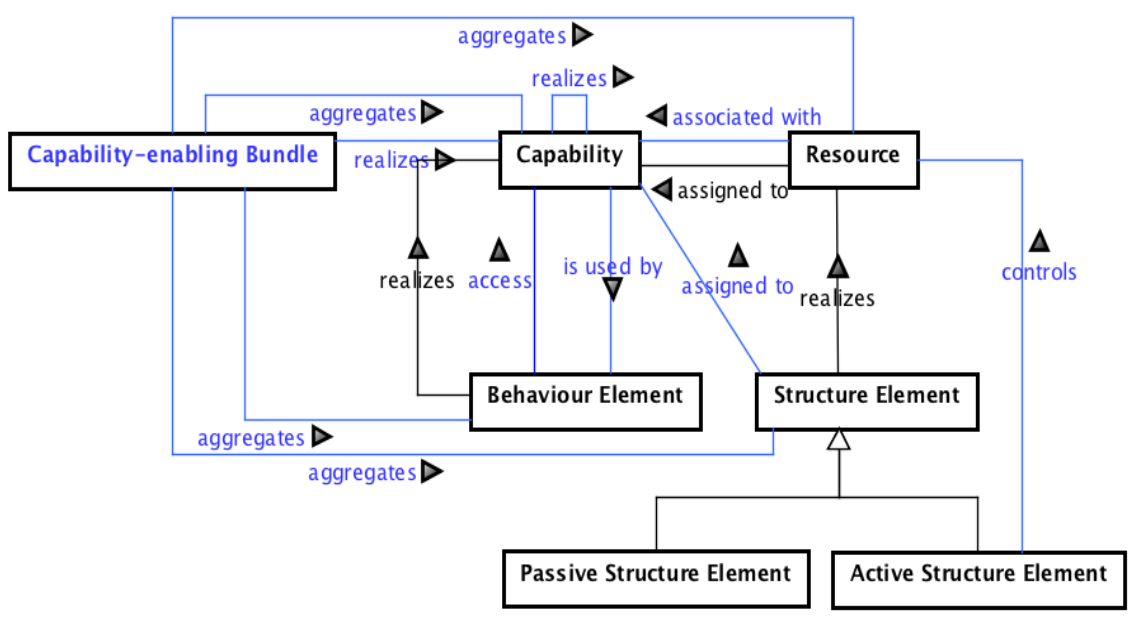

Figure 23 - Fragment of the proposed metamodel for the Capability-enabling Bundle

Figure 24 presents an example of use of the capability and the capabilityenabling bundle. In the example, 'Archisurance' is assigned to an 'Insuring capability'. The 'Insuring capability' is realized by the 'Selling Capability', 'the Policy Administration process', the 'Collect Premium Business Function' and the 'Claim Handling Capability', in the sense that they, altogether, are required to enable the 'Insuring Capability'. To model alternative means of enabling a capability, the modeler should use a Capability-enabling Bundle like the 'Claim Handling Capability', which is realized by 'Capability Bundle 1' or by 'Capability Bundle 2'. In Figure 24, the 'Capability Bundle 2' option uses the 'Damage Assessment Expert', and relies on his capabilities to bring about the desired outcome. In contrast, the 'Capability Bundle 1' relies on its 'outsourcing capability' to outsource the required outcome to a third-party. 


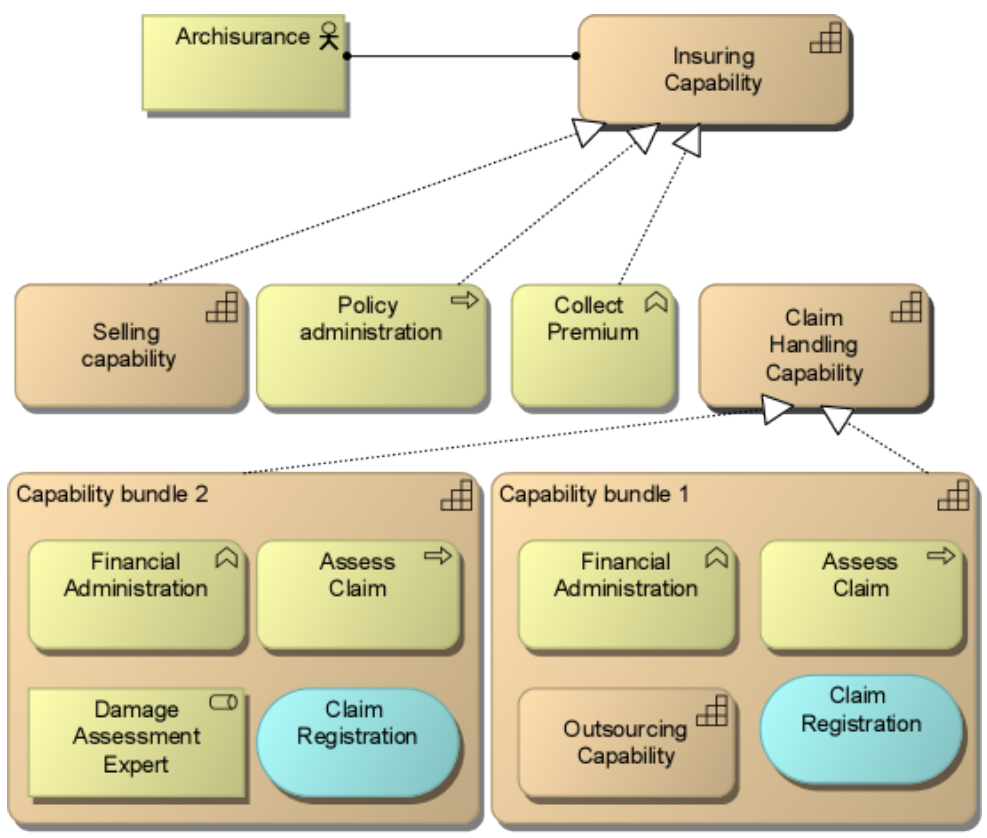

Figure 24 - Capability and Capability-enabling bundle examples

Problem C3 states that if no resource is represented, the object manifesting (or acquiring) the capability is unknown at the 'capability realized by behavior element' and 'resource assigned to capability' relations. The proposed metamodel relates resources to capabilities using the associated with relation for the purpose of indicating the resource that participates on the performance of the capability.

Problem C4 states that the language is not expressive to state the number/amount of resources related to the capabilities when the resource represents a universal (a type). For example, it is not possible to know how many instances of resources are to manifest their capabilities to perform a behavior element. In our proposal, resources should be related to behavior elements through capabilities. However, the solution to problem C4 is similar to the solution to problem R4, described in Section 6.5.1, so that the limitation can be addressed with the addition of a replication attribute to the language, such as a cardinality constraint. Nevertheless, this is out of the scope of this work since it requires modifications to the ArchiMate core. 


\subsection{Related Work}

Some related approaches have addressed the use of capabilities and resources in enterprise architecture and enterprise modeling.

The REA accounting model (McCarthy, 1982), e.g., has included a notion of resource since its inception. In REA, Resources are exchanged through economic Events in which Agents participate, hence the REA acronym. Since REA was conceived as a conceptual framework to support accounting practices, its main focus is on the notion of economic resource as a transactable entity of value. It considers, among other aspects, the "flow" of resources and the accountability for the "custody" of resources (in the "stock" or "inventory"). Similarly to our approach, the authors of REA have been concerned with the ontological foundations of their framework, which has been reported in (Geerts and McCarthy, 2002) and (Geerts and McCarthy, 2000). Differently from our work, REA does not aim at considering the properties or capabilities of resources, and it does not account for how resources and their capabilities may be employed in the organization in order to achieve higher-level capabilities.

The notion of resource is also adopted in the ARIS framework (Scheer, 2000), in order to account for resource bottlenecks and resource availability in the scope of business process management. ARIS captures the relation between resources and organizational entities that controls them, as well as "input" and "output" relations between resources and events ("functions" in ARIS). The ARIS framework does not address the notion of capability.

Dryer et al. (2007) discuss the extension of DoDAF with a Capability Evaluation Model that include the concept of capability. In that work, capabilities are said to be provided by "systems of systems", which comprehend any combination of "doctrine, organization, training, materiel, leadership and education, personnel and facilities (DOTMLPF)". Some of these elements subsumed under DOTMLPF are incorporated into the DoDAF's capability viewpoints, DoDAF's DM2 model and grounded in the IDEAS foundational ontology, which is used as a foundation for the whole DM2. Further investigation is required in order to assess the relations between ArchiMate BSCV constructs and DoDAF Capability Viewpoints, and to establish potential semantic interoperability relations for the representation of capabilities and resources. This task can be made more manageable now that the BSVC constructs have been given a precise semantics in terms of a foundational ontology. That should enable comparison and harmonization of both frameworks (Miranda et al., 2015).

In (Barroero, Motta and Pignatelli, 2010), TOGAF has been extended to support the modeling of the capabilities a Business Component (BC) can perform. A BC is a business unit that encompasses a set of activities, supported by assets including people, processes and technology. The approach uses capabilities 
as "an idealized conceptual structure that describes what a $\mathrm{BC}$ can do to create value for customers".

In recent years, a number of enterprise modeling approaches have been subject to ontology-based analysis. In (Recker et al., 2010), the authors performed an ontological analysis to the Business Process Modeling Notation (BPMN). Nine ontological deficiencies related to modeling when using the BPMN were found. In (Santos Jr et al., 2010), the authors have defined the semantics of the ARIS framework concepts and relationships in terms of UFO. Problems regarding the ARIS Method were exposed, and possible solutions to these problems were proposed. (Azevedo et al., 2011) performed an ontological analysis of the ArchiMate motivation extension proposal, unveiling problems and proposing improvement recommendations. To the best of our knowledge there are no comparable analyses addressing the modeling of capabilities and resources.

\subsection{Conclusions}

In this Chapter, we have discussed an ontological analysis of the BSVC ArchiMate extension and the associated notions of capability, resources and competences. We have employed a comprehensive foundational ontology that incorporates concepts to deal with objects, relations, roles, events, dispositions, as well as social and intentional concepts. Our main aim has been to clarify the semantics of the proposed modeling constructs, which should contribute to the application of the language in practice as a communication tool for stakeholders involved in decision making. We have revised the original language metamodel, in order to accommodate the proposed recommendations.

We have been able to clarify that the resource element represents a type-level entity, capturing the role of an (agentive or non-agentive) object in a particular context of usage. Our well-founded recommendations should lead to a language that allows improved resource planning, as it allows the specification of the context of usage of resources and the ability to explicitly state mandatory and optional resources when related to capabilities.

By considering capabilities as a type of dispositions, we have been able to account for what it means for a behavior element to realize a capability. Our recommendations should lead to a language that allows improved resource and capability oversight, as it allows one to relate capabilities and structure elements that possess capabilities, as well as relate resources with capabilities.

By also considering that competences should be interpreted as types of capabilities, we have been able to identify a case of construct redundancy. We have traced the root of the problem to a lack of relations to express the capabilities of resources. Our recommendations lead to a more regular and 
parsimonious solution for the expression of human resources and their capabilities, which was not fully addressed with the introduction of the competence construct. Our extension is intended to model the organization's core capabilities and key resources with a strategic management focus. With our extension, the enterprise can consider the required capabilities and resources to achieve a desired state without actually having to pursue a complete and extended view on the business processes and tasks that are necessary to realize that state. This means that at the strategic management level enterprise architects are able to focus on the proper level of abstraction, avoiding unnecessary commitments with lower level details. Thus, they are able to accommodate future changes in the operational parts of the enterprise architecture and at the same time realize the higher-level capabilities and resources. This creates a loose coupling between higher-level capabilities and other operational enterprise architecture elements, contributing to flexibility and maintainability of the resulting enterprise architecture descriptions. This approach is especially valuable to competitive and changing environments, which requires both planning and ability to adapt.

The contributions in this Chapter can be assessed from the perspectives of rigor and relevance (as proposed for design-science research by (Hevner et al., 2004)). From the perspective of rigor, we have adopted a well-established ontological analysis methodology (section 3) and clearly defined ontological foundations (section 4). From the perspective of relevance, there is ample support from the business literature discussing the key role of capabilities and resources in strategic management (Barney, 1991) (Ray, Barney and Muhanna, 2004) (Baines et al., 2009) (Helfat and Winter, 2011). Further, capability-based planning has had major interest from research efforts in the literature as well as from the practice in EA, with frameworks such as TOGAF introducing basic notions of capability-based planning and its role in designing, planning and implementing organizational change (The Open Group, 2009). Incorporating capability-based planning in EA is thus relevant for industrial and academic efforts.

Similarly to the discussion in (Azevedo et al., 2011) concerning the analysis of the motivation extension to ArchiMate, we do not intend to suggest that the terminology used in this thesis should replace the terminology used in ArchiMate, and we do not intend to imply that the UFO conceptualization should be exposed directly to users of the standard. The main role of the ontological analysis has been to provide us with a rigorous framework to analyze the modeling constructs.

In order to further stress the relevance of the approach, in the next Chapter, we present two real-world cases, one concerning capability improvement and the other concerning resource consolidation in capability-based strategic management. 



\section{Validation}

In this chapter, we investigate the use of the proposed theoretical foundation and ArchiMate modeling language extensions in different application contexts. We make use of four case studies in order to do that.

\subsection{Introduction}

In the design of the research described in this thesis, we have followed the design science methodology (Hevner et al., 2004) (Wieringa, 2010). In design science, we iterate over two activities: "[i] designing an artifact that improves something for stakeholders and [ii] empirically investigating the performance of an artifact in a context" (Wieringa, 2010). As our general objective in this work is to incorporate strategic plans into EA, our artifact is the proposed theoretical foundation, as well as the proposed EA modeling language extensions. Our context has been the EA discipline and our stakeholders are EA users. In Chapters 4, 5 and 6, we have introduced the artifact. This was intended to show the design science first activity.

This chapter investigates the use of the artifact in application contexts, corresponding to the second design science activity. In order to do that, we make use of case studies. We evaluated the artifact using four case studies.

The first case study uses the strategic plan of a mid-to-large Brazilian pension fund enterprise. This case study has been used to verify that our approach is able to represent a real-world strategic plan. This has been already presented in this thesis as the running example for the introduction of strategic plan concepts in the enterprise architecture discipline, in Chapter 5. Only fragments of this case 
study have been disclosed in this thesis ${ }^{22}$. The other case studies are presented in this chapter.

The second case study is presented in Section 7.2. The case study addresses an automotive industry suppliers' development. The case study has been taken from strategic management literature and is used to show the relevance of capabilities and resources for the enterprise architecture discipline.

The third case is presented in Section 7.3. This case study is instructive in that it links capabilities and resources to enterprise goals, at a strategic level, and to the EA, at an operational level. This case study also reveals the approach to enterprise traceability.

The fourth case study is presented in Section 7.4. The case study describes the usage of the approach in a Brazilian mid-size university. The university currently does not employ EA models. Modeling the strategic plan in EA using our proposal revealed requirements for the enterprise strategic plan implementation that were not previously addressed by the enterprise in its regular strategic planning process.

\subsection{Case Study: Toyota Supplier Capability Enhancement ${ }^{23}$}

This case considers supplier development, which is a procedure undertaken by a company to help improve its supplier's capabilities. This specific case of supplier development can be understood as an organization's attempt to transfer (or replicate) some aspects of its in-house organizational capability across its boundaries. The organizational capabilities being replicated at suppliers include not only well-specified technical routines, "but also the relatively constant dispositions and strategic heuristics that shape the approach of a firm to the nonroutine problems it faces" (Nelson and Winter, 1982). As stated in (Sako, 2004), "the ability to replicate such capability, is, in itself, also a capability".

\subsubsection{Preparation}

Our goals in this case study are as follows:

- Verify that our approach is able to represent enterprises capabilities;

- To demonstrate that capabilities are relevant for enterprises and are relevant for enterprise architectures (as previously demonstrated by a

\footnotetext{
22 Only fragments of the strategic plan are revealed in this thesis, as this strategic plan belongs to a private enterprise and the author has not been authorized to disclose it in full in this thesis.

23 This case and its description was taken and adapted from (Sako, 2004).
} 
number of works in literature, such as: (Teece and Pisano, 1994), (Eisenhardt and Martin, 2000), (Danesh and Yu, 2014), (Stirna et al., 2012) (Miklos, 2012), (Lee and Song, 2011) and (Zdravkovic et al., 2013), among others);

In this case study we focus on the capability improvement efforts of Toyota in one of its suppliers, the JECO instrumentation supplier. For building up the case and modeling it, we refer to the work published by (Sako, 2004). We used the description provided in it. The models presented in this case have been modeled by the thesis author and its co-authors in (C. L. B. Azevedo et al. 2015). In (Sako, 2004), three major Japanese automotive industries were analyzed. Specifically, we take the diffusion of the Toyota Production System at JECO. To perform the description, Sako had access to historical and contemporary documents provided by the companies and also conducted interviews with key respondents (purchasing managers and supplier development engineers) in the organization and at some of its suppliers.

\subsubsection{Toyota Objectives}

The Toyota Production System (TPS) has its roots in the Toyota factories of the 1960's. The Operations Management Consulting Division (OMCD) was established as part of Toyota's Production Control Function, to facilitate a seamless transfer of knowledge between Toyota and its suppliers. OMCD is in charge of implementing TPS both within Toyota factories and its core suppliers, and it intends to guarantee that the same methods, procedures and heuristics are applied to both internal and external factories.

Within Toyota, kojo jishuken (factory autonomous study groups) take place as a culmination of education and training for Toyota's middle managers and first-line supervisors. They are considered the most important repository of know-how on the shop floor. Supervisors are given an incentive to make continuous improvement with concrete results, and are required to regularly present improvement ideas. The transfer of knowledge and reproduction of Toyota's capabilities using jishuken groups (self study autonomous groups) in its suppliers did not become public until the 90's (Sako, 2004).

Figure 25 shows Toyota's intentions, represented by its goals, drivers and assessments, represented using ArchiMate's motivation extension notation. In our case, Toyota has the goals (i) 'Provide Supplier Development'; (ii) 'Human Resource Development'; (iii) 'Supplier Able to Adapt to Demand Fluctuations'; (iv) 'Supplier Able to Adapt to Model Mix Changes'; (v) 'Transfer of Knowledge between Toyota and its Suppliers'; (vi) 'Reduce Dependency of Specific Supplier'; (vii) 'Engage in Target Costing'; and specific goals for the application of TPS in JECO, (viii) 'Reduce Inventory by 54\% (to meet orders fluctuations)' 
and (ix) 'Reduce The Inventory of Rotors by 95\%'. Toyota had some drivers for some of its goals, like the 'Demand Fluctuations' and the 'Model Mix Changes' drivers.

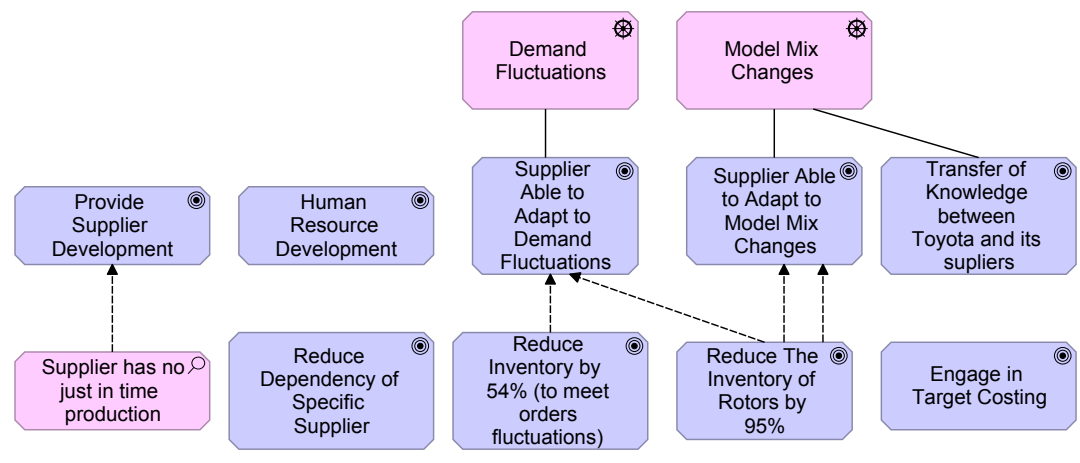

Figure 25 - Toyota's Intentions

The performance of one goal might influence the other goals. In our example, goals viii and ix, influences goals i, iii and/or iv. An important assessment that has been made by Toyota was that 'Supplier has no just in time production'. The crisis in the automotive sector, in which many of Toyota's suppliers were experiencing difficulties adapting to demand fluctuations, enforced this concern.

\subsubsection{Toyota Capabilities}

Figure 26 shows an ArchiMate model that represents an overview of Toyota's capability improvement efforts for JECO, including Toyota's capabilities, JECO's capabilities, the capabilities of the so-called autonomous study groups ('Jishuken study group'), and the key resources.

The 'Jishuken study groups' were designed to help suppliers improve their shop floors by refining the application of TPS. The 'Jishuken Study group' is required to choose a specific theme amongst the ones discussed by the OMCD, and to identify a specific factory area to be studied by the group. JECO study group chose the output fluctuations in the age of low demand ('Demand Fluctuations') and the 'Model Mix Changes'. The specific factory area chosen for the study was 'JECO Parts and Goods logistics'. Toyota has considered mainly geographical location and the absence of direct competitors when forming these groups, to help interaction and sharing of know-how during the "jishuken activities'. 


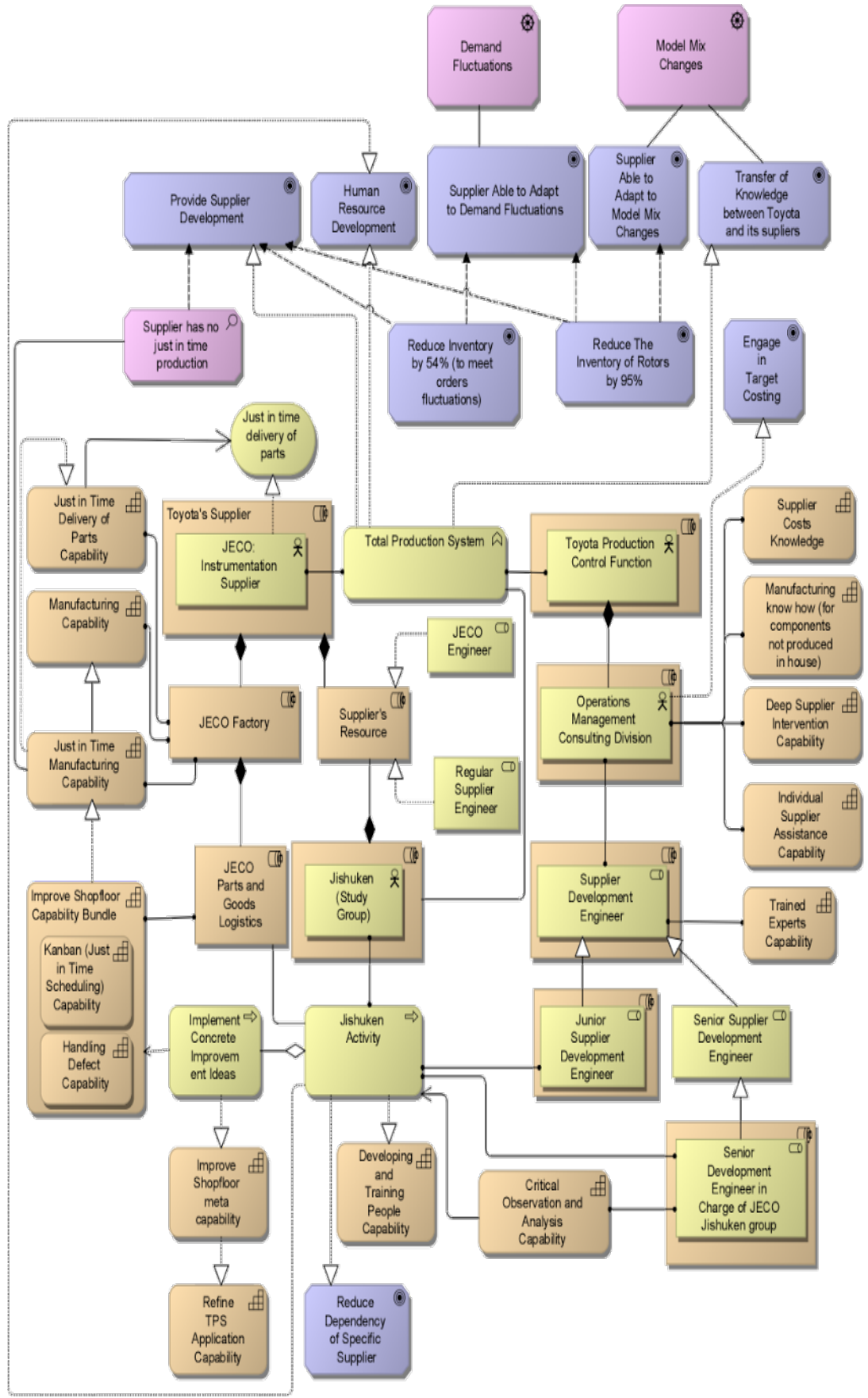

Figure 26 - Toyota's Supplier Capability Enhancement Case 
The study section begins by setting concrete performance targets in terms of shop floor indicators, which should be achieved with the help of the 'Jishuken activities'. Typical indicators to be considered are productivity, cost reduction and/or inventory turns. JECO's targets were to 'Reduce Inventory by 54\%' and to 'reduce the inventory of rotors by 95\%'. This is represented in the model by the dotted lines with a white arrow on the end between the activity and the goal it realizes.

From the Toyota side, trained experts ('Supplier Development Employees') help a jishuken group to achieve its results. A 'Senior OMCD engineer' with 'observation and analysis capability' is in charge of the 'jishuken study group' and visits the company under study during the 'jishuken Activity' period, in which he is responsible for making critical observations. 'Junior Supplier Development Engineers' also visit the company, more often though, to give more detailed guidance.

Jishuken groups are responsible to put forward and 'Implement Concrete Improvement Ideas'. A typical Jishuken group would consist of engineers from various suppliers, not only for the company under study, since this facilitates knowledge sharing, which is important for the 'Developing and Training People Capability' realized by the 'Jishuken Activity'. Most of the ideas are implemented in the study-host company. For example, JECO has implemented 222 of the 248 improvement ideas, an implementation rate of 90\%. Many of the ideas implemented by JECO concerned the improvement of its 'Kanban (Just in Time Scheduling) Capability' and its 'Handling Defects Capability', with the clarification of rules about when defects are discovered. These capabilities helped JECO accomplish the 'Just In Time Manufacturing Capability', a specialization of its 'Manufacturing Capability', which realizes its 'Just in Time Delivery of Parts Capability', used in its 'Just In Time Delivery of Parts' service. The 'Manufacturing Capability' by itself would allow the enterprise to realize the 'Just In Time Delivery of parts' service, since the organization might have all the required parts in its inventory. However, the 'Just In Time Manufacturing' capability has been enable by the 'Kanban (Just in time Scheduling) Capability' and the 'Handling Defect Capability'. This helped the enterprise to diminish its inventory of rotors and its regular inventory, realizing the 'Just in Time Manufacturing Capability' and, thus, addressing Toyota's assessment that 'Supplier has no just in time production', and realizing JECO's goals of 'reducing inventory by $54 \%$ (to meet order fluctuations)' and 'Reduce The Inventory of Rotors by 95\%'. These goal realizations, in their turn, influence the realization of Toyota's goals of 'Provide Supplier Development', 'Supplier Able to Adapt to Model Mix Changes' and 'Supplier Able to Adapt to Demand Fluctuations'.

Besides Jishuken, Toyota's OMCD also provides individual assistance to suppliers on an if-and-when-necessary basis. For that, OMCD have the capability 
of 'Deep Supplier Intervention' and 'Individual Supplier Assistance'. Individual assistance is suitable whenever Toyota is looking for quick results. However, short-term deep intervention is said to come to a halt when the experts go home, since the suppliers do not understand why things are being performed as intervened and short-term deep intervention does not 'provide supplier development' or 'human resource development'. A Toyota OMCD expert understands that the "[i]t would most certain be quicker for an expert to take a lead and provide answers, but this would not result in developing the skills of those who are led. The strength of Toyota Production System lies in creating as many people who can implement and put into practice TPS on their own as possible. So the most important thing for the survival of TPS is 'Human Resource Development'."

Jishuken is a gathering of middle-level production technologists from a stable group of companies, who jointly develop better capabilities for applying TPS through mutual criticism and concrete application. Jishuken also has the benefit of giving Toyota 'Supplier Costs Knowledge', with an enormous access to detailed cost structures of its main suppliers, a capability that inheres in the OMCD. This contributes to Toyota's core capability of 'Engaging in Target Costing' and to retention of 'Manufacturing know-how for components not produced in-house'.

\subsubsection{The Toyota Model Without the Capability Concept}

In order to evidence the role of the capability construct, a model without the capability construct is presented in Figure 27. This model is instructive in that it shows that without the capability construct the model is not able to capture key aspects of Toyota's organizational capability enhancement approach. Instead, it focuses on more operational aspects of the same enterprise setting, failing to reveal the capabilities of JECO that are at stake, the key capabilities of Toyota's OMCD, as well as the link between the activities of the study group and the capabilities improved. 


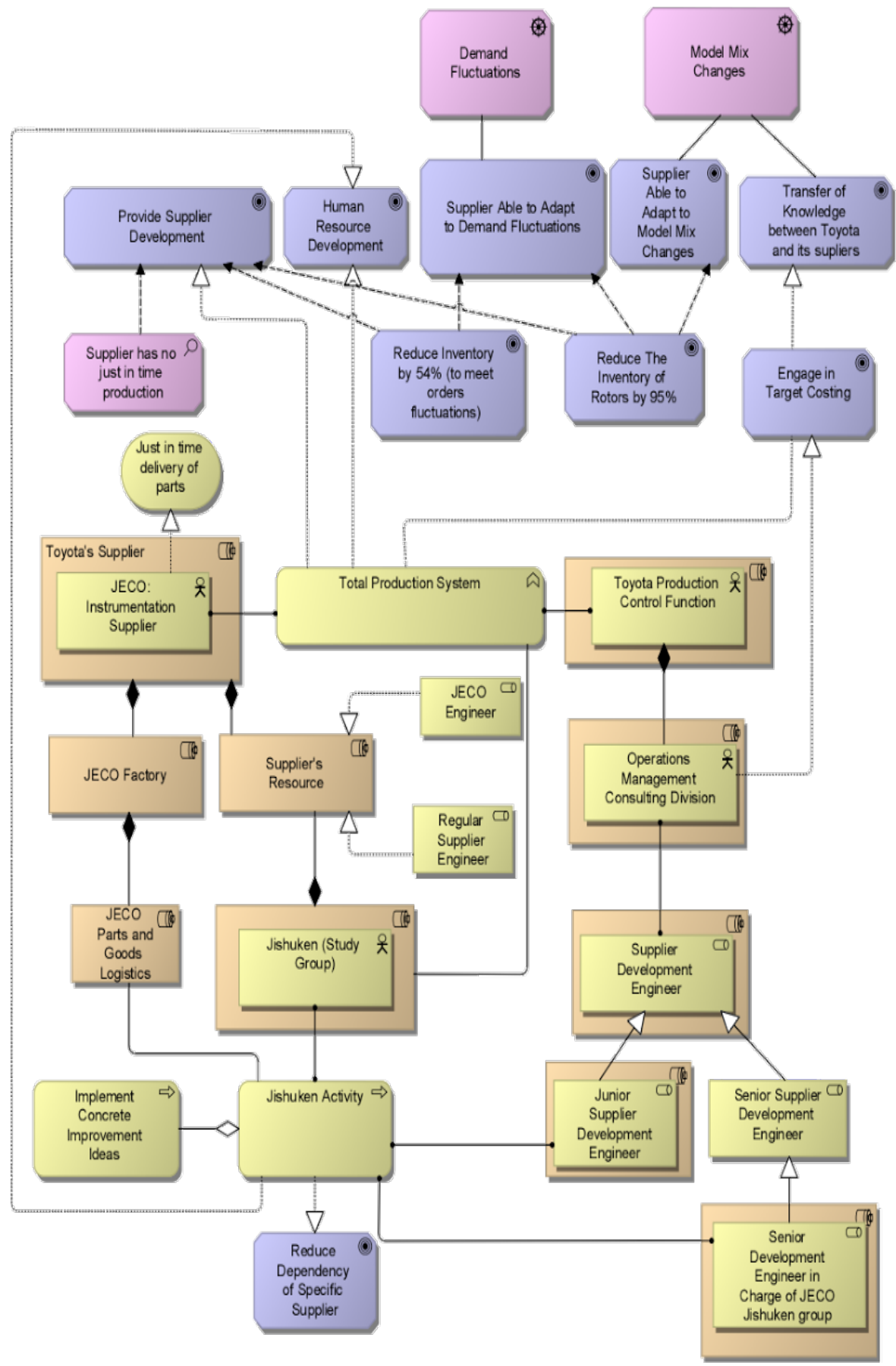

Figure 27 - Toyota's case modeled without the capability concept 


\subsubsection{Concluding Remarks}

This case demonstrates the usefulness of the capability concept in order to support a capability improvement process. The case shows that the capability concept plays an important role in understanding why the enterprise optimized its suppliers' processes and why enterprise goals were actually achieved. Further, the case shows evidences that the approach can be helpful in cases of optimization types of goals, cases in which an enterprise already produces something, but intends to optimize the product or its production. With the capability concept, relations between the optimized element and the 'why' the element/product is optimized are made explicit. Then, the enterprise is able to plan on providing the required capabilities in order to achieve its desired state. Further, the enterprise is able to assign resources to the performance of the capabilities and to design new business processes in order to achieve its desired situation.

We also show that without the capability construct the EA model is not able to capture key aspects of Toyota's organizational capability enhancement approach. The EA model without the capability construct is focused mostly on operational aspects losing the link to 'what is relevant' for strategic management. In other words, the model shows operational elements without revealing the key capabilities that enable achieving enterprise's goals.

\subsection{Case Study: IT Consolidation for an European Energy Supplier}

This case concerns an IT consolidation problem (Iacob, Quartel and Jonkers, 2012). Consolidation of software application portfolios is a typical situation in which portfolio management techniques are applied in a capability-based planning setting. The main goals of the consolidation of IT resources are the elimination of functional and data redundancies. Typical situations in which IT consolidation is necessary include the co-existence of different software systems in an organization that offer the same functionality, or the replication and storage of data by several different systems. The positive effect of IT consolidation on cost reduction has long been recognized in the literature, such as, e.g., in (Hancock, Humphrey and Wilcox, 1999). In particular, we refer to (Franke et al., 2010) that used integer binary programming to solve this IT consolidation problem, while minimizing consolidation and maintenance costs. In this particular case, the organization seeks IT consolidation to gain efficiency without affecting its business capabilities. Expressing business capabilities is thus required in order to make their coherent management possible and plan in a way that matches the organization's business model and strategy. The strategy in this case involves 
gaining efficiency through resource optimization, while the model requires the maintenance of the current capabilities.

\subsubsection{Preparation}

The goals of this case are as follows:

- We demonstrate the benefits of the proposed improved metamodel fragment concerning the quality of models compliant to it. We do this by showing how some of the problems concerning the original metamodel are handled in a concrete setting with the revised construct and relations.

- We demonstrate its usefulness in making the relation between business strategy and enterprise architecture explicit, allowing one to reason about it, as well as to trace these relations. We show how capabilitybased planning bridges the gap between strategy definition and strategy implementation.

- We demonstrate how capabilities and resources can be used in order to represent desired behavior without actually having to pursue a complete and extended view on the business processes and tasks that are meant to realize that state.

The capability-based planning process we follow throughout the case consists of the following steps:

1. Identifying drivers \& problem(s), business strategy and strategic capabilities;

2. Analyzing the baseline capability gaps and creating baseline heat capability map;

3. Relating capability gaps to the baseline architecture;

4. Using resource portfolio management approaches to create a target architecture and target capability map, and;

5. Implementing changes.

We consider and extend the case that was reported in (Iacob, Quartel and Jonkers, 2012), namely of a large European Energy Supplier (EES) that consists of three different units (formerly three different companies that have merged). As a result of the energy market liberalization, customers may now switch between energy suppliers, and thus this energy supplier must be able to ensure a fast and reliable switching process for new and leaving customers. A consequence of the previous merger is that currently the company has seven different systems that all take care of some part of customer switching process for three business units, and provide overlapping functionality. Information about customers, contracts and their consumptions is scattered over different systems and databases. The company aims at consolidating the system architecture, and at 
eliminating redundant functionality with minimal costs. We present the results of each step of the capability-based planning process in the sequel, employing ArchiMate models, some of which include the capability and resource constructs. We omit discussing step 5 (implementing the changes) as this is outside the scope of this $\mathrm{PhD}$ thesis.

\subsubsection{Identifying drivers \& problem(s), business strategy and strategic capabilities}

In this case, the main driver for action was the energy market liberalization. An assessment of EES's current situation in the light of this driver is given in the Figure 28 using ArchiMate's motivation extension. It relates the driver ('Energy market liberalisation') and various assessments ('High IT maintenance costs', 'Inefficient switching process', etc.).

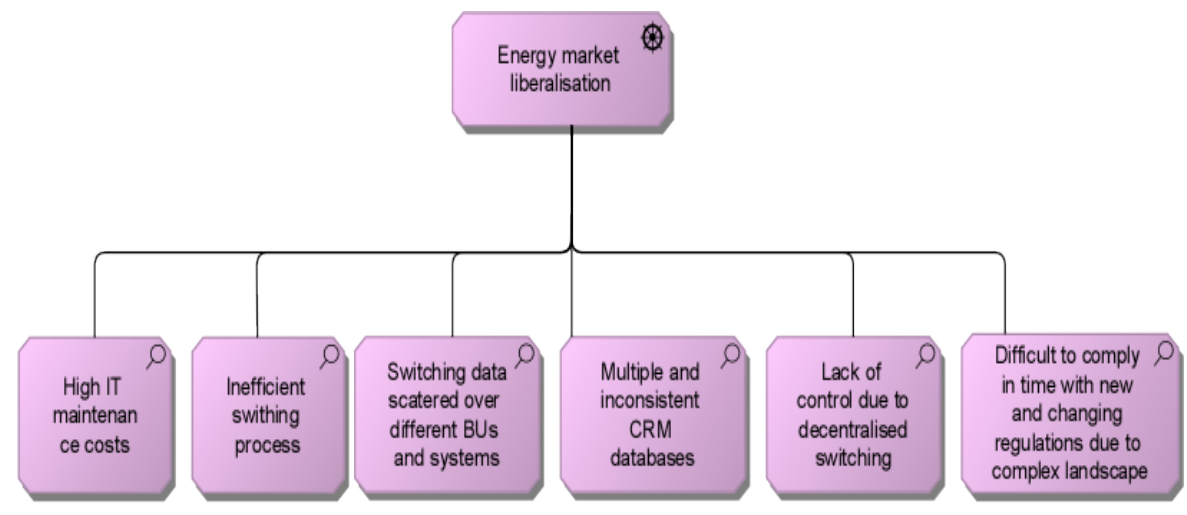

Figure 28 - Assessment and driver

The assessments are related to many of the goals that fall under the overarching "Achieving operational excellence" business strategy (Figure 29).

\subsubsection{Analyzing baseline capability gaps and creating baseline heat capability map}

Figure 30 shows the relation between the assessments and the capabilities whose current realization leads to the challenges identified in the assessments. The identified capabilities are 'Customer order management', 'Customer data management', 'Customer relation management' and 'Risk management'. The lower part of Figure 30 shows a number of operational capabilities that are related to the strategic capabilities. Figure 29 and Figure 30 are actually the upper and lower part of a single diagram, enabling us to trace from strategic elements to capabilities. 


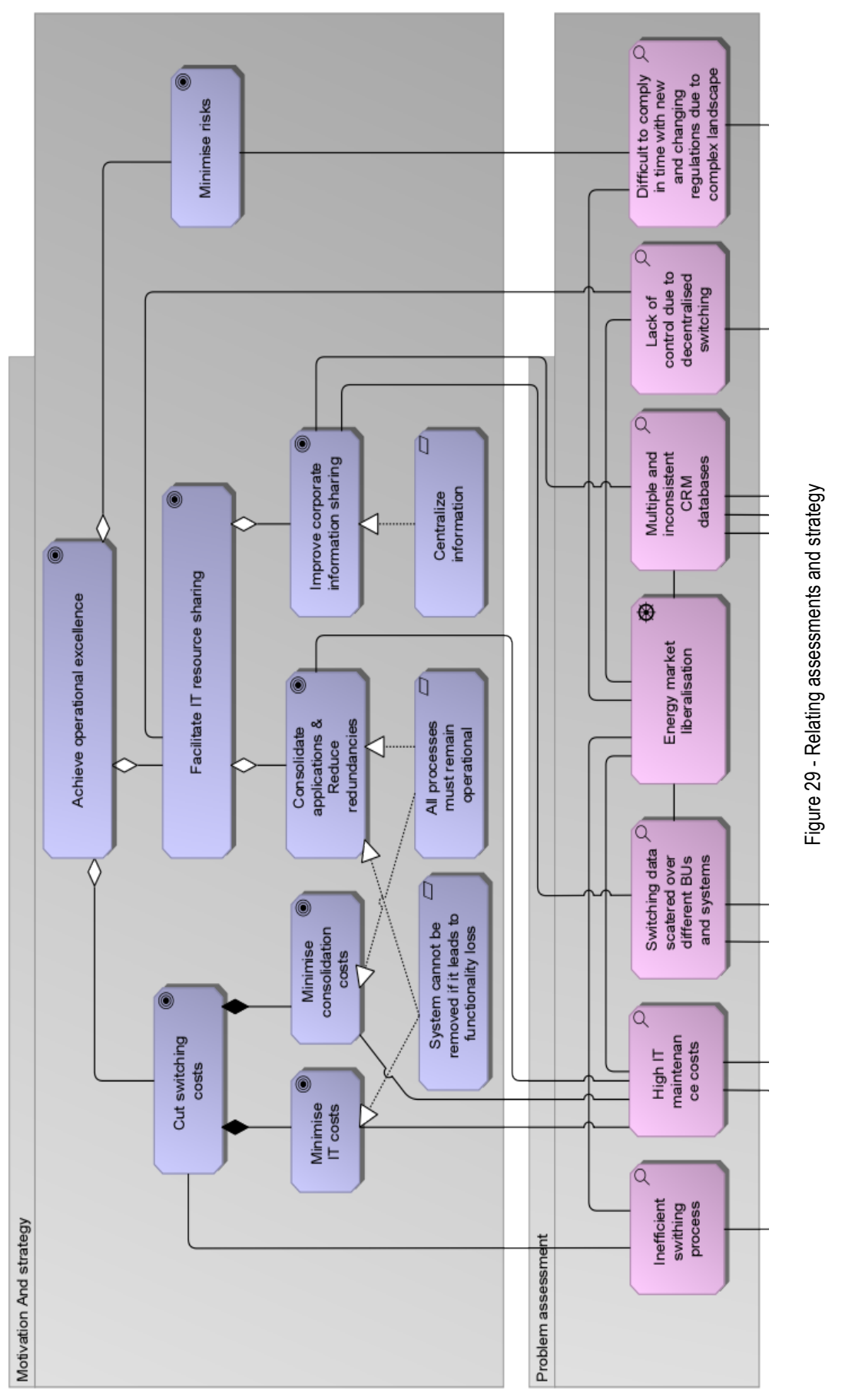




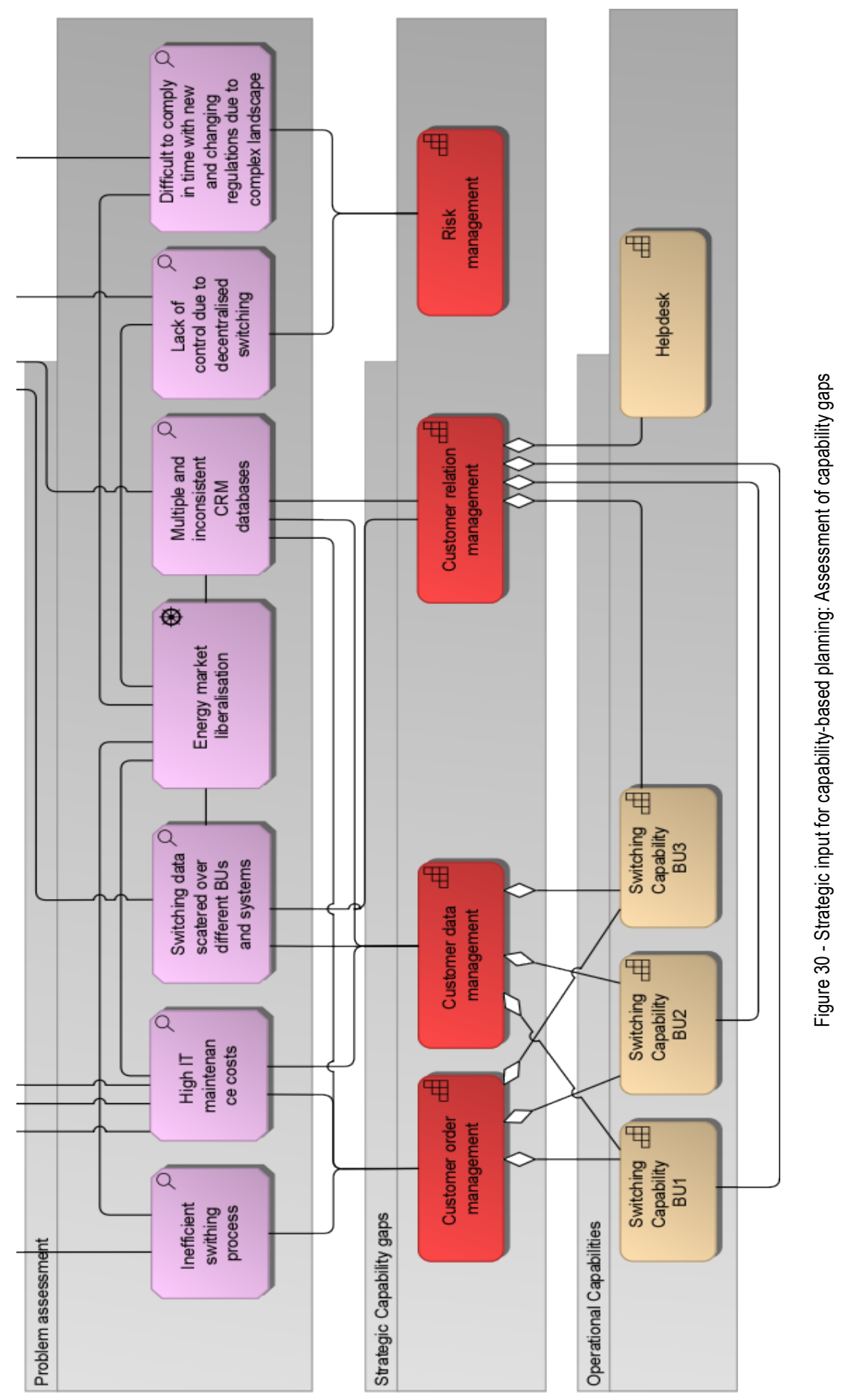


The heat map shown in Figure 31 shows the identified strategic capabilities in context. Strategic capabilities depicted in red are those whose realization needs to be improved in the context of the addressed problem.

\subsubsection{Relating capability gaps to the baseline architecture}

Having identified the strategic capabilities gaps, the next step in the approach concerns relating the capability gaps to the baseline architecture, in order to find paths for possible improvement in capability implementation.

The baseline architecture that focuses on the switching process is shown in Figure 32. It includes seven different application systems that all take care of switching for three business units, and thus provide overlapping functionality. 

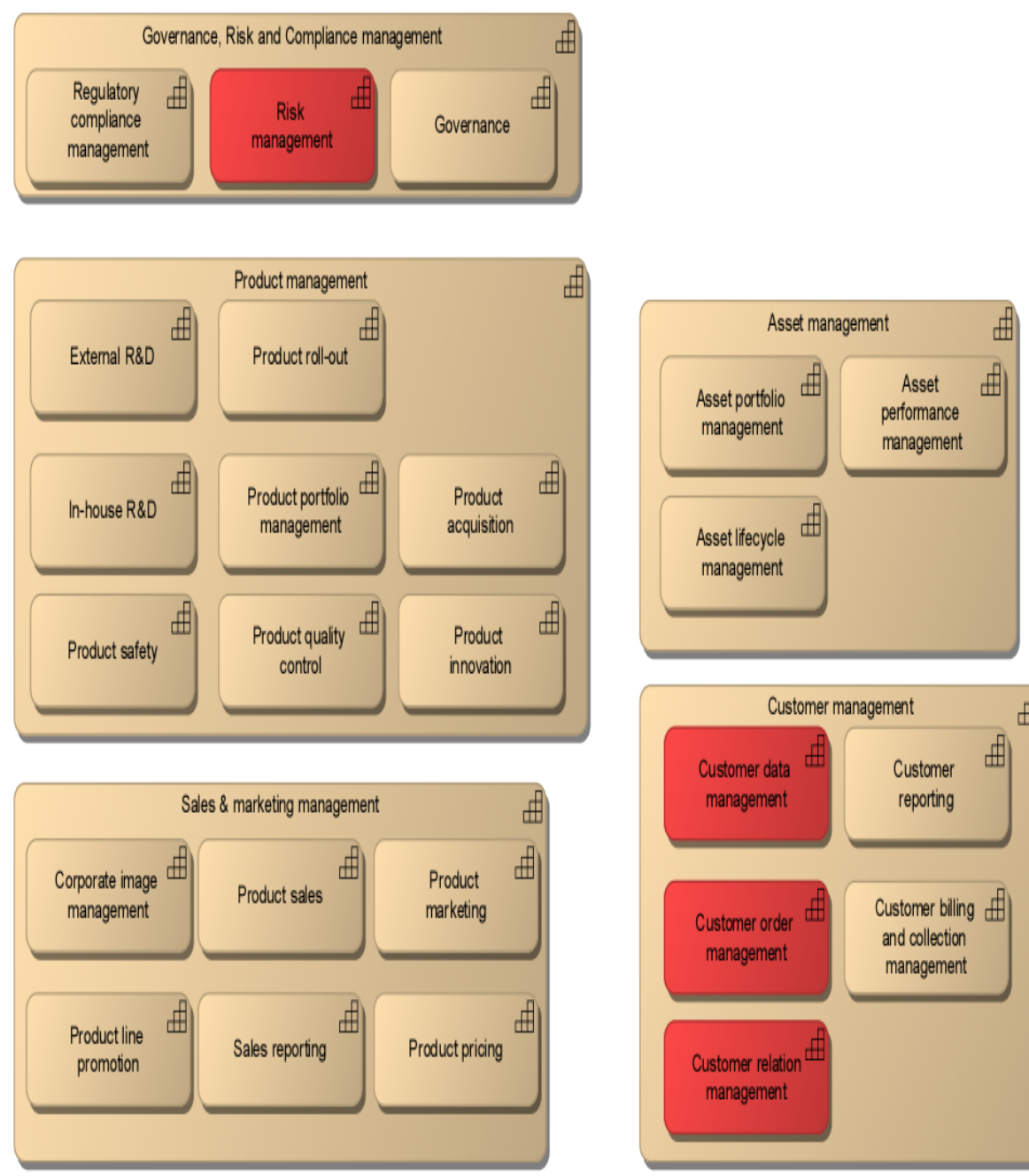

Figure 31 - Heat-map of strategic capabilities associated with the "Achieving operational excellence" strategy in the context of the current case 


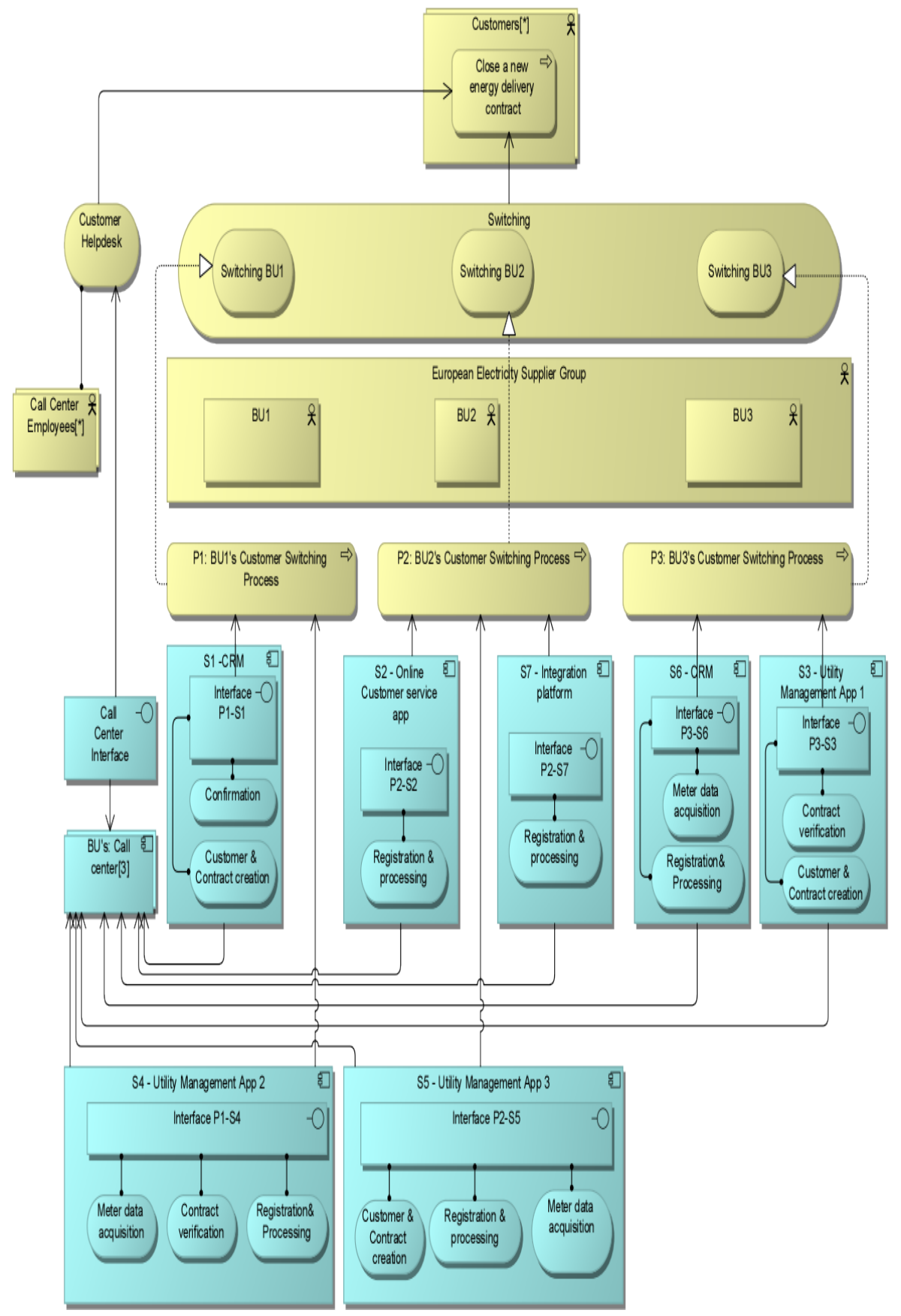

Figure 32 - Baseline architecture 
The main goal of this step is to establish a relation between the previously identified capability gaps and those elements/parts of the baseline architecture that should be changed to resolve the capability gaps, and subsequently to solve the original problem. Nevertheless, examining the heat-map (Figure 31) and the baseline architecture (Figure 32) one can see that the distance between the two models in terms of abstraction level is large, making it unfeasible to establish a precise relationship between them as far as the traceability of capability gaps in the enterprise architecture is concerned.

In order to address this issue, we add an intermediary abstraction level between the baseline architecture and the heat map. This additional level focuses on the specification and refinement of capabilities and resources, so that traceability all the way down to the operational aspects of the baseline architecture becomes possible. In this process we make use of the links between the strategic capabilities and the operational capabilities shown in the bottom part of Figure 30. This refinement step is important because it allows operational capabilities to be easily linked to architecture fragments. Thus, Figure 33 depicts the configuration of resources and capabilities that are involved in the current decision making problem, and represents their usage context in a simple way.

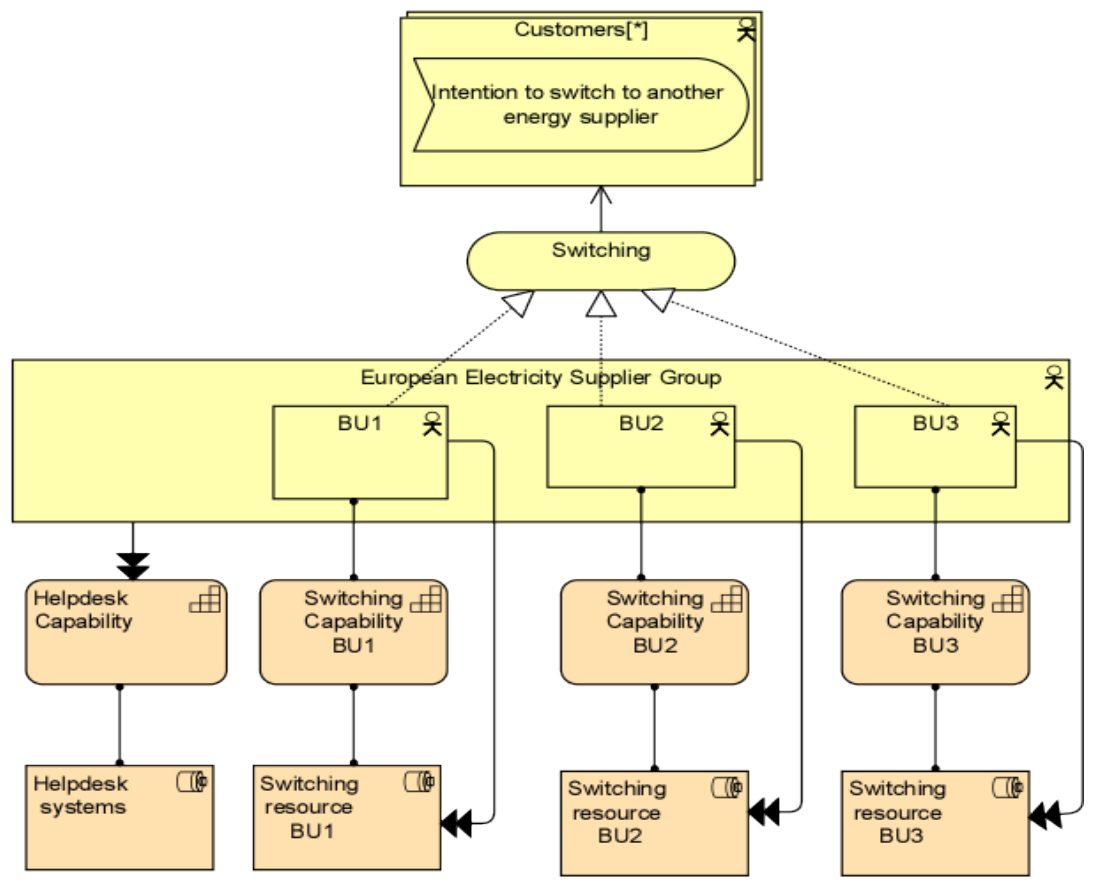

Figure 33 - Resources \& Capabilities configuration 
In Figure 34 we show how the previously identified configuration of resources and capabilities is mapped onto the architecture by focusing on the IT components these capabilities require. 


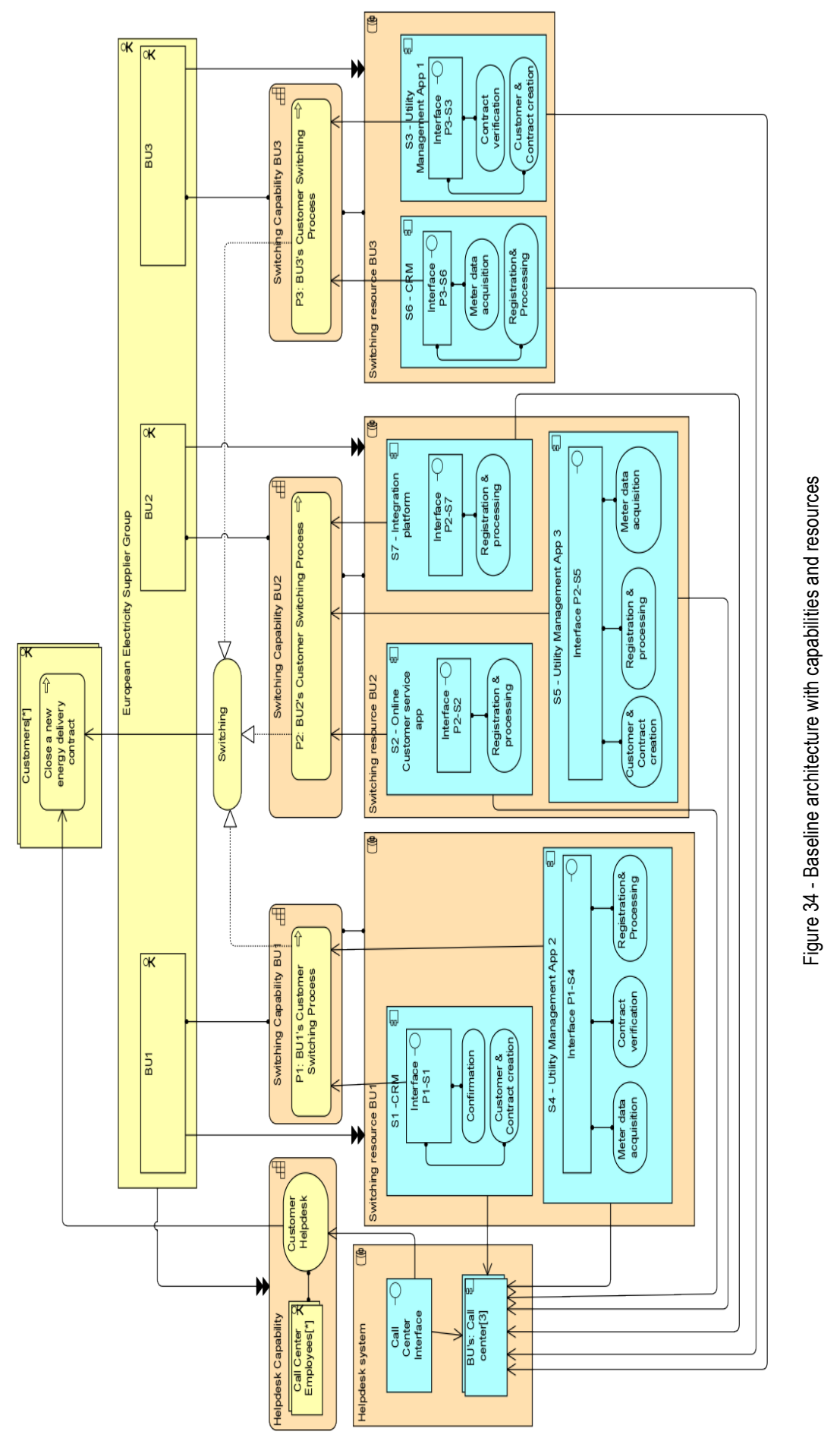




\subsubsection{Using resource portfolio management approaches and creating a target architecture and target capability map}

As explained in (Iacob, Quartel and Jonkers, 2012), the model shown in Figure 34 can be used as basis for the application (in a model-based fashion) of integer binary programming (Franke et al., 2010) to enterprise architecture once it has been enhanced with the concepts covered by the proposed metamodel. The resource portfolio optimization problem to be solved can be shortly formulated as follows: the objective function is to minimize the switching costs, which are defined as the sum of maintenance and consolidation costs, subject to two constraints: (1) all processes must remain functional at all times, meaning that the BUs' switching processes must be all fully supported by the systems that will be selected in the future situation, and (2) no functionality loss is acceptable, meaning that the selected systems must provide all the functionality currently provided by all of them. Details on how maintenance and consolidation costs are calculated can be found in (Franke et al., 2010), (Iacob, Quartel and Jonkers, 2012).

The optimal solution provided by the solver for the cost minimization problem leads to the target switching architecture shown in Figure 35, which includes resources, capabilities and relations defined according to our proposed metamodel. Systems S2, S4, S5 and S7 have been removed from the target architecture, and the remaining systems have to be enhanced with new process interfaces (colored in red in Figure 35) to enable the execution of all BUs' switching processes in the future situation. 


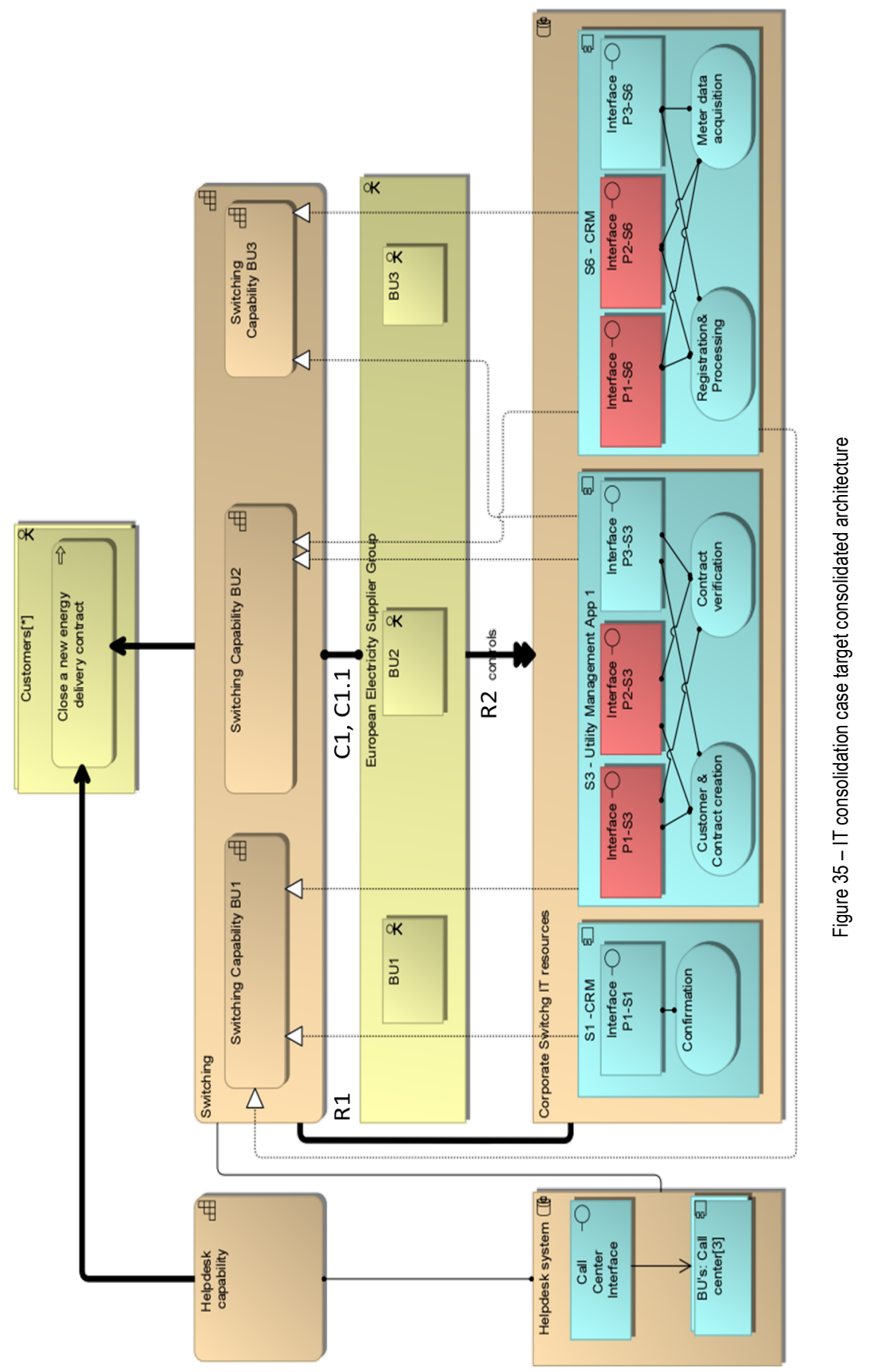




\subsubsection{Concluding remarks}

The case demonstrates the usefulness of the resource and capability concepts to support a capability-based planning process, which is typically carried out at a strategic/tactical level. For such endeavors one should be able to abstract from the details of architecture models but still being able to trace planning decisions concerning resources and capabilities in these architecture models in order to correctly assess the impact they have on the different layers of the architecture. In this particular case we have shown how the problem of multiple, partly overlapping, and hardly maintainable distributed IT resources (Figure 34) can be solved by consolidating them into a single integrated resource (Figure 35), which can be controlled at a corporate level.

Figure 35 shows some relations that could not be represented with the original metamodel, which are drawn with thick lines. These relations facilitate the correct modeling and interpretation of different dependencies between resources, capabilities and architecture elements. In particular, the model shows the relation between the consolidated resources and the controlling structural element, the relation between the resource and its context of usage, and finally, the relation between the capabilities and the (customer-facing) processes that employ the capabilities. Together with the other models discussed here, traceability from business strategy, business capabilities, operational capabilities to (IT) resources has been made possible. Further, the case defined capability models that were more stable and required less effort to maintain than the models based on the operationalization of the enterprise, since the capabilities operationalization had changed while the capabilities itself have been maintained. The organization had been able to assign resources to the performance of the capabilities and had designed new business processes in order to achieve the modeled desired situation while maintaining its capabilities.

\subsection{Case Study: Strategic Planning in a Mid-Size University}

This case considers a university that has a strategic plan and, as a regular enterprise, intends to implement this strategic plan. The university currently employs no enterprise architecture models. In this case, we model the university's strategic plans and also fragments of the enterprise architecture models that are relevant to those plans. We show that these models can support the enterprise in its strategic plan implementation, by revealing gaps that need to be addressed for its implementation. 


\subsubsection{Preparation}

The Federal University of Espírito Santo (UFES) is a mid-size university in Brazil. It currently offers 105 bachelor courses, 58 master courses and 26 doctorate courses. The university has over 23,000 registered students in four different campuses ${ }^{24}$. The university uses an 'umbrella strategy', with general higher-level enterprise goals and guidelines deliberated by the university Office of Planning. Later in the strategic plan process, each university department deliberates its contribution to achieve the defined higher-level goals.

Our goals in this case study are as follows:

- To cover a real-world strategic plan, modeling and representing it;

- To represent relations between enterprise's strategic plan and its operationalization, through enterprise architecture models.

- To show how our approach can be used to facilitate the implementation of a strategic plan. We intend to show that our approach further enables the enterprise architect, and thus the enterprise, to ask questions on how the strategic plan is to be implemented.

In the development of this case study, the thesis author had access to the university strategic plan and other strategic documents. The author interviewed relevant stakeholders (including the university provost for planning and institutional development and many employees of the university's Office of Planning $)^{25}$. The author was responsible for producing the various models which were shared with UFES personnel for validation.

\subsubsection{UFES Strategic Planning}

According to the university's regulations, the responsibilities of the Office of Planning include to "coordinate, monitor, evaluate and propose corrective actions at the university strategic plan". The university strategic plan is proposed and managed by the Office of Planning with support from other university departments. The strategic plan is currently documented in a strategic plan document (termed Plano de Desenvolvimento Institucional) (PDI), which is a 76-page report-like document.

In order to construct the overall strategy, the university performs various meetings with a great number of stakeholders, each of them with a particular area

24 As of January $30^{\text {th }}, 2017$. Available at: http://www.ufes.br/ufes-em-números ; Accessed at January 30, 2017.

25 We would like to thank the UFES provost for planning and institutional development, professor Anilton Salles Garcia, for sponsoring this case-study, certifying the required commitment from UFES personnel and allowing access to university documentation. 
of expertise, including professors and university students, the city council, representatives from close or affected neighborhoods, among others.

The university strategic plan is guided by the university's mission and vision. The university PDI is further divided in 5 strategic areas, as below:

- Education, which concerns the university courses;

- Research, which concerns the research performed by or at the University;

- Extension, which concerns the university impact in the local society;

- Assistance, which concerns the needs of university employees and students;

- Management, which concerns the management of the university.

Each of these five areas has a strategic objective. To achieve the strategic object, the university further defines strategies. For each strategy, strategic projects are defined.

\subsubsection{Strategic Planning within Departments}

After the Office of Planning defines the main areas of the university PDI, the strategic plan can be further refined by university departments, on meetings accompanied by representatives from the university Office of Planning. Each department assess to which general objectives they are willing to commit to ${ }^{26}$. Further, the departments are also encouraged to perform a SWOT (Strength Weaknesses Opportunities and Threats) analysis of the department's reality. Given their relative autonomy, each department, although perceived by the university as a part of it, elaborates an own department mission and vision.

\subsubsection{The UFES Strategic Plan Model}

In this section we present the university's strategic plan model. The plan starts with the university mission and vision, shown in Figure 36.

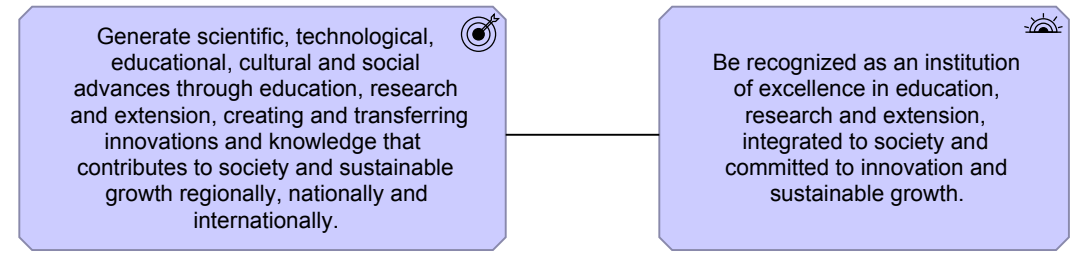

Figure 36 - UFES Mission and Vision

26 Due to the university nature, university departments are autonomous in its management administration, in which departments are not obliged to support university goals. Departments, however, are obliged to comply to all university regulations. 
As described in Section 7.4.2, the plan is divided in 5 strategic areas. In this case study, we focus on the Research area.

\section{The Research Strategic Area}

At UFES, each strategic area has an overarching goal with regards to that specific area. The research strategic area's overarching goal is "To consolidate and expand, with excellence, research committed to innovation, sustainable development and improvement of society living conditions, integrated with university education and extension areas". Figure 37 shows the research overarching goal and the strategy related to it, refined in a number of (sub)goals.

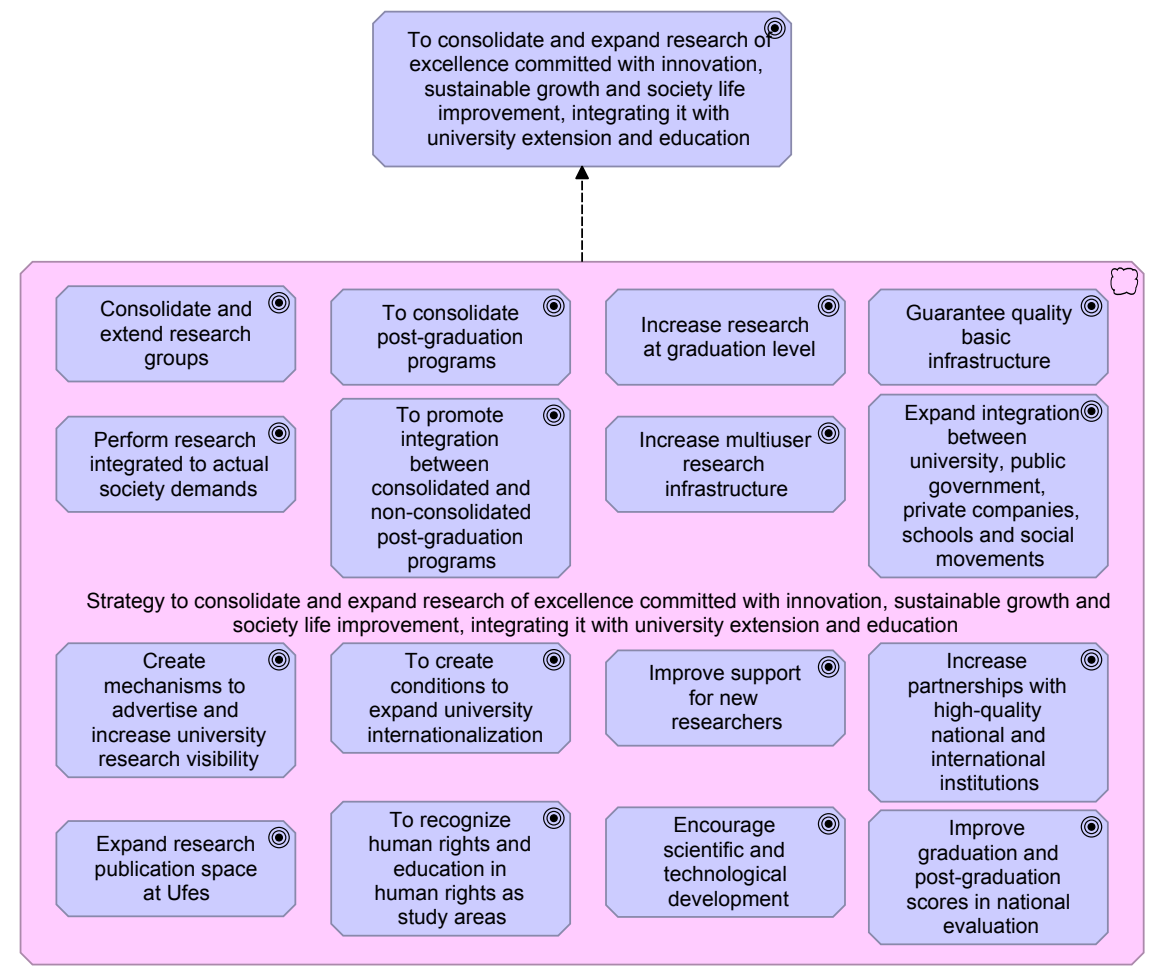

Figure 37 - UFES Research Mission and Strategies View

We now focus on the strategy to achieve the goal to 'Consolidate and extend university research groups' (upper left corner in Figure 37), which is depicted in Figure 38. 


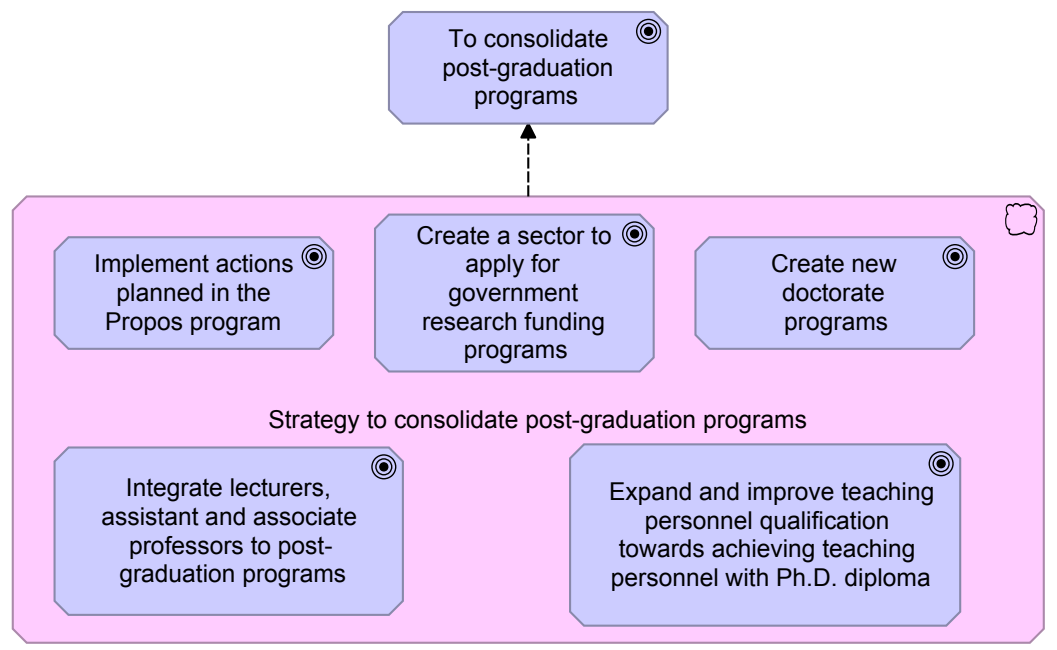

Figure 38 - Strategy to Consolidate and expand university research groups

This strategy encompasses a number of goals, which have a number of relations with the operational aspects of the enterprise architecture. Some of these goals refer to changes in the enterprise's behavior in order to perform new projects or tasks ("implement actions planned in the Propos program"). Some other goals refer to changes in the enterprise's structure, such as creating an organizational unit ("create a sector to apply for government research funding programs"). The goals in this strategy also refer to enterprises resources and capabilities, as they include human resources with advanced capabilities, as required to "create new doctorate programs". The personnel capabilities also play a key role in the "integrate lecturers, assistant and associate professors to postgraduation programs" goal and in the "expand and improve teaching personnel qualification towards achieving teaching personnel with Ph.D. diploma” goal.

The university strategic plan is detailed until this level. The strategic plan, then, is further sent to the university departments.

\section{UFES Strategic Plan Model Follow up in a Department}

The strategic planning effort has a follow up at the level of departments. This is performed using the whole UFES strategic plan as a starting point. The department assess to which general objectives they are willing to commit to.

Figure 39 reveals the Physics Department follow up for the university objective to "consolidate post-graduation programs". 


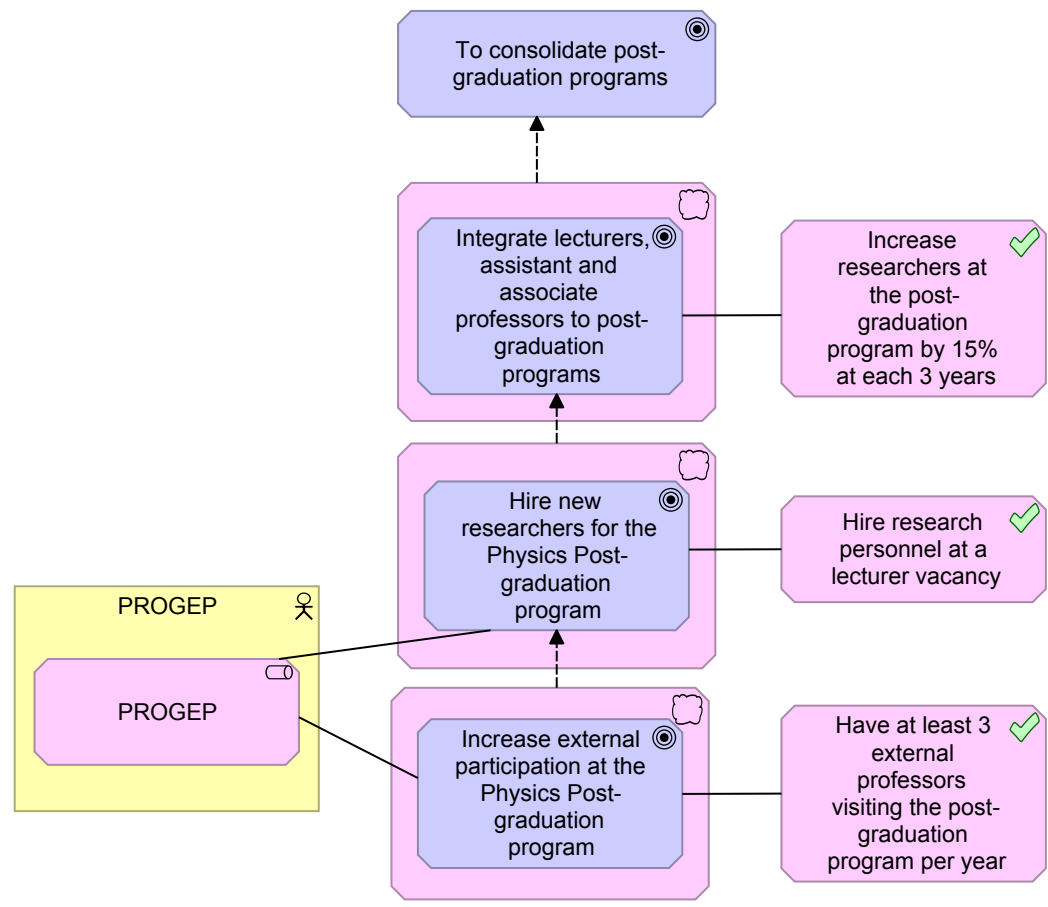

Figure 39 -Physics Department follow up at university objective to consolidate post-graduation programs

The Physics department has committed to support the achievement of the university goal to "consolidate post-graduation programs", refining the university strategy to achieve the goal, also defining sector objectives to the university objective "integrate lecturers, assistant and associate professors to postgraduation programs", with targets for these objectives. Figure 39 also reveals that the Physics department has defined the university's human resource department PROGEP as responsible for the achievement of these two sector objectives.

The Physics department also commits to pursuing the university's "Perform research integrated to society demands" objective (upper left corner in Figure 37), with the strategic depicted in Figure 40. 


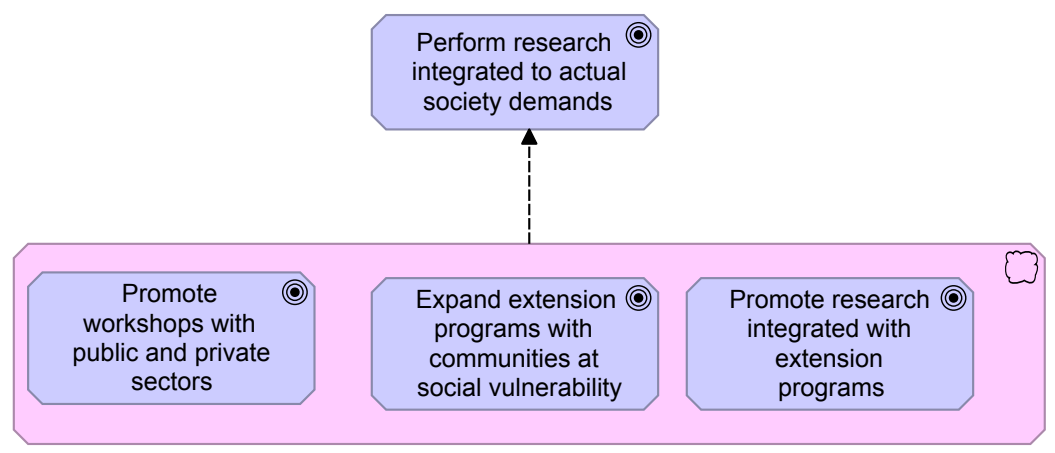

Figure 40 - Physics Department strategy to Perform research integrated to society demands

\subsubsection{The Strategic Plan and EA}

In the above subsections, we have modeled the strategic plan as currently detailed in the university strategic plan. In this subsection, we focus on a selected goal ("To consolidate post-graduation programs") and discuss its relation to operational aspects of the university's EA. This goal and corresponding strategy is shown in in Figure 41 (replicating Figure 38 for convenience).

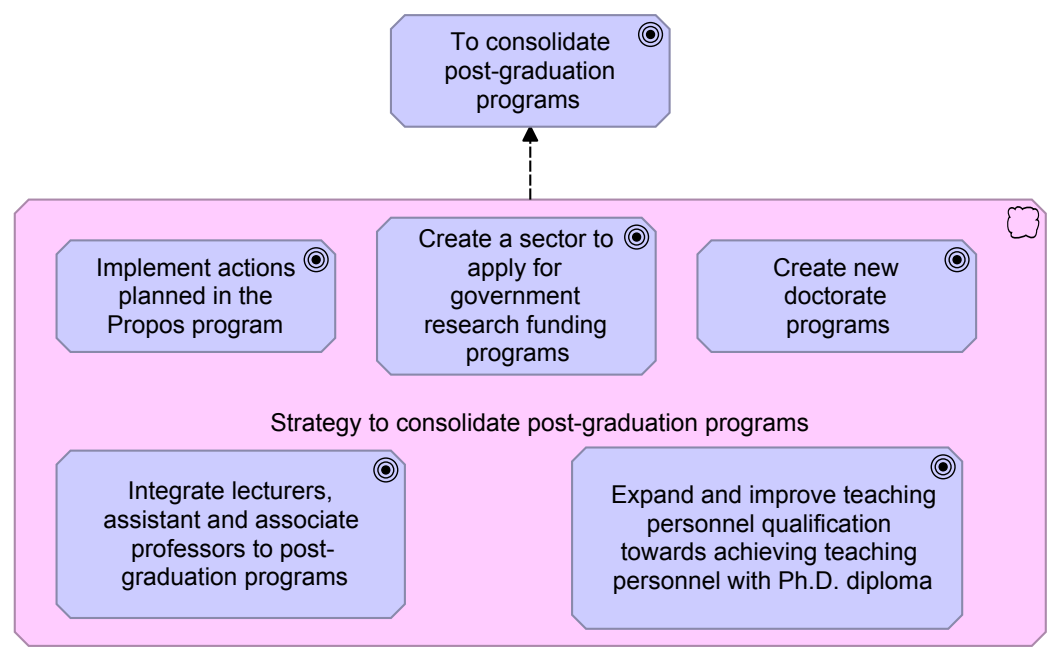

Figure 41 - Strategy to Consolidate and expand university research groups (replica)

The strategy selected here encompasses a number of goals. The implementation of this strategy inevitably affects the operational aspects of the university's EA. However, these affected aspects had not been described in detail in the strategic plan document. 
Some of the goals (such as "Implement actions planned in the Propos program”) refer to changes in the enterprise's behavior in order to perform the newly proposed project and corresponding tasks. The university strategic plan has not stated how "to implement [the] actions planned in the Propos program", which is then depicted as a work package in white in Figure 42.

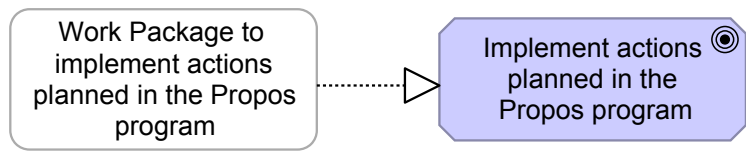

Figure 42 - Work Package to implement actions planned in the Propos program

Some other goals (such as "Create a sector to apply for government research funding programs") require changes in the enterprise's structure, as it requires, at least, the creation of an organizational unit ("Office to facilitate funding from government fostering research programs"), as illustrated in Figure 43.

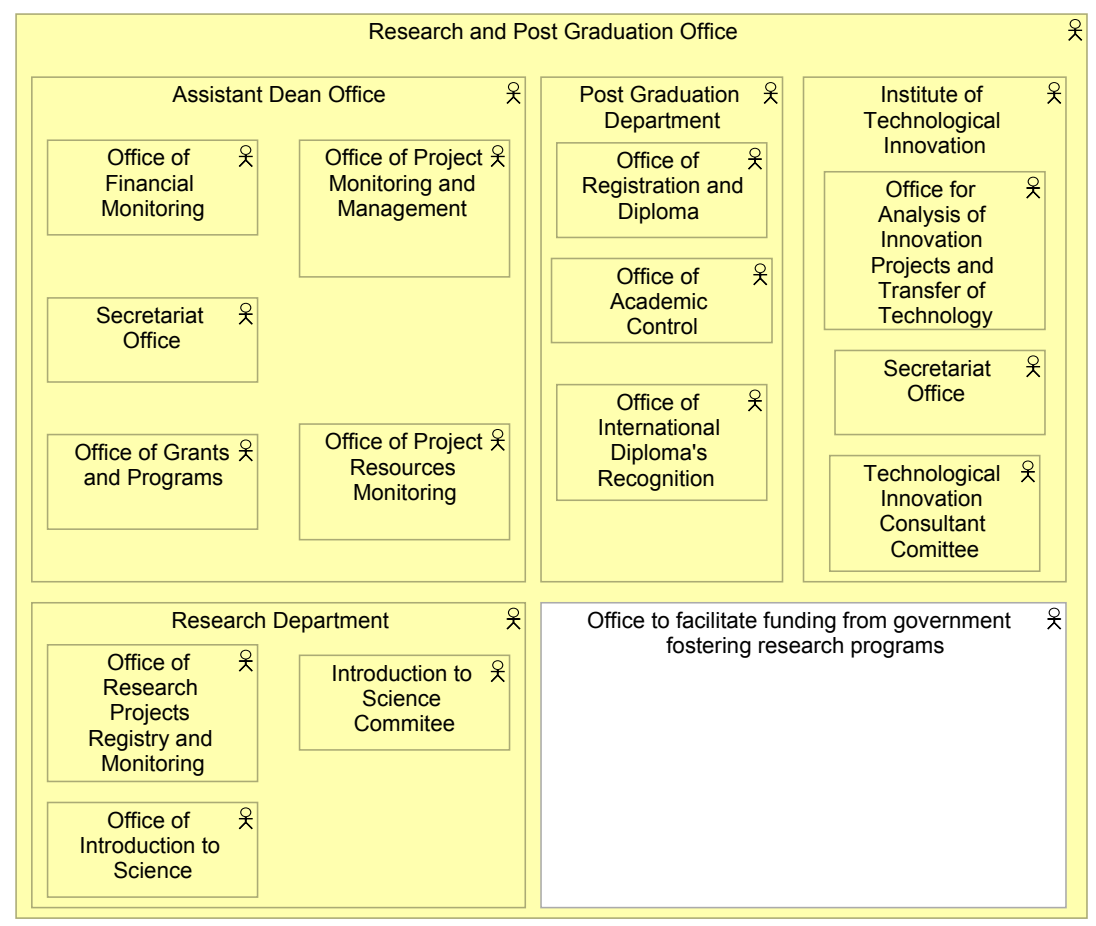

Figure 43 - Research Required Structure

The strategy goals also refer to enterprise's resources and capabilities, as the goal to create "new doctorate programs" requires human resources with advanced 
research capabilities. The university intention to create programs able to award doctorate diplomas to research personnel, requires UFES to be able to understand and modify its own capabilities.

Personnel capabilities also play a key role in the "Integrate lecturers, assistant and associate professors to post-graduation programs" goal and in the "expand and improve teaching personnel qualification towards achieving teaching personnel with Ph.D. diploma” goal, which is shown in Figure 44.

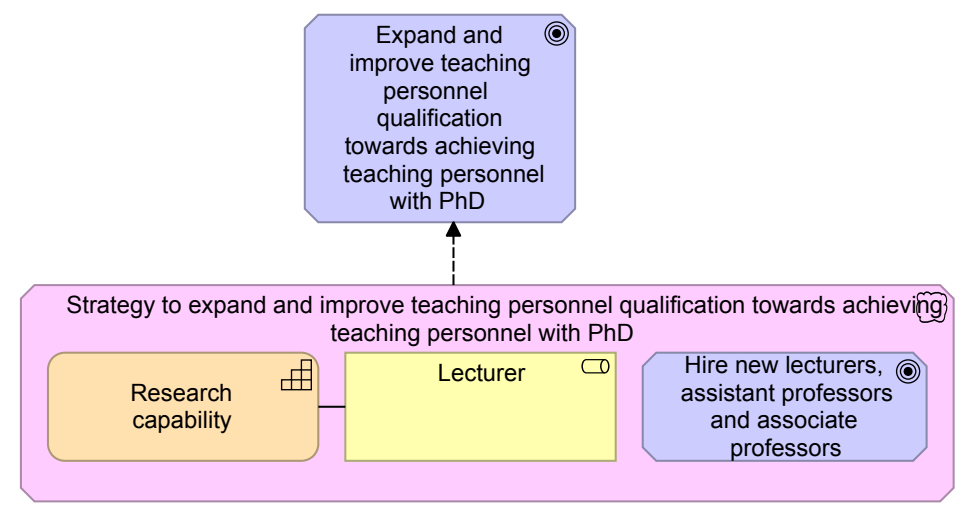

Figure 44 - expand and improve teaching personnel qualification towards achieving teaching personnel with PhD

This enterprise strategy requires UFES to be able to understand and modify its own capabilities, as the university intends to create programs that are able to award doctorate diplomas to research personnel. Further, the university strategic plan also reveals that the UFES current personnel is required to have specific capabilities, in order to enable the university to award these diplomas.

The strategy to implement the "Create new doctorate programs" and "Integrate lecturers, assistant and associate professors to post-graduation programs" goals were not detailed in the university strategic plan. We understand that this will involve the integration of the proposed doctorate programs in the current university structure, as well as the commitment of researchers to these programs. The integration of lecturers, assistant professors and associate professors to post-graduation program also requires details that were not in the strategic plan. Such operational aspects were not discussed in the university strategic plan document, and would inevitably affect the operational aspects of the EA.

\subsubsection{Discussions}

Incorporating strategic plans into EA enables an enterprise architect to identify (potential) relations between the enterprise's strategy and its 
operationalization. In this case study this has been materialized in relevant questions in order to identify gaps for the implementation of the enterprise strategic plan. A number of questions to reveal these gaps have been raised during the modeling of the case study, including: "which capabilities are required to perform these goals?" and "which personnel have the required capabilities?". Although relevant, these questions have not been addressed in the current university strategic plan, and could not be directly answered by university Office of Planning personnel.

Some of the questions that were posed concerning the link between strategic and operational aspects reveal that the achievement of university goals requires the modification of the current university structure, e.g., by creating sectors or departments in its structure, with their corresponding personnel, required resources and capabilities.

Further questions related to resources were also deemed relevant, as "how many human resources should this sector have?" and "which university sectors have the required personnel?". These questions could also further be phrased for non-human resources, encompassing from machinery to buildings or physical locations. Similarly, most of these questions have not been fully answered by the university strategic plan, nor by university Office of Planning personnel. We also have not been able to determine how many employees were required to run the newly to be created offices, such as the one in Figure 43. Also, the required capabilities were not planned in advance.

We believe the lack of answers concerning the link between strategic and operational aspects undermines the success of the strategic plan implementation.

\subsubsection{Concluding Remarks}

The fourth case study has been chosen in order to demonstrate the usage of our approach. It showed that the usage of our approach enabled the enterprise architect, and thus the enterprise, to ask questions on how to implement an enterprise strategic plan. In the case study, it was shown that the university strategic plan as is, as a report-like document, had gaps. These gaps showed that the strategic plan was not detailed enough for the enterprise to implement it as described.

The strategic plan idea of been further detailed in enterprises' departments apparently have not the ideal follow up of university original goals, and consequently, it undermined the ability of the university to implement its goals.

We understand that the enterprise in the fourth case study is has a low maturity level in its strategic plan development and monitoring. However, in similar enterprises we understand that the approach can be of similar usefulness 
for enabling the EA modeler to ask questions about the strategic plan implementation and to reveal gaps in the enterprise implementation plan.

\subsection{Conclusions}

In this chapter we have shown that the approach is able to represent key aspects of real-world cases. In the case study presented in section 7.2, we showed that without the capability construct the EA model is not able to capture key aspects of Toyota's organizational capability enhancement approach. The EA model without the capability construct is focused mostly on operational aspects losing the link to 'what is relevant' for strategic management. In other words, the model shows operational elements without revealing the key capabilities that enable achieving enterprise's goals. In the case study presented in 7.3, we show the application of the approach in portfolio management for an energy supplier company. More specifically, we show the usefulness of the capability-based models in representing a real scenario that required the reconfiguration of resources when the enterprise faced major changes. The enterprise was required to maintain the same capabilities while consolidating its IT systems. The model captures capabilities that remained stable even in the face of changes in the operational elements of the architecture. It also captures traceability from business strategy to EA operational aspects. In the case study presented in section 7.4 , the approach uncovered gaps related to strategic plan implementation that had not been detected by the enterprise in its regular report-like strategic plan. The case study in section 7.4 has also shown the approach's coverage of strategic plans.

Further, we have shown evidences that capabilities and resources can serve as abstractions for (more detailed) business process and structure elements. In the case studies presented in section 7.2 and 7.3, the model makes it possible for the enterprise to selectively assign resources to the performance of the capabilities and to design its business processes in order to achieve the desired situation. In the case studies presented in sections 7.2 and 7.3, the usage of capabilities results in models that are more stable and require less effort to maintain than models based on the operationalization of the represented capabilities. Consequently, the model makes it possible for the enterprise to plan on providing the required capabilities and resources in order to achieve its desired state, without requiring the complete and extended view on the business processes, tasks and detailed actors meant to realize that state.

Additionally, with the case studies, we have demonstrated that our approach is able to fulfill the solution requirements presented in this thesis, specifically presented in chapters 2 and 3. 
The solution was required to allow prescriptive and descriptive theories to be used in combination, in order to encompass the so-called 'umbrella strategy', and to allow the usage of the goal-based strategic model. This was demonstrated using the first, the third and the fourth case studies, which dealt with enterprises' goals and their implementation, with a mix of planned and emerging strategies. Enterprise's strategic plans were modeled encompassing enterprise's mission, vision, planned goals and goals' properties, such as composition and timing.

Further, the solution was required to allow enterprises to express their capabilities and resources, supporting enterprises' usage of resource-based and capability-based theories. This was demonstrated primarily with the second and third case studies, in which the enterprises relied on capabilities and resources, respectively, to capture enterprise's supplier enhancement and to support enterprise's own reconfiguration.

The solution was also required to have coherent architectural descriptions. An ontological basis has been used to precisely describe the intended conceptualization for the strategic notions, in order to avoid inaccurate or ambiguous conceptualizations of the models. This has been performed throughout the thesis. Hence, we understand that we have been able to fulfill the requirements presented in this thesis for a solution to incorporate enterprise strategic plans into EA. 



\section{Conclusions and Future Work}

This chapter summarizes the conclusions of this thesis and identifies some areas for further investigation. This chapter is organized as follows: in section 8.1, we present some general considerations of our work, including our main contributions, in section 8.2 , we present the verification of the thesis objectives and hypothesis and in section 8.3 we provide recommendations for future work.

\subsection{Main Contributions}

In this work, we have incorporated strategic plans into enterprise architecture, exploring the alignment between the enterprise architecture and enterprise strategic planning disciplines. The main contributions of this work can be listed as follows:

- Development of a theoretical foundation for strategic plans in EA

- Development of a theoretical foundation for capabilities and resources in EA

- Traceability between strategic plans and enterprise architecture operational aspects

- $\quad$ Extending ArchiMate to model strategic plans in enterprise architectures These contributions are detailed in the following subsections.

\subsubsection{Strategic Plans in Enterprise Architecture}

We have defined a theoretical foundation for the incorporation of strategic plans in EA (Chapter 4 and Chapter 5). Our intention was to promote precise semantics to allow enterprise architecture community usage, while still maintaining the semantic notions from the strategic management literature.

Our use of UFO and Bratman's Planning theory (1999) has been instrumental in clarifying the semantics of the various notions of strategy and strategic plans 
from the management literature. Using our ontological foundation (Chapter 4) we have been able to distinguish the diverse strategies that can be used to achieve a single strategic plan, and, further, to express the individual strategies that can be used to achieve a single goal or a combination of enterprise goals. These key notions allowed us to express significant distinctions in the planning and achievement of strategic plans. More specifically, these distinctions resulted in the notion of strategy (and a related notion of refinement), being able to express a special type of "bond" that "glue's" intentions together, supporting the definition and expression of a specific strategy, or a set of strategies, to achieve some goal. This is different from the main primitive available for relating goals in current EA frameworks, as well as current goal modeling languages, which seem to be similar to regular decomposition (discussed in Chapter 5). The ability to express nuances of concerns in strategic plans resulted in our theoretical foundation being more expressive than regular EA approaches and, thus, more suitable for strategic plan incorporation in EA.

\subsubsection{Capabilities and Resources in Enterprise Architecture}

We have explored and precisely defined a semantic foundation for the usage of capabilities in enterprise architecture. We have employed a comprehensive foundational ontology that incorporates concepts to deal with objects, relations, roles, events, dispositions, as well as social and intentional concepts.

We have been able to clarify that the resource concept represents a type-level entity, capturing the role of an (agentive or non-agentive) object in a particular context of usage. Our well-founded recommendations allow improved resource planning, as it allows the specification of the context of usage of resources and the ability to explicitly state mandatory and optional resources, when related to capabilities. By considering capabilities as a type of dispositions, we have been able to account for what it means for a behavior element to realize a capability, i.e., we accounted for the usage of capability as an abstraction of behavior.

We have clarified the semantics of the proposed concepts, which should contribute to the application of the ArchiMate language in practice as a communication tool for stakeholders involved in decision making. Our recommendations allow improved resource and capability oversight, as it allows one to relate capabilities and enterprise individuals that possess capabilities, as well as relate resources with capabilities. The defined semantics are compatible with current uses of capabilities in real-world enterprises, as we verified in the management area literature. 


\subsubsection{Traceability Between Strategic Plans and Enterprise Architecture Operational Aspects}

By defining that capabilities can be performed by enterprise behavior, such as business processes, and that structural elements in the enterprise can have capabilities, we have linked enterprise architecture operational aspects to enterprise capabilities.

By defining the intention to have and the intention to perform a capability, as well as allowing their representation, we have allowed the enterprise to relate enterprise architecture operational aspects to enterprise intentions. Further, this allows the enterprise to focus on what is important when plans are defined, without requiring it to prematurely concentrate on an extended view of the business processes and tasks that are necessary to realize that intended state.

Further, by defining the concept of strategy as an intention, which is composed of a collection of intentions, we allowed traceability between the enterprise's strategic plan and enterprise architecture operational aspects.

At the strategic management level, this enables enterprise architects to focus on the proper level of abstraction, avoiding unnecessary commitments with lower level details, which can be further related to the enterprise architecture elements that are necessary to perform the required capabilities. By decoupling higher-level capabilities from other operational enterprise architecture elements, we improve the flexibility and maintainability of the resulting enterprise architecture descriptions. This approach is especially valuable to competitive and changing environments, which requires both planning and ability to adapt.

Additionally, when planning its enterprise architecture, the enterprise can consider the required capabilities and resources without having to define extensively the business processes and tasks that are necessary to realize that state. This allows the enterprise to detail its business processes in a future time, while still maintaining traceability.

\subsubsection{Strategic Plans and Capabilities in ArchiMate}

We have extended the ArchiMate enterprise architecture modeling language in order to enable the modeling of enterprises' strategic plans, as presented in Chapters 5.

We have also proposed an extension to ArchiMate to enable the modeling of capabilities and resources, which can be integrated to the modeling of strategic plans, as presented in Chapter 6.

We have revised the original ArchiMate EA language metamodel to accommodate management notions. Further, using both extensions, the enterprise can trace, in its EA model, the operationalization of its strategic plan. To the best of our knowledge, this is the first approach to an enterprise 
architecture modeling language that allows the modeler to adequately capture strategic plans ${ }^{27}$.

\subsection{Objectives and Thesis Hypothesis Discussion}

In this section we discuss the thesis objectives accomplishment verification and the thesis hypothesis validation.

\section{Thesis Specific Objective S01}

The first thesis specific objective "SO1 - To establish a theoretical foundation for the elements of strategic plans that are relevant for incorporation into the enterprise architecture discipline" demanded the proposal of an artifact, which has been presented mainly in Chapters 4 and 5. The elements of strategic plans that were deemed relevant for incorporation into the EA discipline were discussed in Chapter 2. In order to demonstrate that the artifact proposed is able to represent real-world strategic plans, we rely primarily in the first and fourth case studies, presented in chapters 5 and 7.

The first case study has been instructive to show that our approach was able to represent a real-world mid-to-large Brazilian pension-fund strategic plan. This case study was chosen due its broad coverage of strategic planning elements: the pension-fund strategic plan regarded the enterprise mission and vision, as well as five-year-term goals. It regarded an enterprise's technological goals as well as investment goals, encompassing short, mid and long-term goals. The enterprise had targets for the majority of its goals and had developed business projects and/or updated business processes in order to implement their strategic plan. In the enterprise, different departments and employees were responsible for different enterprise goals. Thus, the case study has been primarily used to verify the representation coverage of strategic plans in our approach.

The fourth case study was also able to demonstrate the usage of our approach. Our approach was able to represent the UFES university strategic plan. Further, in addition to the representation of a real-world strategic plan, the enterprise architect was able to question how strategy was to be materialized into EA elements. This analysis revealed gaps regarding the enterprise strategic plan implementation, which were not addressed in the current strategic plan reportlike document. This suggests that the approach can be further useful for strategic plan implementation.

${ }^{27}$ Current EA frameworks support for strategic plans are depicted in Chapter 3, specifically in Section 3.3. 


\section{Thesis Specific Objective SO2}

The second thesis specific objective "SO2 - Define a theoretical foundation to relate enterprises strategic plans, at a strategic level, to EA, at a more operational level, which includes enterprises' organizational structure, business processes, services, products, IT assets and infrastructure" demanded the proposal of an artifact. We made use of capability and resource based theories from management, also considering the requirements presented in Chapter 2 and Chapter 3, and presented our approach mainly in Chapter 4 and Chapter 6.

We rely primarily in the second and third case studies, presented in sections 7.2 and 7.3, in order to verify the achievement of this thesis objective.

The second case study has been chosen to (i) verify that our approach was able to represent enterprises capabilities and (ii) to demonstrate that capabilities are relevant for enterprises and are relevant for enterprise architectures. The case study has been instructive as it demonstrated that an enterprise architecture model without the capability concept was not able to capture Toyota's key concern in the case study: its suppliers' development. The case study showed enterprise objectives and the business processes that were used to achieve those objectives. The capability concept played an important role in understanding why the enterprise optimized its suppliers' processes and why enterprise goals were actually achieved. The relations between the optimized element and the reason 'why' the element/product is optimized were made explicit.

The third case study is more instrumental in demonstrating the achievement of the second thesis objective. It used the relation between the capabilities and the business process to change the operationalization of an enterprise customerfacing services and products. Further, the case study demonstrates the relation between the defined objectives and the capabilities, offering traceability between the enterprise objectives, at a strategic level, to the enterprise operationalization, through the usage of capabilities and resources. The relation between, first, capabilities and objectives of the enterprise and, second, capabilities and the capabilities operationalization have made possible to achieve traceability from business strategy to the strategy operationalization.

\section{Thesis Specific Objective SO3}

The third thesis specific objective "SO3 - Provide support to express the concepts of strategic plans, as well as their relations to EA operational aspects, into EA models" was addressed in chapters 5 and 6 . We made use of all case studies in order to verify this objective. This objective was related with expressing the required strategic plan concepts in enterprise architecture, as well as their relations to EA. While performing the case studies, we have been able to model in full two real-world strategic plans. We have also been able to model capabilities and resources in the enterprises and in enterprise architecture. Further, modeling the relation 
between, first strategic plans to capabilities and resources and, second, capabilities and resources to the enterprise operational aspects in enterprise architecture, we have been able to achieve traceability between strategic plans to its EA operationalization. Thus, we conclude that the achievement of this objective has been verified.

\section{Thesis Hypothesis Validation and Further Conclusions}

We had hypothesized that the notion of capabilities and resources from management theories makes it possible to incorporate enterprise strategic plans into the enterprise architecture discipline. We had also hypothesized that in this setting, resources and capabilities serve as abstractions of enterprise architecture behavioral and structural elements, and are key to relate strategic level and operational level concerns.

As discussed in the specific thesis objective S02, in chapters 4, 5 and 6 we have presented the theoretical foundation to use capabilities and resources in order to bridge the gap between strategic plan and the strategic level concerns, at a strategic level, to EA operational elements, at a more operational level. For practical application, we have extended the ArchiMate language metamodel. The capability and resource concepts played an important role in this thesis, presenting the enterprise with the possibility of incorporating its strategic plan, which is a long-term plan, in the EA. Further, in the proposed ArchiMate extension, the usage of the capability and resource concepts, in conjunction with the strategy bundle concept, presented the enterprise with the possibility of tracing which goals in fact contribute to each of its 'higher-level' goals.

With the case studies performed in this thesis, we have provided evidences that, indeed, the capabilities and resources concepts are adequate to be used as abstractions of behavior and structure in order to bridge the gap between enterprises strategic plan and enterprise architecture operational level.

With the case studies performed, presented in chapters 5 and 7, we have provided evidences that capabilities and resources can serve as abstractions for (more detailed) business process and structure elements. In the second case study, presented in section 7.2, the enterprise had been able to selectively assign resources to the performance of the capabilities and to design its business processes in order to achieve its desired situation (a concern at the strategic level). In the third case study, presented in section 7.3, the usage of capabilities had allowed the enterprise to define models connected with both strategic level concerns and with its operationalization. Further, the usage of capabilities had allowed the enterprise to define models that were more stable and required less effort to maintain than models based on the operationalization of the represented capabilities. Consequently, the enterprise had been able to plan on providing the required capabilities and resources in order to achieve its desired state, without requiring the complete and extended view of the business processes and tasks that 
were meant to realize that state. The processes and tasks, were then later, planned and implemented.

The enterprise in the third case study, presented in section 7.3, had also been able to selectively assign resources to the performance of the capabilities, designing new services and business processes in order to achieve its desired situation. Additionally, in the fourth case study, presented in section 7.4, we have shown that the university would benefit of an approach using resources and capabilities. The university in the case study currently was not able to describe in full the required structure and behavior to realize their strategic plan. Modeling the enterprise strategic plan and relating it to the enterprise EA revealed gaps for implementation that were not disclosed in the enterprise current report-like strategic plan, decreasing the plan value.

Capabilities and resources have been used in this thesis as used in strategic management, as described in (Mintzberg, 1994), (McKelvie and Davidsson, 2009), (Ray, Barney and Muhanna, 2004), (Baines et al. 2009), (Barney, 1991), (Grant, 1996) and (Penrose, 1959), among others. We also note that our approach can be used in enterprises that pursue the strategy informally termed as 'umbrella strategy', in which the general strategic guidelines are initially deliberated, and the details are left to be deliberated later on in the process, which are the majority, according to (Mintzberg, 1994). We understand that, at least, enterprises with similarities to the enterprises in the case studies performed in this thesis could benefit of the approach.

\subsection{Further Research Opportunities}

In this section we discuss some research opportunities that arise from this work.

\subsubsection{EA Planning}

Our approach supports EA planning by incorporating the notions of strategic plans and strategic concerns into EA. It allows a traceability between the strategic plan to its EA operationalization. It improves the support for EA planning, enabling the modeling of the goals the EA is to support, as well as the capabilities and resources the EA is to operationalize. Nevertheless, we understand that longterm EA planning requires the planning of successive versions of the EA over time, in which each version is intended to support the achievement of a different set of goals. Further, the transformation between each EA version must also be planned.

The work performed in this thesis supports the representation of each of these versions. This brings up the challenge of having various successive EA versions 
and the transformations between these versions. Another challenge is the branching for diverse future possibilities, as for long-term planning. An additional challenge would be the representation of diverse contexts in order to fully allow the usage of EA for scenario planning.

We speculate that the UFO notion of situation may be useful for these future efforts. More specifically, successive versions of the EA might be conceptualized using pre-situations and post-situations of EA 'transformation' events.

The representation of successive versions of an architecture using the ArchiMate language could be further investigated in the scope of the implementation and migration elements, e.g., exploring elements such as plateau and gap.

Additionally, with these advances, we speculate a series of opportunities for analysis of the enterprise using the EA. The speculated opportunities include analysis of capability gaps (which could support capability-based planning) and strategic plan implementation monitoring. We further speculate that EA planning over time would be greatly enhanced.

\subsubsection{Strategic Plan Monitoring}

The work performed in this thesis allowed the incorporation of strategic plans into enterprise architecture. Further, it allowed traceability between the strategic goals described in the strategic plan and the operations that implement it in the EA model. An extension of this work could be the monitoring of the strategic plan implementation.

In order to do so, the enterprise should be instrumented to collect enterprise data. In this scenario, the EA model could be extended to represent which data should be collected.

The enterprise architecture could then be used to relate actual enterprise data to enterprise's Key Performance Indicators (KPI) or milestones, commonly defined in strategic plans. The traceability between the data from its operationalization point to the enterprise strategy could support this task.

Also, special business intelligence applications can be developed (and modeled in the EA) to extract information from these data, perform analysis, and provide decision support. Additionally, if a scenario planning approach is applied, the analysis can be relevant to support decision making.

\subsubsection{The Ontological Basis}

The concept of Intention has played a key role in this thesis to understand the management strategy concept. We have been able to understand how a strategy 'glues' the goals due to the intention concept. We have observed that the enterprises have different intentions, as to achieve a future desired state (e.g., 'to 
be one of the five largest European health providers'), to perform some sort of action (e.g., 'to build a new British headquarter'), to achieve a desired capability (e.g., 'to be able to achieve Mach 3 Speed') or to acquire some desired resources (e.g., 'to have three airplanes that achieve Mach 3 speed'). Intuitively, it appears that each of these intention types (and others may exist) might have specific properties. Understanding these properties might be relevant to further support analysis of goal requirements, for enterprise planning, and goal achievement, for enterprise monitoring. These different properties of intentions could be applied as different goal properties, and that could enable further EA support when detailing the strategies' achievement plan. Theories from other scientific areas than information systems, such as Bratman's Intention, Plans and Practical Reasoning theory (1999), could support unveiling Intentional properties, which could then be related to properties of different types of goal.

In this thesis, we have used UFO, Bratman's Intention, Plans and Practical Reasoning theory (1999) and Molnar's Power theory (2006) in our ontological basis. These theories have been key to precisely describe the intended conceptualization for the strategic notions. However, the ontological basis used in this thesis was not completely formalized. Incorporating the various theories into a comprehensive formal ontological basis is thus an opportunity for further work. This would then enable the formalization of the theoretical foundation presented in Chapters 5 and 6.

Furthermore, in this thesis we dealt with strategic plans, and in such, our theoretical foundation, and consequently the models, were conceived to represent the strategic plan. Incorporating these various theories into a formal ontological basis might raise the abstraction level requirement and pose to the necessity of state about the strategic plan with regards to other elements in the ontological basis. In such a case, we speculate that a specific concept for strategic plans in the ontological basis might be required.

\subsubsection{Revisit the Modeling Extensions After Appropriation by the Community}

The ArchiMate modeling extensions proposed in this thesis have been applied in a number of case studies, as reported in this work. We have outlined recommendations raised by the ontological analysis performed here, and we believe that they can have direct application in the revision of community proposals before they reach standardization efforts. For example, when performing this work, we closely worked with key people that contributed to the newly released ArchiMate 3.0 specification. We believe this work had indirectly impacted the ArchiMate 3.0 specification, particularly in the introduction of the 
capability concept ${ }^{28}$. Further analysis of the modeling extensions proposed in this thesis are desirable, considering the pragmatic impact of amendments on the ArchiMate standard and its users. It is natural that, once the approach is incorporated into EA tools, new insights will arise from the appropriation of the technique by the industry. These insights should inform an ex post evaluation effort.

28 We closely worked with three contributors that the ArchiMate 3.0 specification, in its Acknowledgements section, specifically thanked: Maria-Eugenia Iacob, at the University of Twente, and Adina Aldea and Dick Quartel, at BizzDesign, with whom the author collaborated for a year. We discussed in length with them the concepts of capabilities and resources. 


\section{Appendix A}

\section{Remarks Concerning ArchiMate 3.0}

While the research of this thesis was performed, the ArchiMate modeling language has evolved. The bulk of the thesis work was performed with ArchiMate version 2.1 and proposed extensions (BSVC). However, during the writing of this thesis, ArchiMate version 3.0 was published (The Open Group, 2016). In this appendix, we briefly discuss the ArchiMate 3.0 introduced elements and consider the impact of this new version to the analysis that was performed in Chapters 5 and 6.

We should note that, while performing this thesis' research there was close cooperation with contributors of the ArchiMate (3.0) specification, and this close collaboration have impacted both the thesis research and, indirectly, the latest version specification.

The following elements have been introduced in ArchiMate 3.0: capabilities, resources and course of action in the new "strategy elements" part of the specification and the outcome element in the motivation elements part of the specification.

The strategy elements part of the specification was meant to incorporate features that were conceived originally in the BSVC extension, which was addressed in Chapter 6. A metamodel fragment of ArchiMate 3.0 with the strategy elements and its relations to ArchiMate core elements is shown in Figure 45. 


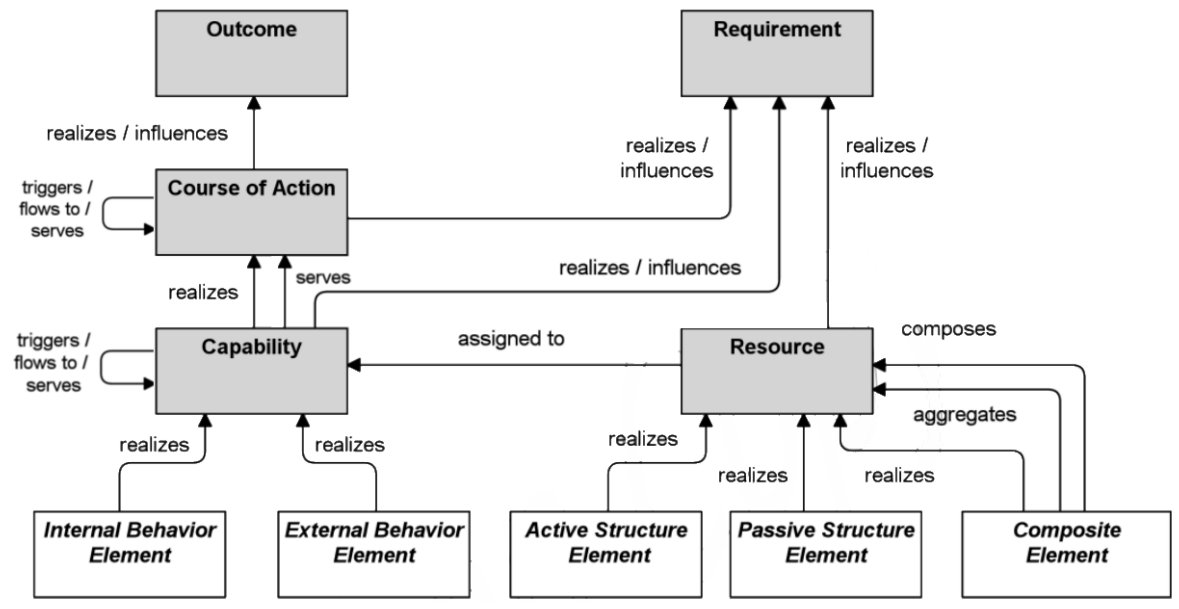

Figure 45 - ArchiMate v3.0 Strategy Elements Metamodel Fragment - adapted from (The Open Group, 2016)

The BSVC metamodel is shown in Figure 46 (replicating Figure 20 for convenience).

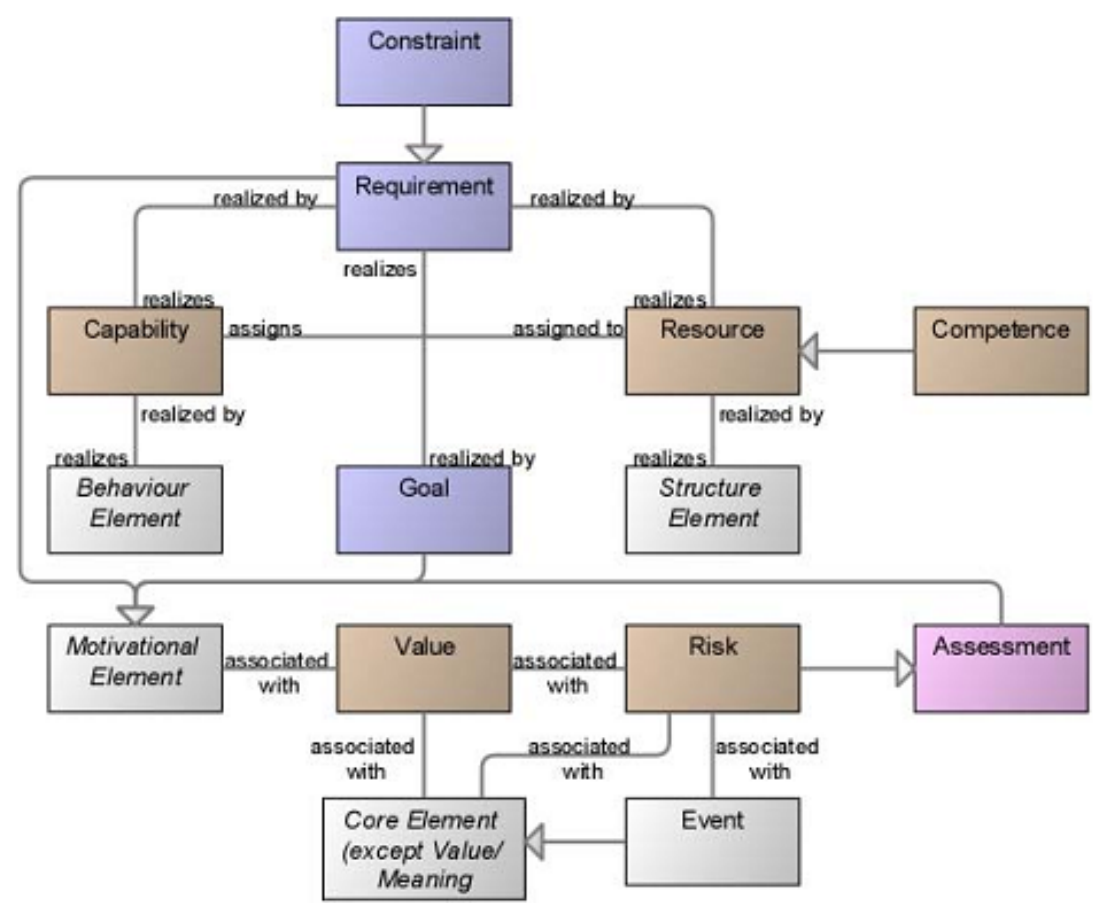

Figure 46 - BSVC metamodel fragment (lacob, Quartel and Jonkers, 2012) (replica) 


\section{Resource}

The resource element was introduced in ArchiMate 3.0 (The Open Group, 2016) with a similar definition as in the BSVC (Iacob, Quartel and Jonkers, 2012). The textual definition in ArchiMate 3.0 is the same as the textual definition in the BSVC (presented in Section 6.1). A resource "represents an asset owned or controlled by an individual or organization".

The relationships observed in the metamodel are also similar in ArchiMate and in the BSVC. An assessment of the metamodels shows that most of the relations are the same. In both metamodels the resource element is realized by structure elements, realizes requirements and is assigned to capabilities. The different relations are the influence relation to requirement, in which a resource can influence a requirement and the relation to state that composite elements can compose/aggregate resources, in addition to the lack of the competence element, and, thus, its relation to resource. Due to this, we speculate that most of the ontological analysis applied to the BSVC resource element in Chapter 6 might be applicable to the resource element in ArchiMate 3.0.

\section{Capability}

The ArchiMate capability element shares similarities to the BSVC capability element. In BSVC, capability was "the ability [...] to employ resources to achieve some goal" and in ArchiMate capability "represents an ability that an active structure element, such as an organization, person, or system, possesses" and capabilities are "aimed at achieving some goal or delivering value".

A metamodel assessment shows that the capability element both in BSVC and in ArchiMate realizes requirements, have resources assigned to it and are realized by behavior elements. The differences from the analyzed version are that in ArchiMate 3.0 capability can also serve, trigger or flow to a capability, capability can serve a course of action (which appears to be similar to a plan) and capability can also influence requirements. We conclude indicating that there are some similarities between the elements, but since the metamodel relations and textual definitions are different, the analysis should be revisited.

\section{Course of Action and Outcome}

The course of action is a new element added to the language and it is a complete new addition when compared to the BSVC. The course of action element is intended to be used as "an approach or plan for configuring some capabilities and resources of the enterprise, undertaken to achieve a goal". A course of action "represents what an enterprise has decided to do" and can be "categorized as strategies and tactics". The textual description of the course of action element appears to state that the element is to be used to plan required capabilities in order 
to achieve goals. However, the course of action element in the metamodel only has a relation with the outcome element. The outcome element, in its way, has a textual definition stating that it necessarily has been achieved, as an "outcome represents an end result that has been achieved" and outcome "names should unambiguously identify end results that have been achieved". For such, although a course of action appears to be a plan in its textual description, the outcome element states about a something that has been achieved. Thus, it is counterintuitive to plan for something that has already been achieved. Furthermore, a deeper ontological analysis is required in order to draw conclusions, especially in relation to the outcome element. 


\section{Appendix B}

\section{Author Publications}

During the development of this thesis, the author has published various parts of this work in the following papers (listed in reverse chronological order):

Azevedo, C. L. B., Iacob, M.-E., Almeida, J. P. A., Van Sinderen, M., Pires, L. F. and Guizzardi, G. (2013) 'An ontology-based well-founded proposal for modeling resources and capabilities in ArchiMate', in Proceedings IEEE International Enterprise Distributed Object Computing Workshop, EDOC. Elsevier, pp. 39-48. doi: 10.1109/EDOC.2013.14.

Azevedo, C. L. B., Almeida, J. P. A., Van Sinderen, M. and Pires, L. F. (2015) 'Towards Capturing Strategic Planning in EA', in Enterprise Distributed Object Computing Conference (EDOC), 2015 IEEE 19th International. IEEE, pp. 159-168.

Azevedo, C. L. B., Van Sinderen, M., Pires, L. F., Almeida, J. P. A., Sinderen, M. Van, Pires, L. F. and Almeida, J. P. A. (2015) 'Aligning Enterprise Architecture with Strategic Planning', in Persson, A. and Stirna, J. (eds) Advanced Information Systems Engineering Workshops. Springer, pp. 426437. doi: 10.1007/978-3-319-19243-7_39.

Azevedo, C. L. B., Iacob, M.-E., Almeida, J. P. A., Van Sinderen, M., Pires, L. F., Guizzardi, G., Sinderen, M. van, Pires, L. F. and Guizzardi, G. (2015) 'Modeling Resources and Capabilities in Enterprise Architecture: A Well-Founded Ontology-Based Proposal for ArchiMate', Information Systems, 54, pp. 235-262. doi: 10.1016/j.is.2015.04.008. 



\section{References}

Al-Shammari, H. A. and Hussein, R. T. (2007) 'Strategic planning-firm performance linkage: empirical investigation from an emergent market perspective', Advances in Competitiveness Research, 15, pp. 15-26.

Almeida, J. P. A., Fonseca, C. M. and Carvalho, V. A. (2017) 'A Comprehensive Formal Theory for Multi-level Conceptual Modeling', in Mayr, H. C., Guizzardi, G., Ma, H., and Pastor, O. (eds) Conceptual Modeling: 36th International Conference, ER 2017, Valencia, Spain, November 6--9, 2017, Proceedings. Cham: Springer International Publishing, pp. 280-294. doi: 10.1007/978-3-319-69904-2_23.

Almeida, J. P. A. and Guizzardi, G. (2013) 'An ontological analysis of the notion of community in the RM-ODP enterprise language', Computer Standards \&Interfaces. 35(3), pp. 257-268. doi: 10.1016/j.csi.2012.01.007.

Almeida, J. P. A., Guizzardi, G. and Santos Jr, P. S. (2009) 'Applying and extending a semantic foundation for role-related concepts in enterprise modelling', Enterprise Information Systems. Taylor \& Francis, 3, pp. 253-277.

Andrews, K. R. (1997) 'The Concept of Corporate Strategy', in Resources, Firms, and Strategies: A Reader in the Resource-based Perspective, pp. 52-59. doi: $10.2307 / 3380432$.

Ansoff, H. I. (1991) 'Critique of Henry Mintzberg's "the Design School: Reconsidering the Basic Premises of Strategic Management"', Strategic Management Journal, 12, pp. 449-461. doi: 10.1002/smj.4250120605.

Azevedo, C. L. B., Almeida, J. P. A., Van Sinderen, M. and Pires, L. F. (2015) 'Towards Capturing Strategic Planning in EA', in Enterprise Distributed Object Computing Conference (EDOC), 2015 IEEE 19th International. IEEE, pp. 159-168.

Azevedo, C. L. B., Almeida, J. P. A., Van Sinderen, M., Quartel, D. and Guizzardi, G. (2011) 'An ontology-based semantics for the motivation extension to archimate', in Proceedings - IEEE International Enterprise Distributed Object Computing Workshop, EDOC. IEEE, pp. 25-34. doi: 10.1109/EDOC.2011.29.

Azevedo, C. L. B., Iacob, M.-E., Almeida, J. P. A., Van Sinderen, M., Pires, L. F. and Guizzardi, G. (2013) 'An ontology-based well-founded proposal for modeling resources and capabilities in archimate', in Proceedings IEEE International Enterprise Distributed Object Computing Workshop, EDOC. Elsevier, pp. 39-48. doi: 10.1109/EDOC.2013.14.

Azevedo, C. L. B., Iacob, M.-E., Almeida, J. P. A., Van Sinderen, M., 
Pires, L. F., Guizzardi, G., Sinderen, M. van, Pires, L. F. and Guizzardi, G. (2015) 'Modeling Resources and Capabilities in Enterprise Architecture: A Well-Founded Ontology-Based Proposal for ArchiMate', Information Systems, 54, pp. 235-262. doi: 10.1016/j.is.2015.04.008.

Azevedo, C. L. B., Van Sinderen, M., Pires, L. F., Almeida, J. P. A., Sinderen, M. Van, Pires, L. F. and Almeida, J. P. A. (2015) 'Aligning Enterprise Architecture with Strategic Planning', in Persson, A. and Stirna, J. (eds) Advanced Information Systems Engineering Workshops. Springer, pp. 426437. doi: 10.1007/978-3-319-19243-7_39.

Baines, T. S., Lightfoot, H. W., Benedettini, O. and Kay, J. M. (2009) 'The servitization of manufacturing: a review of literature and reflection on future challenges', Journal of Manufacturing Technology Management. Emerald Group Publishing Limited, 20(5), pp. 547-567. doi: 10.1108/17410380910960984.

Baker, J., Jones, D. R., Cao, Q. and Song, J. (2011) 'Conceptualizing the dynamic strategic alignment competency', Journal of the Association for Information Systems, 12(4), pp. 299-322.

Barney, J. (1991) 'Firm resources and sustained competitive advantage', Journal of management. Sage Publications, 17(1), pp. 99-120.

Barney, J. B. (2001) 'Resource-based theories of competitive advantage : A ten- year retrospective on the resource-based view', Journal of Management, 27, pp. 643-650. doi: 10.1177/014920630102700602.

Barreto, I. (2009) 'Dynamic Capabilities: A Review of Past Research and an Agenda for the Future', Journal of Management, 36(1), pp. 256-280. doi: 10.1177/0149206309350776.

Barroero, T., Motta, G. and Pignatelli, G. (2010) 'Business capabilities centric enterprise architecture', in Enterprise architecture, integration and interoperability. Springer, pp. 32-43.

Bart, C. K., Bontis, N. and Taggar, S. (2001) 'A model of the impact of mission statements on firm performance', Management Decision, 39(1), pp. 19-35.

Bock, C. and Odell, J. (1998) 'A more complete model of relations and their implementation: Roles', Journal of Object Oriented Programming. SIGS Publication Incorporation, 11, pp. 51-54.

Bodart, F., Patel, A., Sim, M. and Weber, R. (2001) 'Should optional properties be used in conceptual modelling? A theory and three empirical tests', Information Systems Research. INFORMS, 12(4), pp. 384-405.

Boynton, A. C. and Zmud, R. W. (1987) 'Information Technology Planning in the 1990's: Directions for Practice and Research', MIS Quarterly, 11(1), p. 59. doi: 10.2307/248826.

Bringuente, A. C. O., Falbo, R. A. and Guizzardi, G. (2010) 'Using a Foundational Ontology for Reengineering a Software Process Ontology'.

Bryson, J. M. (1988) 'A strategic planning process for public and nonprofit organizations', Lang Range Planning, 21(1), pp. 73-81. doi: 10.1016/0024-6301(88)90061-1. 
Bryson, J. M. (2011) Strategic planning for public and nonprofit organizations: A guide to strengthening and sustaining organizational achievement. John Wiley \& Sons.

Cardoso, E. C. S., Almeida, J. P. a. and Guizzardi, R. S. S. (2010) 'On the Support for the Goal Domain in Enterprise Modelling Approaches', 2010 14th IEEE International Enterprise Distributed Object Computing Conference Workshops. Ieee, pp. 335-344. doi: 10.1109/EDOCW.2010.45.

Cardoso, E. C. S., Santos Jr, P. S., Almeida, J. P. A., Guizzardi, R. S. S. and Guizzardi, G. (2010) 'Semantic Integration of Goal and Business Process Modeling', in International Conference on Research and Practical Issues of Enterprise Information Systems (CONFENIS 2010).

Carvalho, V. A., Almeida, J. P. A. and Guizzardi, G. (2014) 'Using Reference Domain Ontologies to Define the Real-World Semantics of Domain-Specific Languages', in Advanced Information Systems Engineering, pp. 488-502.

Chan, Y. E. and Reich, B. H. (2007) 'IT alignment: What have we learned?', Journal of Information Technology, 22(4), pp. 297-315. doi: 10.1057/palgrave.jit.2000109.

Chen, D. Q., Mocker, M., Preston, D. S. and Teubner, A. (2010) 'Information Systems Strategy: Reconceptualization, Measurement, and Implications', MIS Quarterly, 34(2), pp. 233-A8. doi: Article.

Danesh, M. H. and Yu, E. (2014) 'Modeling Enterprise Capabilities with i * ', pp. 112-123.

Davies, I. G., Rosemann, M. and Green, P. (2000) 'Exploring proposed ontological issues of ARIS with different categories of modellers, in Proceedings of the Australasian Conference on Information Systems. Hobart, Australia.

Department of Defense Architecture Framework Working Group (2007) DoD architecture framework.

Dibrell, C., Craig, J. B. and Neubaum, D. O. (2014) 'Linking the formal strategic planning process, planning flexibility, and innovativeness to firm performance', Journal of Business Research. Elsevier Inc., 67(9), pp. 20002007. doi: 10.1016/j.jbusres.2013.10.011.

Dryer, D. A., Bock, T., Broschi, M. and Beach, T. D. (2007) 'DoDAF limitations and enhancements for the Capability Test Methodology', in Proceedings of the 2007 spring simulation multiconference - Volume 3. San Diego, CA, USA: Society for Computer Simulation International (SpringSim '07), pp. 170-176.

Eisenhardt, K. M. and Martin, J. A. (2000) 'Dynamic capabilities: what are they?', Strategic Management Journal. Boston, 21(10-11), pp. 1105-1121.

Engelsman, W., Quartel, D., Jonkers, H., van Sinderen, M. and Van, M. (2011) 'Extending enterprise architecture modelling with business goals and requirements', Enterprise Information Systems. Taylor \& Francis, 5(1), pp. 9-36.

Forbes Magazine and SAP (2009) 'Closing the Alignment Gap', Forbes Insights, pp. 1-14. 


\section{REFERENCES}

Franke, U., Holschke, O., Buschle, M., Närman, P. and Rake-Revelant, J. (2010) 'IT consolidation - An optimization approach', in Proceedings - IEEE International Enterprise Distributed Object Computing Workshop, EDOC, pp. 21-26. doi: 10.1109/EDOCW.2010.11.

Gailly, F., Geerts, G. and Poels, G. (2009) 'Ontological Reengineering of the REA-EO Using UFO', in International OOPSLA Workshop on Ontology-Driven Software Engineering.

Gangemi, A., Guarino, N., Masolo, C., Oltramari, A. and Schneider, L. (2002) 'Sweetening ontologies with DOLCE', in Knowledge Engineering and Knowledge Management: Ontologies and the Semantic Web, Lecture Notes in Computer Science, vol. 2473, pp. 223-233. doi: 10.1007/3-540-45810-7_18.

Geerts, G. L. and McCarthy, W. E. (2002) 'An ontological analysis of the economic primitives of the extended-REA enterprise information architecture', International Journal of Accounting Information Systems, 3, pp. 116. doi: 10.1016/S1467-0895(01)00020-3.

Geerts, G. and McCarthy, W. (2000) 'The ontological foundation of REA enterprise information systems', Annual Meeting of the American Accounting Association, pp. 1-34.

Gemino, A. and Wand, Y. (2005) 'Complexity and clarity in conceptual modeling: comparison of mandatory and optional properties', Data \& Knowledge Engineering. Elsevier, 55(3), pp. 301-326.

Gerow, J. E., Grover, V., Thatcher, J. and Roth, P. L. (2014) 'Looking Toward the Future of IT-Business Strategic Alignment Through the Past: A Meta-Analysis', MIS Quarterly, 38(4), pp. 1159-1185.

Gordijn, J. and Akkermans, H. (2001) 'Designing and Evaluating EBusiness Models', IEEE Intelligent Systems. Piscataway, NJ, USA: IEEE Educational Activities Department, 16(4), pp. 11-17. doi: 10.1109/5254.941353.

Grant, R. M. (1996) 'Toward a knowledge-based theory of the firm', Strategic management journal. JOHN WILEY \& SONS LTD, 17, pp. 109-122.

Green, P. and Rosemann, M. (2005) 'Ontological analysis of business systems analysis techniques: experiences and proposals for an enhanced methodology', Business systems analysis with ontologies. Hershey, PA: Idea Group Publishing, pp. 1-27.

Guarino, N. (1998) 'Formal Ontology and Information Systems', (June), pp. 3-15.

Guizzardi, G. (2005) Ontological foundations for structural conceptual models. Univeristy of Twente.

Guizzardi, G., Falbo, R. and Guizzardi, R. S. S. (2008) 'Grounding software domain ontologies in the unified foundational ontology (ufo): The case of the ode software process ontology', in Proceedings of the XI Iberoamerican Workshop on Requirements Engineering and Software Environments, pp. 244-251.

Guizzardi, G., Wagner, G., de Almeida Falbo, R., Guizzardi, R. S. S. and Almeida, J. P. A. (2013) 'Towards Ontological Foundations for the Conceptual Modeling of Events', in Conceptual Modeling. Springer, pp. 327- 
341.

Guizzardi, R., Franch, X., Guizzardi, G. and Wieringa, R. (2013) 'Using a foundational ontology to investigate the semantics behind the concepts of the i* language', in CEUR Workshop Proceedings, pp. 13-18.

Guizzardi, R. S. S. and Guizzardi, G. (2011) 'Ontology-based transformation framework from TROPOS to AORML', Social Modeling for Requirements Engineering, Cooperative Information Systems Series, pp. 547-570.

Guizzardi, R. S. S., Guizzardi, G., Perini, A. and Mylopoulos, J. (2007) 'Towards an ontological account of agent-oriented goals', in Software Engineering for Multi-Agent Systems V. Springer, pp. 148-164.

Hancock, D., Humphrey, D. B. and Wilcox, J. A. (1999) 'Cost reductions in electronic payments: The roles of consolidation, economies of scale, and technical change', Journal of Banking \& Finance, pp. 391-421. doi: 10.1016/S0378-4266(98)00108-3.

Heil, J. (2003) From an ontological point of view. Clarendon Press Oxford.

Helfat, C. C. E. and Winter, S. G. S. (2011) 'Untangling Dynamic and Operational Capabilities: Strategy for the (N) ever-Changing World', Strategic Management Journal. Wiley Online Library, 1250(June), pp. 1243-1250. doi: $10.1002 / \mathrm{smj}$.

Herre, H., Heller, B., Burek, P., Hoehndorf, R., Loebe, F. and Michalek, H. (2006) 'General Formal Ontology (GFO)--a foundational ontology integrating objects and processes', Onto-Med Report, 8.

Hevner, A. R., March, S. T., Park, J. and Ram, S. (2004) 'Design Science in Information Systems Research', MIS Quarterly, 28(1), pp. 75-105. doi: 10.1007/s12599-012-0246-0.

Iacob, M.-E. M.-E., Quartel, D. A. C. and Jonkers, H. (2012) 'Capturing Business Strategy and Value in Enterprise Architecture to Support Portfolio Valuation', in 2012 IEEE 16th International Enterprise Distributed Object Computing Conference. Ieee, pp. 11-20. doi: 10.1109/EDOC.2012.12.

IEEE (2000) IEEE Recommended Practice for Architectural Description of Software-Intensive Systems - IEEE Std 1471-2000, October. doi: 10.1109/IEEESTD.2000.91944.

ISO_-International Organization for Standardization (2004) Open Distributed Processing - Reference Model - Enterprise Language ISO/IEC 15414 | ITU-T Recommendation X.911.

ISO, IEC and IEEE (2011) 'ISO/IEC/IEEE 42010:2011 - Systems and software engineering -- Architecture description', ISOIECIEEE 420102011 E Revision of ISOIEC 420102007 and IEEE Std 14712000, 2011(March), pp. 146. doi: 10.1109/IEEESTD.2011.6129467.

Kappelman, L. A. and Zachman, J. A. (2013) 'The Enterprise and its Architecture: Ontology \& Challenges', Journal of Computer Information Systems, 53(4).

Kappelman, L., Luftman, J., Mclean, E. and Johnson, V. (2013) 'Key Issues of IT Organizations and Their Leadership: The 2013 SIM IT Trends Study', MIS Quarterly Executive, 12(4), pp. 227-240. 


\section{REFERENCES}

Keller, W. (2010) 'Using Capabilities in Enterprise Architecture Management'.

Kogut, B. and Zander, U. (1992) 'Knowledge of the firm, combinative capabilities, and the replication of technology', Organization science. INFORMS, 3(3), pp. 383-397.

Kraaijenbrink, J., Spender, J.-C. and Groen, A. J. (2010) 'The resourcebased view: a review and assessment of its critiques', Journal of management. SAGE Publications, 36(1), pp. 349-372.

Van Lamsweerde, A. (2009) Requirements Engineering: From System Goals to UML Models to Software Specifications. Wiley.

Lankhorst, M. (2005) Enterprise architecture at work: Modelling, communication and analysis. Springer-Verlag.

Laurier, W. and Poels, G. (2009a) Enterprise Ontology-Based Structuring of Conceptual Data Modeling Patterns.

Laurier, W. and Poels, G. (2009b) 'Extending REA Models with a Reference Model for Abstraction Mechanisms', in 4th International Workshop on Value Modeling and Business Ontologies, Amsterdam.

Lee, H. and Song, Y. T. (2011) 'Bridging enterprise architecture requirements to archimate', in Studies in Computational Intelligence, pp. 63-78. doi: 10.1007/978-3-642-21375-5_6.

Lee, J.-N. (2001) 'The impact of knowledge sharing, organizational capability and partnership quality on IS outsourcing success', Information \& Management, 38(5), pp. 323-335. doi: 10.1016/S0378-7206(00)00074-4.

Leiblein, M. J. (2011) 'What Do Resource- and Capability-Based Theories Propose?', Journal of Management, 37(4), pp. 909-932. doi: $10.1177 / 0149206311408321$.

Levin, I. M. (2000) 'Vision Revisited: Telling the Story of the Future', The Journal of Applied Behavioral Science, 36(1), pp. 91-107. doi: 10.1177/0021886300361005.

Linington, P. F., Milosevic, Z., Tanaka, A. and Vallecillo, A. (2011) Building enterprise systems with ODP: an introduction to open distributed processing. CRC Press.

Lowe, E. J. (2006) The four-category ontology: a metaphysical foundation for natural science. Clarendon Press.

McCarthy, W. E. W. (1982) 'The REA accounting model: A generalized framework for accounting systems in a shared data environment', Accounting Review. JSTOR, 57, pp. 554-578. doi: 8.

McKelvie, A. and Davidsson, P. (2009) 'From Resource Base to Dynamic Capabilities: an Investigation of New Firms', British Journal of Management, 20, pp. S63-S80. doi: 10.1111/j.1467-8551.2008.00613.x.

McNamara, C. (2001) 'Strategic planning (in nonprofit or for-profit organizations)', Free Management Library. http://managementhelp. org/plan_dec/str_plan/str_plan. htm (accessed April 19, 2015).

Michael E. Bratman (1999) Intention, Plans, and Practical Reason, Intention, Plans, and Practical Reason. doi: 10.2307/2185304. 
Miklos, J. (2012) 'A Meta-Model for the Spatial Capability Architecture', Journal of Theoretical and Applied Information Technology, 43(2).

Miller, C. C. and Cardinal, L. B. (1994) 'Strategic Planning and Firm Performance: A Synthesis of More Than Two Decades of Research', Academy of Management Journal, 37(6), pp. 1649-1665. doi: 10.2307/256804.

Mintzberg, H. (1994) 'The Rise and Fall of Strategic Planning', Harvard Business Review, 72, pp. 107-114. doi: 10.1016/0024-6301(94)90173-2.

Mintzberg, H., Ahlstrand, B. and Lampel, J. (1998) Strategy safari: a guided tour through the wilds of strategic management, Free Press.

Mintzberg, H. and Quinn, J. B. (2003) The Strategy Process (4th edition), Mt Eliza Business Review.

Miranda, G. M., Almeida, J. P. A., Azevedo, C. L. B. and Guizzardi, G. (2015) 'An Ontological Analysis of Capability Modeling in Defense Enterprise Architecture Frameworks'.

Molnar, G. (2006) Powers: A study in metaphysics. Edited by S. Mumford. Oxford University Press.

Moody, D. (2009) 'The "physics" of notations: toward a scientific basis for constructing visual notations in software engineering', Software Engineering, IEEE Transactions on. IEEE, 35(6), pp. 756-779.

Mumford, S. (2003) Dispositions. Oxford University Press.

Mylopoulos, J., Castro, J. and Kolp, M. (2013) 'The Evolution of Tropos', in Seminal Contributions to Information Systems Engineering. Springer, pp. 281-287.

Nardi, J. C., Falbo, R. de A. and Almeida, J. P. A. (2014) 'An Ontological Analysis of Service Modeling at ArchiMate's Business Layer', in Enterprise Distributed Object Computing Conference (EDOC), 2014 IEEE 18th International, pp. 92-100.

Nelson, R. R. and Winter, S. G. (1982) An evolutionary theory of economic change, The Economic Journal. doi: 10.2307/2232409.

Object Management Group (2014) Business Motivation Model v1.2.

OMG (2010) 'Business Motivation Model', Omg, (November), p. /. doi: formal/2008-08-02.

Op 't Land, M., Proper, E., Waage, M., Cloo, J., Steghuis, C., Opt' Land, M., Proper, E., Waage, M., Cloo, J. and Steghuis, C. (2009) Enterprise Architecture: Creating Value by Informed Governance, Springer. doi: 10.1007/9783-540-85232-2.

Oxford (2005) Oxford Dictionary of English, The Oxford Dictionary of English. Edited by C. Soanes and A. Stevenson. doi: Online Version: 2010 eISBN: 9780191727665.

Penrose, T. (1959) The theory of the growth of the firm. Oxford University Press.

Peteraf, M. A. and Barney, J. B. (2003) 'Unraveling the resource-based tangle', Managerial and decision economics. Wiley Online Library, 24(4), pp. 309-323.

Pijpers, V., Gordijn, J. and Akkermans, H. (2009) 'e3 alignment : 


\section{REFERENCES}

Exploring inter-organizational alignment in value webs', 2009 Third International Conference on Research Challenges in Information Science. Ieee, (1), pp. 1-12. doi: 10.1109/RCIS.2009.5089262.

Porter, M. E. (1980) 'Competitive Strategy', Techniques for analyzing industries and competitors, 1, p. 396.

Porter, M. E. (1991) 'Towards a dynamic theory of strategy', Strategic management journal, 12, pp. 95-117. doi: 10.1002/smj.4250121008.

Prahalad, C. K. and Hamel, G. (1990) 'The core competence of the corporation', Resources, firms, and strategies: A reader in the resource-based perspective, pp. 235-256.

Quartel, D., Engelsman, W. and Jonkers, H. (2010) 'ArchiMate $\mathbb{~}$ Extension for Modeling and Managing Motivation , Principles and Requirements in TOGAF DRAFT version', (August).

Quartel, D., Steen, M. W. a. A. and Lankhorst, M. (2010) 'IT Portfolio Valuation - Using Enterprise Architecture and Business Requirements Modeling', 2010 14th IEEE International Enterprise Distributed Object Computing Conference. Ieee, pp. 3-13. doi: 10.1109/EDOC.2010.24.

Ravishankar, M. N., Pan, S. L. and Leidner, D. E. (2011) 'Examining the strategic alignment and implementation success of a KMS: A subculture-based multilevel analysis', Information Systems Research, 22(1), pp. 39-59. doi: 10.1287/isre. 1080.0214 .

Ray, G., Barney, J. B. and Muhanna, W. a. (2004) 'Capabilities, business processes, and competitive advantage: choosing the dependent variable in empirical tests of the resource-based view', Strategic Management Journal, 25(1), pp. 23-37. doi: 10.1002/smj.366.

Recker, J., Indulska, M., Rosemann, M. and Green, P. (2010) 'The ontological deficiencies of process modeling in practice', European Journal of Information Systems. Palgrave Macmillan, 19(5), pp. 501-525. doi: 10.1057/ejis.2010.38.

Recker, J., Rosemann, M., Green, P. and Indulska, M. (2011) 'Do Ontological Deficiencies in Modeling Grammars Matter?', 35(1), pp. 1-9.

Rosemann, M., Green, P. and Indulska, M. (2004) 'A reference methodology for conducting ontological analyses', in Conceptual Modeling--ER 2004. Springer, pp. 110-121.

Ross, J. W., Weill, P. and Robertson, D. (2006) Enterprise architecture as strategy: Creating a foundation for business execution. Harvard Business Press.

Sabegh, M. A. J. and Motlagh, S. M. (2012) 'The role and relevance of IT governance and IT capability in Business--IT alignment in medium and large companies', Business and Management Review, 2(6), pp. 16-23.

Sako, M. (2004) 'Supplier development at Honda, Nissan and Toyota: comparative case studies of organizational capability enhancement', Industrial and Corporate Change, 13(2), pp. 281-308. doi: 10.1093/icc/dth012.

Santos Jr, P. S., Almeida, A., Guizzardi, G., Sérgio Santos, P. and Almeida, J. P. a. (2013) 'An ontology-based analysis and semantics for organizational structure modeling in the ARIS method', Information Systems, 
38(5), pp. 690-708. doi: 10.1016/j.is.2012.09.004.

Santos Jr, P. S., Almeida, J. P. A., Guizzardi, G., Sérgio, P. and Jr, S. (2010) 'An ontology-based semantic foundation for ARIS EPCs', in Proceedings of the 2010 ACM Symposium on Applied Computing, pp. 124-130. Available at: http: / / dl.acm.org/ citation.cfm?id=1774114.

Scheer, A.-W. (2000) ARIS - Business Process Modeling, ARIS Business Process Modeling.

Scott, J. (2009) 'Business Capability Maps--The missing link between business strategy and IT action', Architecture \& Governance, 5(9), pp. 1-4.

Searle, J. R. (1983) Intentionality: An essay in the philosophy of mind. Cambridge University Press.

Shanks, G., Tansley, E., Nuredini, J., Tobin, D. and Weber, R. (2008) 'Representing part-whole relations in conceptual modeling: an empirical evaluation', MIS Quarterly, 32, pp. 553-573. doi: Article.

Song, M., Im, S., Van Der Bij, H. and Song, L. Z. (2011) 'Does strategic planning enhance or impede innovation and firm performance?', Journal of Product Innovation Management, 28, pp. 503-520. doi: 10.1111/j.15405885.2011.00822.x.

Sowa, J. F. and Zachman, J. A. (1992) 'Extending and Formalising the Framework for Information Systems Architecture', IBM Systems Journal, 31, pp. 590-616. doi: 10.1147/sj.313.0590.

Stirna, J., Grabis, J., Henkel, M. and Zdravkovic, J. (2012) 'Capability driven development--an approach to support evolving organizations', in The Practice of Enterprise Modeling. Springer, pp. 117-131.

Teece, D. J., Pisano, G. and Shuen, A. (1997) 'Dynamic capabilities and strategic management', Strategic management journal. World Scientific, 18(7), pp. 509-533.

Teece, D. and Pisano, G. (1994) 'The dynamic capabilities of firms: An introduction', Industrial and Corporate Change, 3, pp. 537-556. doi: 10.1093/icc/3.3.537-a.

The Open Group (2009) TOGAF Version 9, Architecture.

The Open Group (2012) ArchiMate 2.0 Specification, C 118. The Open Group.

The Open Group (2016) ArchiMate 3.0 Specification.

Trainer, J. F. (2004) 'Models and tools for strategic planning', in New Directions for Institutional Research, pp. 129-138. doi: 10.1002/ir.127.

UK Ministry of Defense (2013) UK MoD. Architecture Framework (MODAF) M3 v1.2.004.

Venkatraman, N. (2000) 'IT Agenda 2000 : Not Fixing Technical Bugs But Creating Business Value', 16(5), pp. 573-585.

Wand, Y. and Weber, R. (1989) 'An ontological evaluation of systems analysis and design methods', Information System Concepts: An In-Depth Analysis. Elsevier Science Publishers BV, North-Holland, 1989.

Wand, Y. and Weber, R. (1990) 'Mario Bunge's Ontology as a formal foundation for information systems concepts', Studies on Mario Bunge's Treatise, 


\section{REFERENCES}

Rodopi, Atlanta, pp. 123-149.

Weber, R. (1997) Ontological foundations of information systems. Coopers \& Lybrand and the Accounting Association of Australia and New Zealand Melbourne.

Weihong, X., Yongjian, W., Luan, J. and Guangyu, Z. (2010) 'A Study on the Relationship Between IT Capabilities, Organization Structure and Enterprise Performance: Empirical Research through the Manufacturing Enterprises in PRD', 2010 International Forum on Information Technology and Applications. Ieee, pp. 373-376. doi: 10.1109/IFITA.2010.333.

Wernerfelt, B. (1984) 'A Resource-based View of the Firm', 5(June 1982), pp. 171-180.

Wieringa, R. J. (2010) Design science methodology, the 32nd ACM/IEEE International Conference. Springer-Verlag Berlin Heidelberg. doi: 10.1145/1810295.1810446.

Zachman, J. A. (1987) 'A Framework For Information Systems Architecture', IBM Systems Journal, 26(3), pp. 276-292. doi: $10.1147 /$ sj. 263.0276 .

Zandi, F. and Tavana, M. (2010) 'A multi-attribute group decision support system for information technology project selection', International Journal of Business Information Systems. Inderscience, 6(2), pp. 179-199.

Zdravkovic, J., Stirna, J., Henkel, M. and Grabis, J. (2013) 'Modeling business capabilities and context dependent delivery by cloud services', in Advanced Information Systems Engineering, pp. 369-383. 